\title{
Recurso Didáctico para la Educación en COMPROMISOS SOCIALES Y MediOAMBIENTALES DEL S.XXI A TRAVÉS DE LOS Objetivos de Desarrollo Sostenible
}

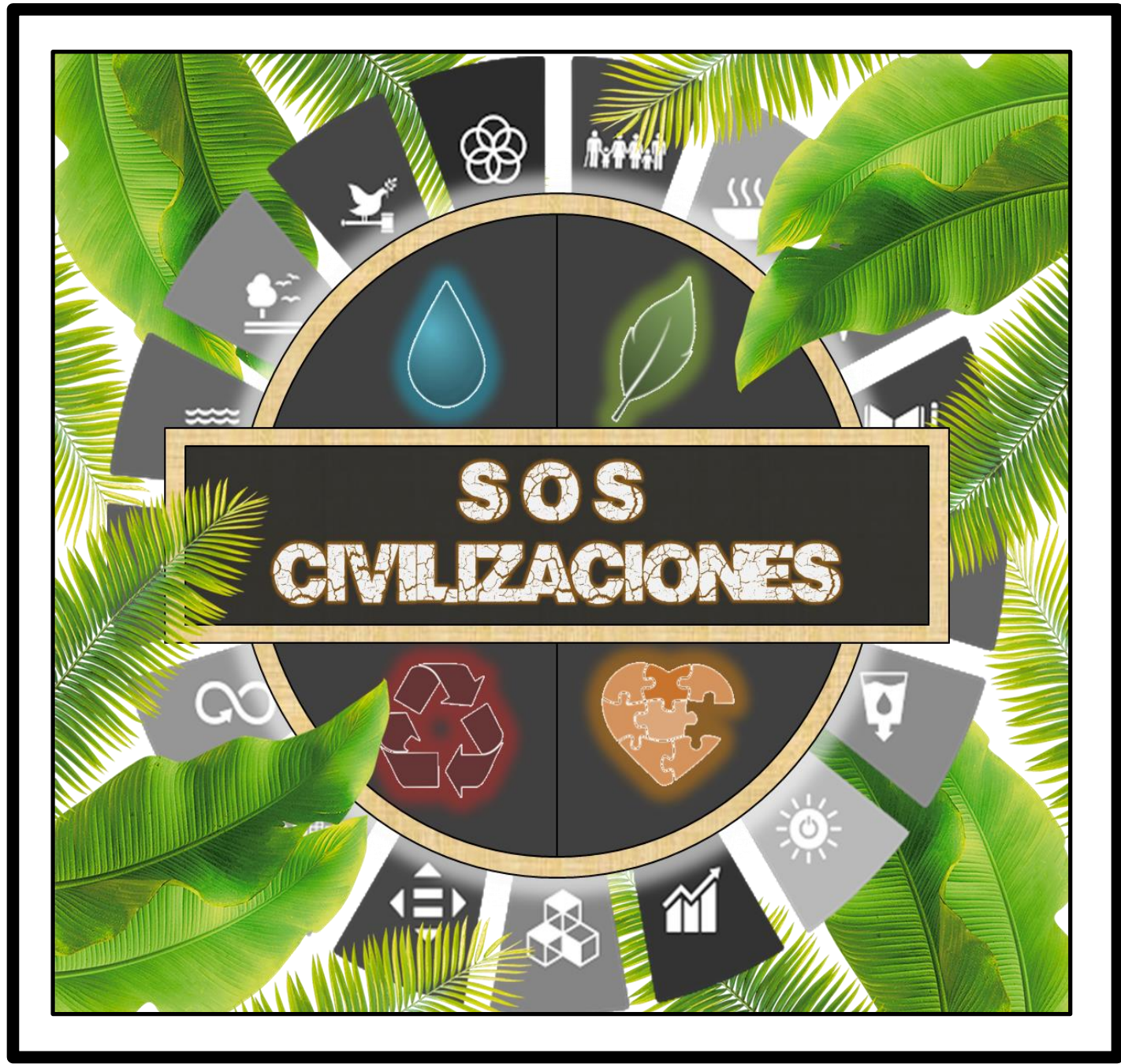

Realizado por

\section{Ana González Robles}

Dirigido por Dra. Mercedes Vázquez Vilches Dpto. Didáctica de las Ciencias Experimentales

de Idiomas. Especialidad Biología y Geología 


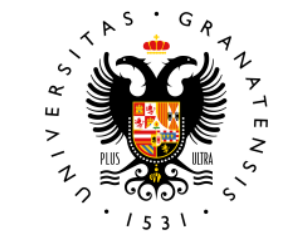

UNIVERSIDAD

DE GRANADA

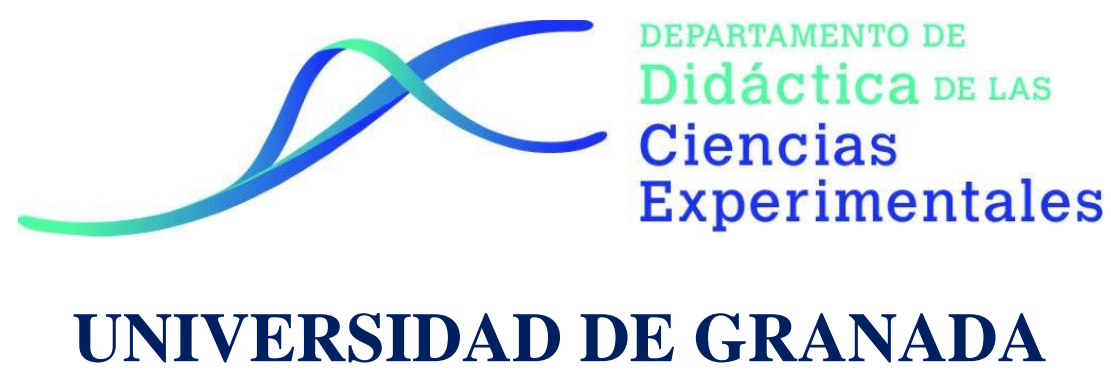

Máster Universitario en Formación del Profesorado de Educación Secundaria, Bachillerato, Formación Profesional y Enseñanza de Idiomas. Especialidad Biología y Geología

Curso 2019-2020

\section{TRABAJO FIN DE MÁSTER}

Autora: Ana González Robles

Título: Recurso didáctico para la educación en compromisos sociales y medioambientales del s.XXI a través de los Objetivos de Desarrollo Sostenible

\begin{tabular}{|l|l|}
\hline El/la autor/a & V.B. Tutor/a \\
\hline & \\
\hline Fdo: Ana González Robles & \\
\hline & Fdo: Dra. Mercedes Vázquez Vílchez \\
\hline
\end{tabular}




\section{Resumen:}

Este Trabajo Fin de Máster presenta el diseño y elaboración de un recurso didáctico del tipo 'juego de mesa', titulado 'S.O.S. Civilizaciones'. Fundamentándose en el 'aprendizaje basado en juegos', su objetivo es contribuir a la formación y conocimiento del alumnado de centros de secundaria y bachillerato de ámbito nacional en problemáticas medioambientales y sociales del s. XXI, a través de los Objetivos de Desarrollo Sostenible (ONU) y la puesta en valor de los mismos. Para el diseño y desarrollo del recurso se ha tomado como base el juego de mesa colaborativo 'La Isla Prohibida: Lánzate a la aventura... si te atreves'. Los retos/preguntas incluidas en el 'juego' han sido ajustados al nivel y currícullum de $2^{\circ}$ Bachillerato de la asignatura CTMA, con la finalidad de que el recurso pueda ser usado por el profesorado como una actividad dentro de las unidades didácticas del curso, o incluso como un método de evaluación, figurando ambas propuestas en esta memoria. Adicionalmente, se plantea también la posibilidad de utilizar el recurso para trabajar temáticas transversales propias de la etapa de secundaria en aulas de $4^{\circ}$ ESO. El uso de Tecnologías de la Información y la Comunicación ha sido incluido en el recurso mediante la inclusión de códigos QR que guían al alumnado en el proceso de aprendizaje y enseñanza. La evaluación del recurso como elemento educativo con alumnos reales queda prevista para estudios posteriores a este trabajo.

\section{Palabras clave:}

Aprendizaje basado en juegos; compromiso social; educación ambiental; juegos de mesa; ODS.

\footnotetext{
Abstract:

This Master Thesis describes the design and development of a didactic resource based on 'game-based learning', a 'board game' entitles 'S.O.S. Civilizaciones'. Its goal is improving the knowledges of high school students in the environmental and social problems of twenty first century, using the Sustainable Development Goals (UN). This resource is based on the collaborative board game entitles 'La Isla Prohibida: Lánzate a la aventura... si te atreves'. Game challenges/questions have been designed according to the $2^{\circ}$ Bachelor curricullum of CTMA subject, in order to this resource could be used by teachers as an academic activity, or even as an assessment method. Additionally, we showed how this resource could be also used to work transversal items of secondary school in $4^{\circ}$ ESO classes. The use of Information and
} 
Communication Technologies is also worked by QR codes to lead students' learning process.

Resource assessment as educational element is expected in future studies within this project.

\section{Keywords:}

Environmental education; game-based learning; global goals; serious game; social engagement. 


\section{AGRADECIMIENTOS}

Agradecer a mi tutora, Dra. Mercedes Vázquez Vílchez la oportunidad de poder realizar este TFM, su atención y el tiempo dedicado al mismo.

A mi familia y amigos, por seguir a mi lado etapa tras etapa.

A mis compañeros de máster, especialmente a los cafeteros y tapeadores, por alegrarme cada una de las tardes de clase. 


\section{Índice:}

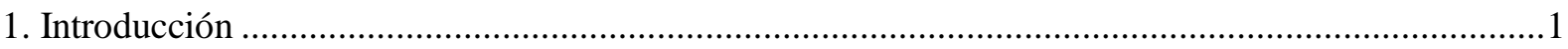

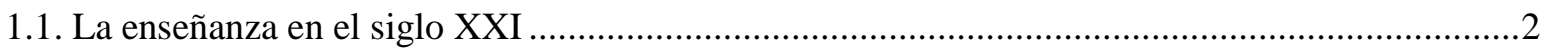

1.2. La gamificación en el aula: 'aprendizaje basado en juegos' .......................................................4

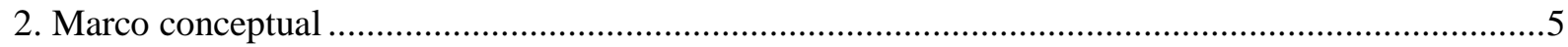

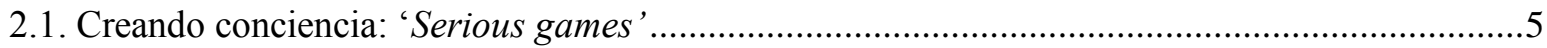

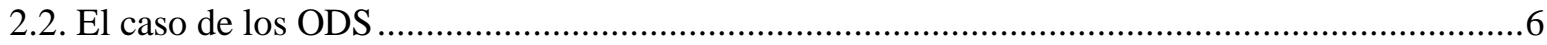

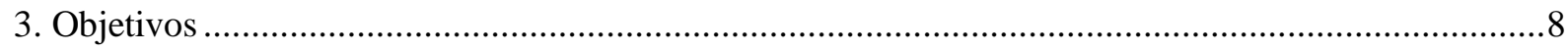

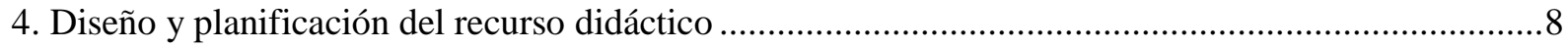

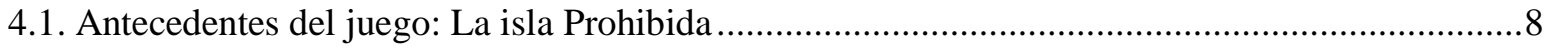

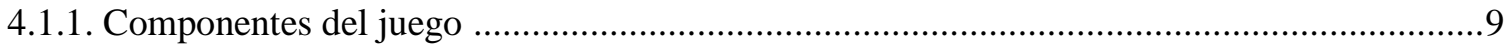

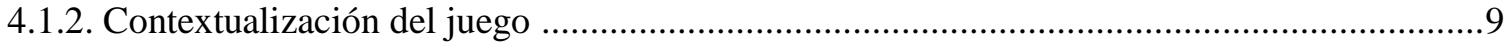

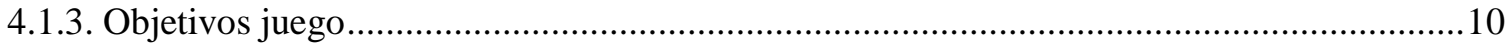

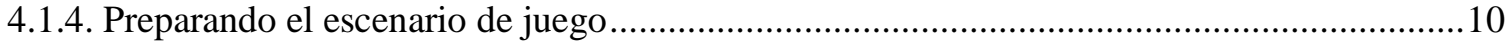

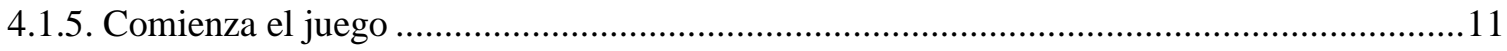

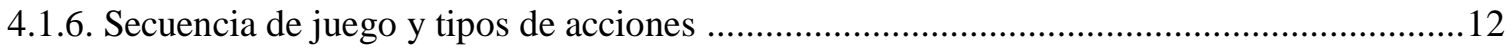

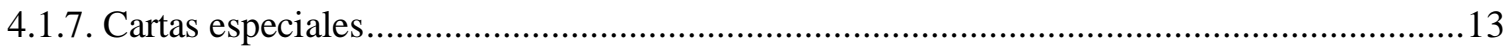

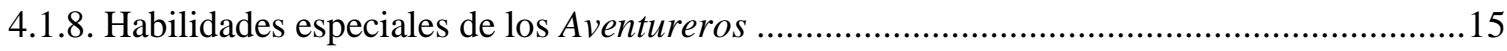

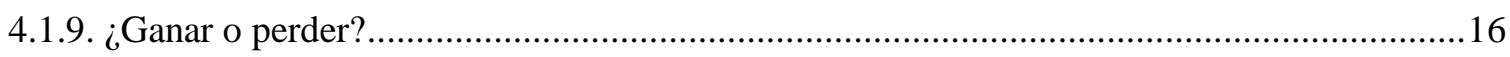

4.2. Modificaciones del juego para la creación del recurso ............................................................ 17

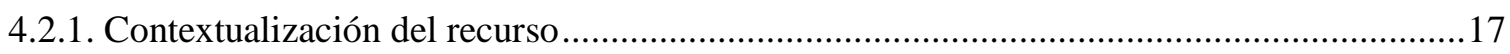

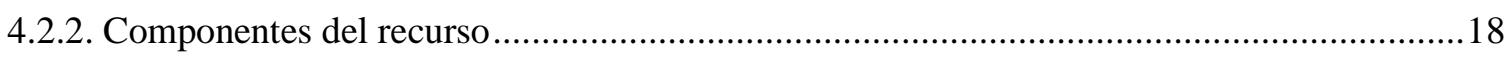

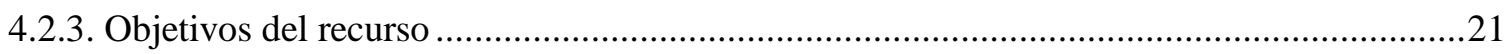

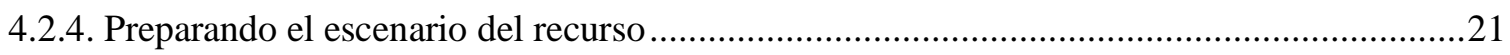

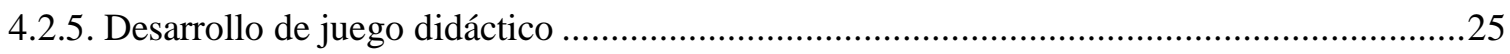

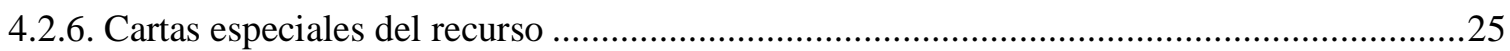

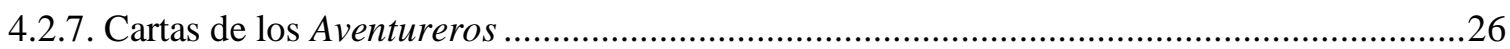

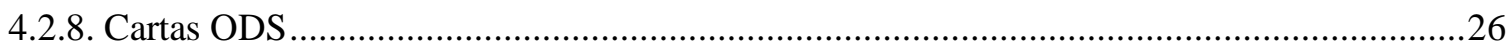

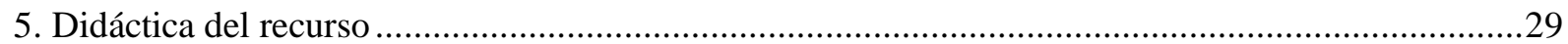

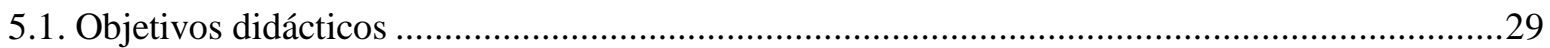

5.2. Contenidos, criterios de evaluación y estándares de aprendizaje evaluables ..............................31

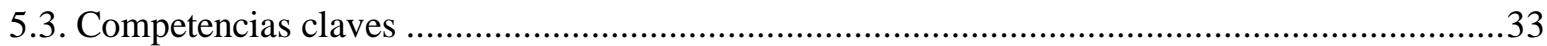

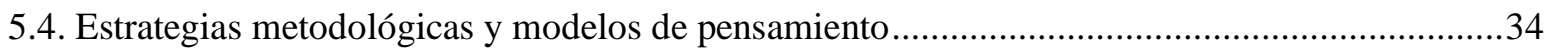

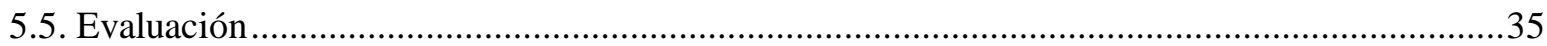

5.6. Otros usos del recurso: Temáticas transversales en la ESO .......................................................39

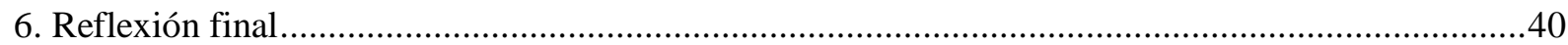


Anexo 1. Diseño del envés de las distintas familias de las cartas ODS del recurso . .46

Anexo 2. Diseño del envés de cada una de las cartas Aventurero del recurso . .47

Anexo 3. Diseño del haz de cada una de las cartas Aventurero del recurso . .48

Anexo 4. Llaves-insignia (Tesoros) asociadas a cada una de las familias de cartas del recurso.

Anexo 5. Diseño del marcador e indicador de agua del recurso elaborado.....

Anexo 6. Detalle de las losetas Isla diseñadas para el recurso

Anexo 7. Detalle de las cartas del mazo Inundación diseñadas para el recurso.

Anexo 8. Detalle de las cartas especiales diseñadas para el recurso. .66

Anexo 9. Diseño del haz de las cartas del mazo ODS.

Anexo 10. Asociación entre las actividades diseñadas para el recurso didáctico presentado y los criterios de evaluación y estándares de aprendizaje evaluables de la asignatura de CTMA de $2^{\circ}$ de Bachillerato. 


\section{Introducción}

Este Trabajo Fin de Máster desarrolla un recurso didáctico del tipo 'juego de mesa' con el objetivo de contribuir a la formación y conocimiento del alumnado de centros de secundaria y bachillerato en las problemáticas medioambientales y sociales actuales, a través de los Objetivos de Desarrollo Sostenible y la puesta en valor de los mismos. Para, el diseño y desarrollo del mismo se ha tomado como base el juego de mesa "La Isla Prohibida: Lánzate a la aventura... si te atreves', creado por Matt Leacock y distribuido por Devir Iberia y GameWright@. Este recurso, pretende que, mediante el 'aprendizaje basado en juegos' y el trabajo colaborativo, el profesorado no solo consiga formar al alumnado en temas de importancia ambiental y social, si no también potenciar su compromiso con los problemas globales, haciéndolos protagonistas de la resolución de los mismos. Para ello, el recurso ha sido contextualizado dentro de los Objetivos de Desarrollo Sostenible (ODS) de las Organización de las Naciones Unidas (ONU), haciendo especial hincapié en los ODS que tienen que ver con: i) la valoración y preocupación por el medio ambiente y su biodiversidad; ii) el impacto de las actividades humanas y la sostenibilidad; y iii) la salud. Por su naturaleza ambiental y social, el recurso didáctico se ha contextualizado dentro de la materia de Ciencias de la Tierra y Medio Ambiente (CTMA) de $2^{\circ}$ de Bachillerato, siendo la materia que mejor se ajusta la temática del juego según la normativa educativa vigente. Sin embargo, en dicho trabajo exponemos también la posibilidad de usar este recurso dentro de la etapa de secundaria, especialmente en $4^{\circ}$ ESO por ser el nivel más avanzado, para completar la formación en temáticas transversales de índole ambiental y social, al mismo tiempo que en habilidades de comunicación interpersonal y empatía.

Al mismo tiempo, al tratarse de un juego colaborativo, fundamenta el trabajo en metodologías activas en el aula, donde el diálogo y el trabajo en grupo son la clave para el éxito en el juego. El recurso trabaja también el uso de nuevas tecnologías (Tecnologías de la Información y la Comunicación, TICs) a través de tarjetas de preguntas asociadas a códigos QR, que harán que el alumnado tenga que trabajar con ellos para hallar respuesta a las mismas. Todo ello, junto con la adquisición de roles por los participantes, hace que el recurso desarrollado presente los ingredientes claves para, no solo dar al alumnado una clase diferente, sino también para dotarles de ese compromiso en problemáticas globales, que tan difícil es transmitir desde las aulas. Esto, además de servir para contextualizar problemáticas globales, contribuirá a que el alumnado deje de percibirlas como algo ajeno. 
Para ello, en este trabajo, primero se presenta la justificación teórica para el desarrollo del recurso didáctico; en segundo lugar se describen sus bases y como se ha realizado su elaboración y diseño; y posteriormente se plantea su adecuación dentro de la normativa educativa y la evaluación dentro de la misma.

\subsection{La enseñanza en el siglo XXI}

La educación es un campo que está en constante evolución, hecho que hace difícil concretar cuáles son sus objetivos. Según a quien preguntemos encontraremos diferentes respuestas. El principal objetivo que suele atribuírsele suele ser 'la adquisición de conocimientos', sin embargo 'tener accesos a oportunidades laborales', 'la formación de futuros ciudadanos y empleados', o 'preparar para la vida', se encuentran también entre ellos. Nos encontramos ante un campo que está totalmente supeditado a los avances del tiempo en el que nos encontramos. En los últimos años, el gran desarrollo de las tecnologías y la globalización del mundo ha supuesto un antes y un después en las corrientes educativas y en los métodos de enseñanza (Fundación de la Innovación Bankinter, 2011; Hayes et al., 2017).

A mediados del siglo pasado el sistema educativo apostaba por metodologías en las que los docentes eran los protagonistas del proceso de aprendizaje. Estos se encargaban de la transmisión de conocimientos, en su mayoría a través de las llamadas "clases magistrales", en las cuales el alumnado, como objeto-pasivo, recibía el mensaje de las mismas. El conjunto de la clase era entendido como un todo, un grupo de chicos/as que se movían al unísono, y en el que todo aquel que no lograse seguir el ritmo que el profesor marcaba, estaba claramente condenado al fracaso escolar. Las clases estaban totalmente alejadas de metodologías prácticas y la preocupación por la trasmisión de los conceptos era mayor que por la asimilación de los mismos por parte del alumnado. Sin embargo, con el s. XXI comienza a vislumbrarse un cambio en el sistema educativo, con la intención de que la formación en las aulas sea más acorde a las demandas del mundo actual (Gimeno-Sacristán, 1999). El mundo necesita ciudadanos resolutivos, políglotas, con capacidad y ganas de aprender e innovar, y capaces de adaptarse a los cambios de manera rápida (Fundación de la Innovación Bankinter, 2011). Hablamos de ciudadanos prácticos, con inquietudes por el saber y con capacidad de dar respuesta a las preguntas que se les planteen. Claramente un sistema educativo basado en la transmisión pasiva y verbal de los conceptos difícilmente puede conseguir despertar este tipo de inquietudes en su sociedad. Es por ello, que el sistema educativo con el que nos encontramos hoy ha fundamentado sus bases en alejarse de esa metodología del siglo pasado, 
y ha replanteado el papel de todos los agentes involucrados en el proceso de enseñanzaaprendizaje (alumnado, profesorado, centros, familias, etc.) (Díaz-Barriga-Arceo, 2006). Ahora el alumnado es entendido como el agente protagonista de su propio aprendizaje. Es quien se pregunta, analiza y resuelve los retos que se le plantean, encontrando utilidad a lo que aprende en el aula (aprendizaje significativo) (Rodríguez-Palmero, 2011) (ver Tabla 1). El profesorado simplemente ejerce una función de guía en dicho proceso, transmitiendo y facilitando la adquisición del nuevo conocimiento mediante distintas metodologías y recursos didácticos (Esteve-Gilbert, 2008; Rosefsky-Saavedra y Opfer, 2011). Así, cada alumno es entendido de manera independiente, siendo el profesor el principal responsable de encontrar la mejor forma de adecuar su enseñanza a cada uno de ellos, atendiendo a sus fortalezas particulares y a sus conocimientos previos. Con todo ello, la educación actual en las aulas debe ser entendida como un proceso colaborativo, activo y práctico (Díaz-Barriga-Arceo, 2006), en el que todos sus agentes deben encontrar la mejor forma de conseguir los objetivos didácticos de cada etapa trabajando juntos.

Tabla 1. Tabla comparativa de las características de un estudiante de escuela tradicional y uno del s. XXI [Extraída de Blog Juan Carlos Moir]

\begin{tabular}{ll}
\hline ESTUDIANTE TRADICIONAL & ESTUDIANTE DEL S.XXI \\
\hline Se sienta y escucha & Se mueve y experimenta \\
El aprendiz es un receptor & El aprendiz es un iniciador \\
Se espera lo mismo de cada uno & El estudiante "navega" entre \\
opciones
\end{tabular}




\subsection{La gamificación en el aula: 'aprendizaje basado en juegos'}

La palabra gamificación surge de la palabra inglesa 'gamification' y hace alusión a la utilización de juegos de cualquier índole, con la finalidad de entretener a su público. A principios del s. XX, este término empieza a formar parte de los círculos educativos, tomando protagonismo como estrategia de educación activa (Gómez-Trigueros, 2018). Podríamos decir que, gamificar es “aplicar estrategias (pensamientos y mecánicas) de juegos en contextos no jugables, ajenos a los juegos, con el fin de que las personas adopten ciertos comportamientos" (Ramírez, 2014). Así, la idea de aplicar los juegos en contextos no lúdicos, como la educación ('game-based learning'), es conseguir que el público no solo aprenda, sino que además despierte interés por el tema con el que trabaja, desarrolle habilidades sociales y cívicas, y potencie sus capacidades en la resolución de problemas (Conteras-Espinosa, 2016; GómezTrigueros, 2018).

El juego es algo que ha estado ligado a todos los niños desde las primeras etapas de su vida. Es entendido por ellos como una manera de desconectar y entretenerse, por lo que suelen mostrar una alta disposición a los mismos (Sosa-Espinosa et al., 2018). Estas características han propiciado que el empleo de juegos como método de enseñanza y aprendizaje en las aulas lleve aparejado un aumento en la motivación del alumnado por el desarrollo de la clase (Cheong et al., 2014). Además, distintos autores constatan la existencia de mejoras en el pensamiento complejo, lógico y crítico, en planificación estratégica y en la asimilación multidisciplinar de conceptos por parte del alumnado que aprende mediante técnicas de gamificación (Higgins et al., 1999; Kirriemuir y McFarlane, 2004; Mitchell y Savill-Smith, 2004; Emblen-Perry, 2018). Conseguir la atención e implicación del alumnado es el principal objetivo de cualquier docente, ya que cuando hay interés por lo que se aprende el resultado del proceso suele ser altamente satisfactorio (Conteras-Espinosa, 2016).

Dependiendo de cómo sea la participación de los agentes protagonistas, podemos diferenciar juegos individuales o grupales, competitivos o colaborativos, digitales o físicos, entre otros (Sosa-Espinosa et al., 2018). Aunque según los objetivos que el docente persiga deberá usar un tipo u otro en función de su adecuación a cada situación y público, los juegos grupales y colaborativos son especialmente positivos dentro de un entorno docente. Con ellos, además de trabajar los conceptos de materia que el docente plantee, el alumnado potencia también competencias sociales y cívicas (Rosefsky-Saavedra y Opfer, 2011; Perrota et al., 2013; Cheong et al., 2014; Emblen-Perry, 2018), y contribuyen a que aquellos alumnos más introvertidos o con mayor dificultad para las relaciones sociales puedan sentirse más acogidos 
por sus compañeros al encontrar una manera de acercarse a dialogar y participar con ellos. Todas estas virtudes han hecho que, actualmente, los juegos sean considerados importantes elementos docentes en las planificaciones didácticas de cualquier etapa educativa (SosaEspinosa et al., 2018).

\section{Marco conceptual}

\subsection{Creando conciencia: 'Serious games'}

Como se ha comentado en el apartado anterior, en los últimos años, el 'aprendizaje basado en juegos' ('game-based learning') es un término que ha ido tomando fuerza en el mundo de la educación (Gómez-Trigueros, 2018), siendo un campo con una gran cantidad de adeptos y que ofrece un abanico de posibilidades casi infinito para el docente. Dentro del mundo del 'aprendizaje basado en juegos', existe una rama de especial utilidad para los docentes de las disciplinas de ciencias. Hablamos de los llamados, en inglés, "serious games" (“juegos serios", en su traducción al castellano) (Schmidt et al., 2014). Este término se usa para hacer referencia aquellos juegos cuya finalidad no es entretener, si no enseñar, además de crear algún tipo de conciencia, sensibilidad o compromiso en sus participantes. Buscan hacer de sus jugadores personas implicadas con los problemas actuales, generalmente de índoles medioambiental, económica, social o cívica (Ouariachi et al., 2017; Baaden et al., 2018) (ver Tabla 2). Hablamos así de juegos de participación activa, generalmente colaborativa, y en los cuales el diálogo y escucha entre los distintos jugadores fundamenta el éxito del juego, al mismo tiempo que el aprendizaje y formación del alumnado. Dado que además este tipo de juegos potencian el pensamiento crítico y sistémico, el razonamiento y la puesta en común de ideas, son elementos idóneos para ser empleados como recursos didácticos dentro de las asignaturas de ciencias (Moroe et al., 2013; Ouariachi et al., 2017; Baaden et al., 2018).

En los últimos años, los 'serious game' fundamentados en el cambio global han sufrido un drástico auge, debido a la necesidad de hacer llegar a una mayor audiencia los problemas que acarrea y mejorar así la implicación e interés por ellos (Moroe et al., 2013; Wu y Lee, 2015). Numerosos países fundamentan gran parte de sus retos gubernamentales en conseguir paliar los efectos antrópicos sobre el medio natural (degradación de hábitat y paisajes, contaminación de aire y agua, introducción de especies invasoras, sobre-explotación de recursos naturales, contaminación de suelos, entre otros), a la par que disminuir las desigualdades sociales. Por ello, si esperan poder conseguirlos su objetivos en un futuro próximo resulta indispensable, a la vez que obvio, que aumentar la conciencia, implicación y 
preocupación de la sociedad por estos temas debe ser una de los primeras metas a conseguir (Wu y Lee, 2015).

Tabla 2. Diferencia entre un 'juego' (game) y un 'juego serio’ (serious game). [Adaptado de Mittal (2018)]

\section{GAME}

Los juegos son divertidos y pueden o no tener reglas y objetivos definidos.

Ganar y perder, si corresponde, forma parte del juego.

El juego es lo primero, las recompensas son secundarias.

La historia y las escenas son el fundamento del juego.

\section{SERIOUS GAME}

Los juegos tienen objetivos de aprendizaje definidos.

Perder puede no ser posible, porque el objetivo es motivar a los participantes, animarlas a tomar decisiones/medidas $\mathrm{y}$ aprender como resultado final.

A veces solo jugar es intrínsecamente gratificante.

La historia y escenarios sirven para contextualizar el juego, pero su fundamento son los objetivos de aprendizaje definidos.

Actualmente, el desarrollo de este tipo de "juegos serios" dentro de las aulas y centros educativos, es considerada una herramienta útil para acercar las problemáticas sociales al público más joven, dotándoles de una mentalidad ganadora y optimista, de tal manera que en su futuro profesional puedan contribuir a conseguir los objetivos ambientales y sociales globales (Corner et al., 2015; Wu y Lee, 2015).

\subsection{El caso de los ODS}

El 25 de diciembre de 2015 la Organización de las Naciones Unidas (ONU) estableció en una reunión con los principales líderes mundiales 17 objetivos globales a cumplir en los próximos 15 años (2030), con la finalidad de asegurar el futuro y prosperidad de todos los países de mundo. Hablamos de los llamados Objetivos de Desarrollo Sostenible (ODS): (1) fin de la pobreza, (2) hambre cero, (3) salud y bienestar, (4) educación de calidad, (5) igualdad de género, (6) agua limpia y saneamiento, (7) energía asequible y no contaminante, (8) industria, innovación e infraestructura, (10) reducción de las desigualdades, (11) ciudades y comunidades sostenibles, (12) producción y consumo responsable, (13) acción por el clima, (14) vida submarina, (15) vida de ecosistemas terrestres, (16) paz, justicia e instituciones 
sólidas, y (17) alianzas para lograr los objetivos. Estos objetivos surgen como una continuidad de los Objetivos del Milenio, definidos en el año 2000, los cuales fue necesario re-evaluar y reestructurar en 2015 para definir los ODS. Así, nos encontramos ante unos objetivos globales e interdisciplinares, que no solo conciernen temáticas medioambientales, sino que además albergan temáticas que competen a la salud pública, la igualdad de derechos y la educación, entre otros. Para conseguir estas metas, la ONU evidencia la necesidad y obligatoriedad de trabajar juntos y unidos desde todos los sectores, públicos y privados, y desde todas las disciplinas laborales (United Nations website). Estas líneas del tratado de la ONU, no hacen más que evidenciar lo importante que es la inclusión de estos objetivos dentro del currícullum de todas las etapas educativas. De tal manera que, los jóvenes de hoy lleguen a tener unas conciencias activas y comprometidas con el mundo (ambiental y socialmente) (Dieste et al., 2019), y lleguen a ser en un futuro los líderes que esperamos. Logrando esto, podremos ver como los ODS acaban siendo una realidad.

En el panorama educativo actual, nos encontramos que los ODS a pesar de haber sido definidos hace 5 años y tratarse de objetivos globales, no están considerados como tal dentro del currícullum de ninguna etapa educativa, por lo que resulta difícil tratarlos en los distintos cursos. De esta forma, nos encontramos con una formación difusa de los mismos (Dieste et al., 2019), trabajados siempre de manera secundaria dentro de las distintas asignaturas y contenidos, pero nunca definidos ni con su nombre, ni como lo que son: objetivos de interés global, que deben ser conocidos por su nombre, y estar representados e interiorizados así en toda la comunidad docente (centros, profesorado y alumnado).

Distintos autores, conocedores de estas lagunas dentro del currícullum educativo en nuestro país, han desarrollado y puesto en marcha iniciativas para intentar llevar los ODS y sus valores formativos dentro de las aulas (ESD Expert Net; Organización de las Naciones Unidas, 2017; Dieste et al., 2019; para nivel universitario ver Sánchez-Carracedo et al., 2017 y/o Aparicio-Chofré et al., 2018). Dieste et al. (2019) ponen especialmente sobre la mesa la necesidad de llevar los ODS a las aulas desde todas las disciplinas, no solo desde las optativas o Valores Éticos, siendo este uno de los principales retos a abordar para la educación.

Por la naturaleza de los temas que definen los ODS, y el papel fundamental que tiene la comunicación entre distintos sectores sociales para conseguirlos, es especialmente favorable que el alumnado se acerque a ellos a través de actividades donde el dialogo entre compañeros y el pensamiento crítico y lógico sea la base fundamental de las mismas (Baaden et al., 2018; Dieste et al., 2019). Es por ello que, un recurso didáctico basado en 'el juego' y 
cuya base sea el trabajo colaborativo, parece poder conseguir todos estos objetivos planteados. Estas características fundamentan el recurso (tipo 'juego de mesa') que presenta este TFM, donde además los participantes, al adquirir el rol de "salvadores del mundo", se sienten piezas fundamentales y protagonistas del proceso (Corner et al., 2015; Wu y Lee, 2015; Ouariachi et al., 2017). Este rol podrá contribuir a despertar en los participantes cierto compromiso y conseguir un sentimiento de empoderamiento ante la crisis ambiental y social que vivimos (Ouariachi et al., 2017).

\section{Objetivos}

El objetivo general del presente TFM es "desarrollar un recurso didáctico del tipo 'juego de mesa' que contribuya a la formación y conocimiento del alumnado de centros de secundaria y bachillerato en las problemáticas medioambientales y sociales actuales, a través de los Objetivos de Desarrollo Sostenible y la puesta en valor de los mismos”.

Entre los objetivos específicos se encuentran:

1. Diseñar un juego de mesa acorde al objetivo general tomando como base el juego de mesa 'La Isla Prohibida: Lánzate a la aventura... si te atreves' de Devir Iberia y GameWright ${ }^{\circledR}$.

2. Ajustar el recurso didáctico a los requerimientos curriculares de la asignatura de Ciencias de la Tierra y del Media Ambiente de $2^{\text {a }}$ Bachillerato.

3. Ajustar el recurso didáctico de tal manera que pueda ser usado como elemento didáctico para trabajar temáticas transversales medioambientales, sociales y cívicas dentro de la etapa educativa de secundaria.

\section{Diseño y planificación del recurso didáctico}

\subsection{Antecedentes del juego: La isla Prohibida}

'La Isla Prohibida: Lánzate a la aventura... si te atreves' (en adelante La Isla Prohibida), es un juego de mesa colaborativo creado por Matt Leacock y distribuido por Devir Iberia y GameWright®, diseñado para 2-4 jugadores, a partir de 10 años. Se trata de un juego colaborativo, donde los jugadores deben trabajar como un equipo para ganar. Este juego ha servido de base para diseñar y elaborar el recurso didáctico que se presenta en este trabajo fin de máster. A continuación se recogen los componentes y principales reglas que figuran en el libro de instrucciones de este juego comercial, con la finalidad de que puedan facilitar la 
comprensión de los cambios realizados en nuestro recurso didáctico docente (expuestos más adelante, en el apartado 4.2. Modificaciones del juego para la creación del recurso).

\subsubsection{Componentes del juego}

Consta de los siguientes componentes:

- 58 cartas, subdivididas a su vez en:

- 28 cartas de Tesoro: 5 de cada uno de los cuatro tesoros; 3 de ;Las aguas suben!; 3 de Ascenso al Helicóptero; y 2 de Sacos Terreros.

- 24 cartas de Inundación.

- 6 cartas de Aventurero.

- 24 losetas Isla de doble cara.

- 6 peones de madera (fichas Aventurero).

- 4 figuras de Tesoro: i) La Piedra de la Tierra; ii) La Estatua del Viento; iii) El Cristal de Fuego; y iv) El Cáliz del Océano.

- 1 Marcador de agua.

- 1 Indicador de Nivel de Agua.

\subsubsection{Contextualización del juego}

Para contextualizar el escenario y presentar los objetivos a los jugadores, La Isla Prohibida cuenta con el siguiente texto introductorio:

'La Isla Prohibida había sido el remoto refugio de un antiguo y misterioso imperio conocido como los Arcanos. Cuenta la leyenda que los Arcanos tenían la habilidad de controlar los cuatro elementos de la Tierra (fuego, viento, agua y tierra) mediante cuatro tesoros sagrados: El Cristal del Fuego, La Estatua del Viento, El Cáliz del Océano y La Piedra de la Tierra. Debido a que se podían usar para causar un daño catastrófico si cayeran en manos de sus enemigos, los Arcanos mantuvieron los tesoros escondidos en La Isla Prohibida y la prepararon de tal modo que se hundiera si algún intruso intentase hacerse con ellos. En los siglos que pasaron desde la inexplicable desaparición de su imperio, La Isla Prohibida permaneció olvidada...hasta ahora. ¿Será tu equipo el primero en desembarcar en sus orillas, recuperar los tesoros y salir con vida?' 


\subsubsection{Objetivos juego}

El objetivo del grupo de aventureros es conseguir los cuatro tesoros y salir de la isla antes de que esta se hunda, todo ello trabajando en equipo. Una vez tengan los tesoros en su poder, los jugadores deberán llegar a la Pista de Aterrizaje para escapar en helicóptero de la isla y ganar la partida. Si la isla se hunde antes de que lo jugadores completen su tarea, los tesoros se perderán en lo más profundo del océano y, por tanto, los aventureros no podrán concluir su misión.

\subsubsection{Preparando el escenario de juego}

Para preparar el juego, se deberán mezclar las 24 losetas que formarán la isla y colocarlas al azar, por el lado que no es azul y blanco, siguiendo la disposición que se indica en la Imagen 1. A la izquierda y derecha de la isla se situarán el mazo de cartas de Tesoro y el mazo de cartas de Inundación, ambos barajados. En cada una de las esquinas de la isla se situarán los cuatro tesoros, y al lado del mazo de Inundación situaremos el marcador del Nivel de Agua y su indicador.

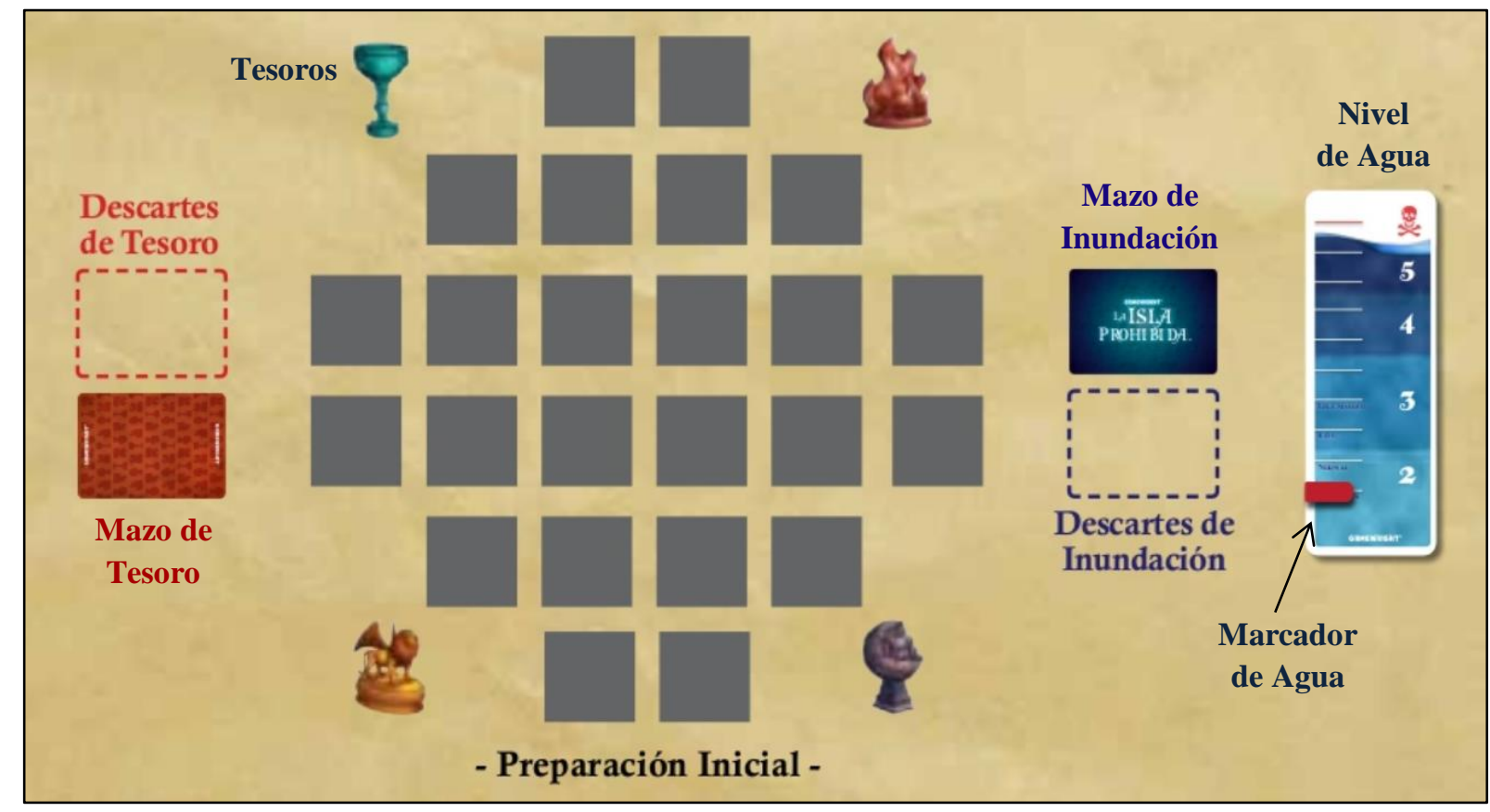

Imagen 1. Disposición inicial del juego antes de comenzar la partida.

Los exploradores verán que hay 8 losetas de juego donde aparecen cada uno de los tesoros (dos losetas por cada tesoro, ver Imagen 2). Para poder conseguir los tesoros durante 
el juego, un jugador deberá tener en su poder 4 cartas de ese tesoro y situarse en una de las losetas asociadas a dicho tesoro.

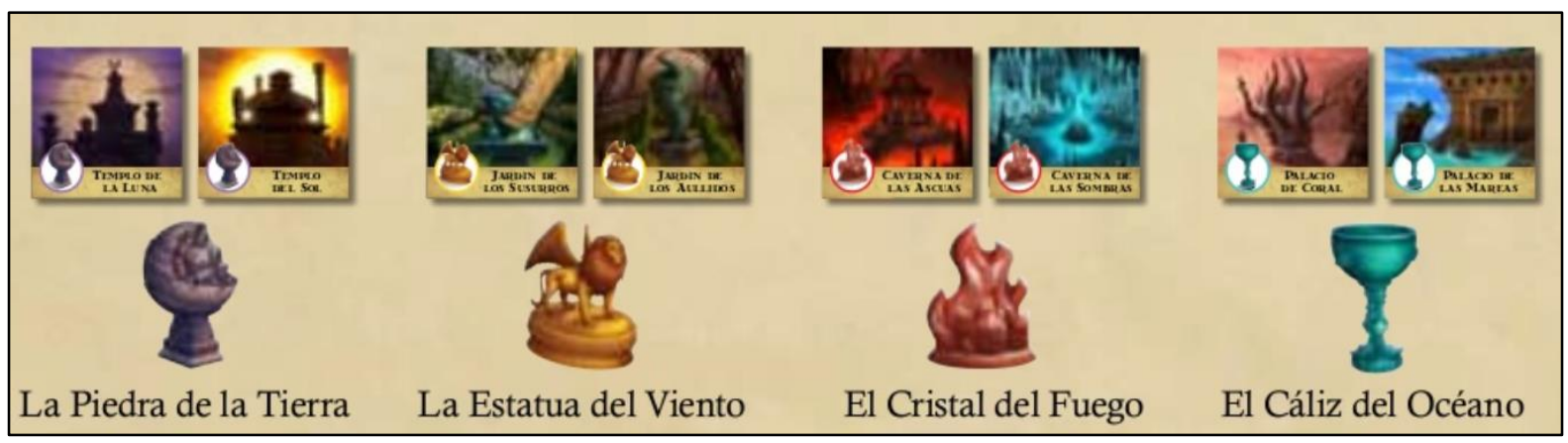

Imagen 2. Tesoros de La Isla Prohibida y losetas de la isla asociadas a cada uno de ellos.

\subsubsection{Comienza el juego}

En primer lugar, la isla comienza a hundirse. Se roban 6 cartas del mazo de Inundación. Los jugadores deberán buscar las 6 losetas homólogas que indiquen las cartas, y girarlas. Esas losetas pasarán de estar 'a color' a estar en tonos 'azules y blancos', lo que indica que están inundadas (ver Imagen 3). Deja boca arriba las 6 cartas que has robado del mazo de Inundación en la pila de descartes de Inundación (ver Imagen 1).

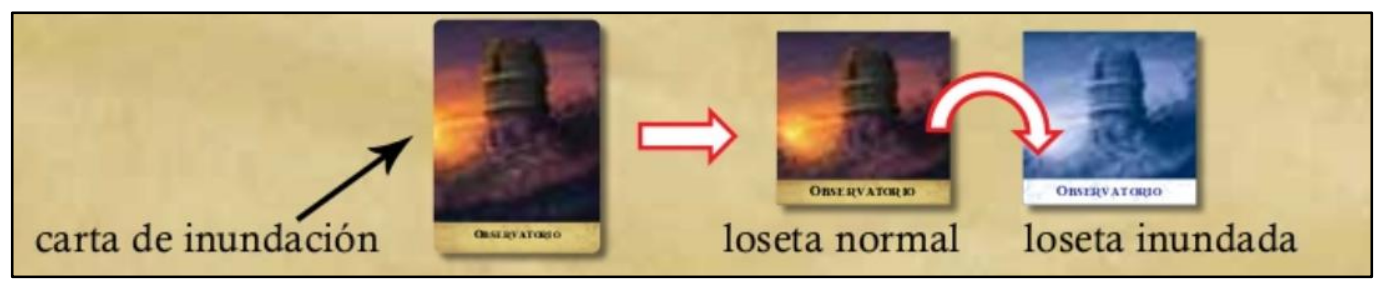

Imagen 3. Muestra como una loseta de la isla (a color) pasa a estar inundada (en tonos celeste y blanco) cuando sale su carta de Inundación homóloga.

En segundo lugar, los jugadores toman el rol de Aventurero. Para ello, se mezclan las 6 cartas de Aventurero, y se reparte una al azar a cada jugador. Cada aventurero cuenta con una habilidad especial, especificada en su carta, que debe comunicar a sus compañeros para que todos puedan conocer los puntos fuertes del equipo (ver apartado 4.1.8. Habilidades especiales de los Aventureros para más información). Además las cartas de Aventurero recogen las pautas y posibles acciones que puede realizar cada jugador durante su turno. Los aventureros deberán situar el peón de su color en su correspondiente loseta de salida de la isla, 
(tiene un peón de su color en la parte inferior). Las losetas de salida de los jugadores pueden estar inundadas o no, sin que suponga un problema.

En tercer lugar, se reparten dos cartas de Tesoro a cada jugador. Cada uno situará estas cartas delante de él y boca arriba en la mesa, para que todo el equipo pueda ver fácilmente que cartas tiene en su poder. Si en este reparto inicial de cartas de Tesoro, un jugador recibiera una carta de 'iLas aguas suben!', esta carta se mete de nuevo en el mazo de Tesoro barajándolo y se da una carta nueva de Tesoro a ese jugador.

Y por último, hay que establecer el Nivel de Agua del que parte el juego (para ello se usan el marcador e indicador de nivel). En función de la dificultad con la que se quiera empezar la partida, podremos elegir (de menor a mayor): primera línea del nivel 2 (Iniciación); segunda línea del nivel 2 (Normal); primera línea del nivel 3 (Élite); y segunda línea del nivel 3 (Legendario).

\subsubsection{Secuencia de juego y tipos de acciones}

Empieza la partida el Aventurero que haya visitado la isla más recientemente, y se continua siguiendo las agujas del reloj. Cada turno consta de las siguientes fases (se especifican también en las cartas de Aventurero): i) hacer hasta 3 acciones; ii) robar 2 cartas del mazo de Tesoros (de una en una); y iii) robar tantas cartas de Inundación cómo indique el nivel de agua. Cada jugador como máximo puede tener en su poder (delante de él sobre la mesa y boca arriba) un máximo de 5 cartas (incluidas las cartas de Tesoros y las de Acción Especial). Si en algún momento un jugador tiene 6 o más cartas (ya sea por robarlas o porque un jugador le ha pasado cartas) debe descartar inmediatamente el exceso a la pila de descartes de Tesoro (antes de descartar una carta de Acción Especial, el jugador puede usarla).

En cuanto a los tipos de acciones permitidas en el juego, son cuatro:

- Mover: Gastando 1 o más acciones puedes mover tu peón a una loseta adyacente, ya sea arriba, abajo, a la derecha o a la izquierda. No está permitido moverse en diagonal. Puedes moverte a una loseta inundada, pero no puedes ocupar o pasar por encima de una loseta perdida (aquella que ha desaparecido del juego por ser inundada dos veces).

- Asegurar: Significa reflotar una loseta que ha sido previamente inundada (es decir, damos la vuelta a una loseta de tonos celestes y blancos, y volvemos a ponerla por su lado de color). Gastando 1 o más acciones puedes asegurar 
cualquier loseta adyacente a tu posición (arriba, abajo, a la izquierda o a la derecha) o aquella loseta en la que te encuentres.

- Entregar una carta de Tesoro a otro jugador: Cuando dos peones se encuentre dentro de la misma loseta, pueden intercambiar cartas de Tesoro (1 o más) durante su turno. Cada intercambio cuesta 1 acción, y no está permitido el intercambio de cartas especiales (ver apartado 4.1.7. Cartas especiales).

- Recuperar un Tesoro: Cuando un Aventurero tenga 4 cartas iguales de un Tesoro, siempre que se encuentre en una de las losetas asociadas a ese Tesoro, podrá descartar esas cartas y recuperar dicho Tesoro (ver Imagen 4). Recordamos que en la isla cada Tesoro cuenta con dos losetas asociadas (muestran el Tesoro en una de sus esquinas). Puedes recuperar un Tesoro en una loseta inundada (en tonos celestes y blancos). Las cartas de Tesoro descartadas se ponen en la pila de descartes de Tesoro (ver Imagen 1).

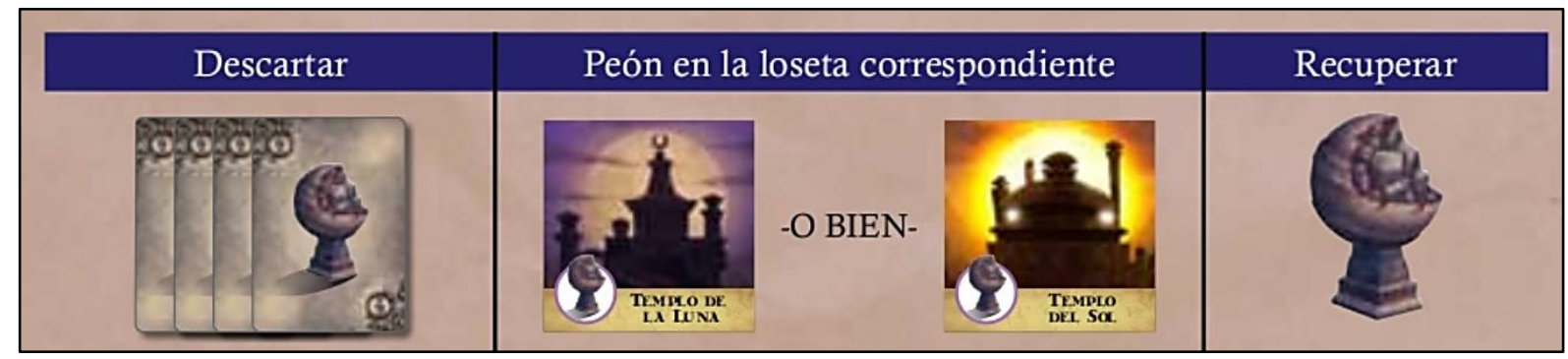

Imagen 4. Proceso para recuperar de un Tesoro por parte de un jugador.

Recordamos que cada Aventurero cuenta con habilidades especiales que pueden permitir modificaciones particulares de las acciones aquí detalladas (ver apartado 4.1.8. Habilidades especiales de los Aventureros para más información). Cada jugador puede realizar un máximo de 3 acciones por turno (puede también hacer 0,1 o 2). Ya que es un juego colaborativo, es recomendable que los jugadores se ayuden en la elección de acciones durante los turnos.

\subsubsection{Cartas especiales}

En el mazo de Tesoro, además de las cartas asociadas a cada uno de los Tesoros (hay 5 cartas por Tesoro), podemos encontrar tres tipos de cartas especiales (Imagen 5):

- Ascenso en Helicóptero: Es considerada una carta de acción especial para los Aventureros. Permite: i) mover uno o más peones que estén en una misma loseta 
a otra cualquiera (sin necesidad de que se adyacente); y ii) salir de la isla desde a pista de aterrizaje con todo el equipo (una vez conseguidos todos los tesoros) y ganar la partida. Puede ser usada en cualquier momento (no solo durante el turno del jugador que la posee) y no gasta ninguna acción por su uso. Cuando se usa esta carta, es descartada inmediatamente a la pila de descartes de Tesoro.
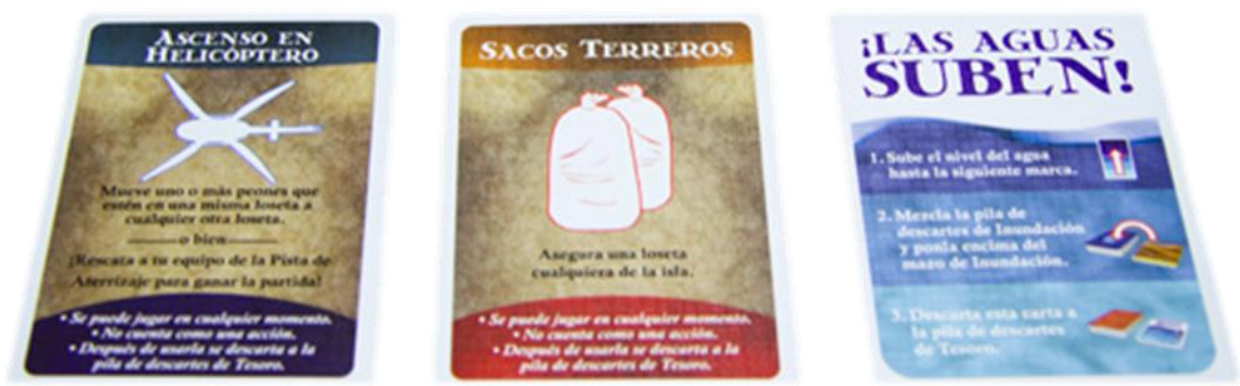

Imagen 5. Los tres tipos de cartas especiales que se encuentran dentro del mazo de Tesoro: i) cartas de acción especial ('Ascenso en Helicóptero' y 'Sacos Terreros'); y ii) carta de 'iLas aguas suben!'.

- Sacos Terreros: Es considerada también una carta de acción especial para los Aventureros. Permite asegurar una loseta inundada de la isla aunque no sea adyacente a la posición del Aventurero que posee dicha carta. Puede ser usada en cualquier momento (no solo durante el turno del jugador que la posee) y no gasta ninguna acción por su uso. Cuando se usa esta carta, es descartada inmediatamente a la pila de descartes de Tesoro.

- ¿Las aguas suben!: Esta carta es la causante de que el nivel de agua de la isla vaya subiendo. Cuando un jugador robe una carta de ¡Las aguas suben!, debe hacer lo siguiente: i) subir el indicador del Nivel de Agua hasta la siguiente línea de nivel; ii) baraja las cartas del mazo de descartes de Inundación y ponla boca abajo sobre el mazo de Inundación (esto hace que las cartas que habían sido ya usadas, vuelven a estar disponibles en el mazo y, además, sean robadas pronto); iii) robar (de una en una) tantas cartas del mazo de Inundación como indique ahora el marcador del Nivel de Agua e inundar las losetas de la isla que te indiquen estas; y iv) dejar la carta de ;Las aguas suben! en el mazo de descartes de Tesoro. Cuando las cartas de Inundación indiquen que debemos inundar una loseta que se encuentre ya inundada (color celeste y blanco), deberemos eliminar 
del juego tanto esa loseta de la isla como su carta de Inundación asociada (ver Imagen 6). La eliminación de losetas hace que la isla sea cada vez más pequeña y los Aventureros vean dificultados sus movimientos por ella (ya que no pueden usar los huecos de las losetas eliminadas para moverse por la isla).

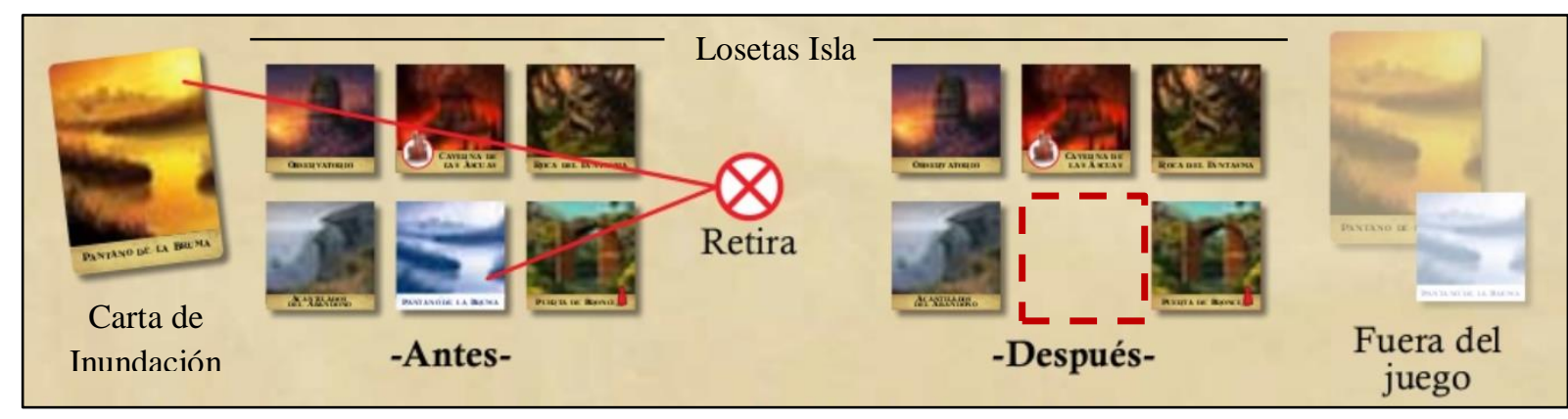

Imagen 6. Proceso por el cual se produce la eliminación de una loseta de la isla y de su carta asociada del juego.

Nota: Si se roba una carta de ;Las aguas suben!, no se roba luego otra carta para sustituirla. // Si cuando se roba una cartas de ¡Las aguas suben! no hay ninguna carta en la pila de descartes de Inundación, simplemente se sube el Nivel de Agua hasta la siguiente marca y se siguen el resto de pasos indicados arriba. // Si se roban dos cartas seguidas de ;Las aguas suben!, se suben dos líneas el Nivel de Agua, pero se mezcla solo una vez la pila de descartes de Inundación.

\subsubsection{Habilidades especiales de los Aventureros}

En total el juego cuenta con 6 posibles roles de Aventurero (ver Imagen 7), cada uno de ellos con una habilidad especial, la cual posibilita a cada jugador ligeras modificaciones en sus posibles acciones durante el juego. Así, encontramos:

- El Ingeniero: Puede asegurar hasta 2 losetas gastando sólo una acción.

- El Navegante: Puede mover a otro jugador hasta 2 losetas adyacentes, gastando una acción.

- El Piloto: Puede volar a cualquier loseta de la isla, una sola vez en cada turno, gastando una acción

- El Explorador: Puede moverse o asegurar losetas en diagonal. 
- El Submarinista: puede moverse a través de una o más losetas adyacentes inundadas y/o perdidas, gastando una acción. Debe terminar su turno en una loseta.

- El Mensajero: Puede entregar cartas de Tesoro a un jugador que se encuentre en cualquier lugar de la isla. Gasta una acción por cada carta que entregue.

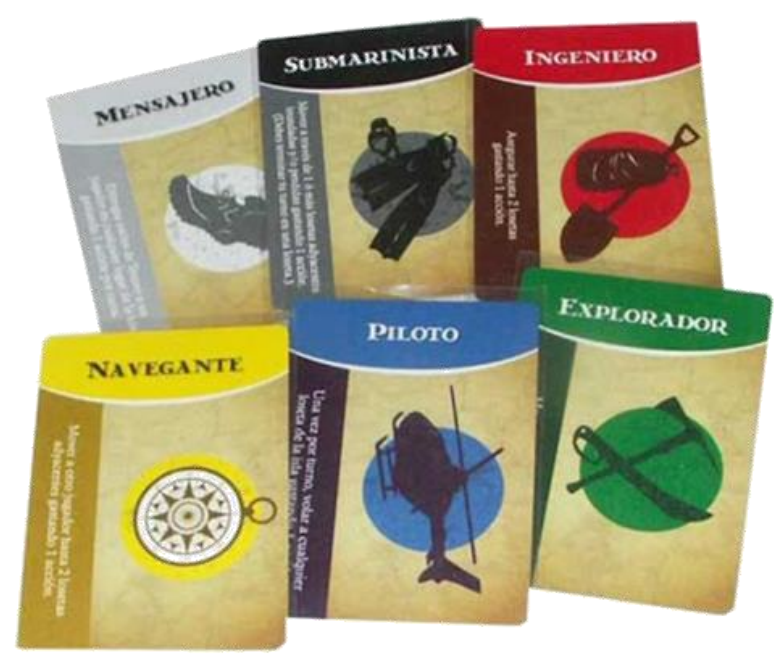

Imagen 7. Cartas de Aventurero donde se muestran los seis posibles roles de juego.

\subsection{9. ¿Ganar o perder?}

Para ganar el juego, todo el equipo de Aventureros no solo debe llegar a la Pista de Aterrizaje y tener los 4 Tesoros en su poder, sino que además un jugador debe disponer de una carta de 'Ascenso en Helicóptero'. Ese jugador deberá hacer uso de esa carta, descartándola, para sacar volando a todo el equipo de La Isla Prohibida y resultar victoriosos en su misión. Por el contrario, se pierde la partida si se cumple alguno de los siguientes supuestos:

- Cuando una loseta deba ser eliminada del juego (Imagen 6) y tenga un peón encima, ese jugador deberá moverse inmediatamente a una loseta adyacente (arriba, abajo, izquierda o derecha). Si el jugador no tuviera posibilidad de moverse a ninguna loseta adyacente, se hundirá en el abismo, y todos perderán la partida al no poder salir juntos de la isla.

- Cuando se eliminen las dos losetas asociadas a un Tesoro, y los Aventureros aún no hayan sido capaces de recuperarlo, se perderá la partida al no poder ya conseguir todos los Tesoros. 
- Cuando se elimine del juego la loseta de la Pista de Aterrizaje, los Aventureros nunca podrán salir de la isla, y no podrán completar su misión.

- Cuando el Nivel de Agua llegue hasta la calavera del último nivel, la isla se habrá hundido completamente y el juego habrá concluido

\subsection{Modificaciones del juego para la creación del recurso}

El recurso didáctico desarrollado para este trabajo toma como referencia el juego de mesa colaborativo 'La Isla Prohibida' (para más información ver apartado 4.1 Antecedentes del juego: La Isla Prohibida). A continuación se recogen las modificaciones realizadas al mismo con la finalidad de crear un recurso didáctico acorde a los criterios de evaluación de interés en este trabajo (ver apartado 5.2. Contenidos, criterios de evaluación y estándares de aprendizaje evaluables para más detalles).

\subsubsection{Contextualización del recurso}

En este caso, hemos realizado un cambio del contexto en el que se desenvuelve la historia y objetivos del juego. Nuestro recurso pretende trabajar temas que quedan encuadrados dentro del currícullum de bachillerato, concretamente en la asignatura de Ciencias de la Tierra y del Medio Ambiente (CTMA) de $2^{\circ}$ de Bachillerato, tales como la valoración y preocupación por el medio ambiente y su biodiversidad, el impacto de las actividades humanas, el desarrollo social y económico así como trabajar la implicación social y empática del alumnado. De esta forma, el texto introductorio que se presenta a los jugadores en nuestro juego de mesa es el siguiente:

'El día de mañana ha llegado. El ser humano lleva años haciendo y deshaciendo el planeta a su antojo. Sin estar nunca suficientemente satisfecho, y sin saber poner adecuadamente un límite a sus acciones. Tras años inmersos en esta mentalidad, la especie humana ha llevado al planeta a una situación crítica, poniendo en peligro su propia supervivencia. El nivel del mar está subiendo de manera acelerada, ciudades y pueblos costeros comienzan a quedarse sumergidos bajo los fondos del océano, las tierras de cultivo son cada vez menores, la temperatura del planeta aumenta cada año y nuestra atmosfera es cada vez más pobre en oxígeno. Algunas de las civilizaciones más recónditas del mundo se preparan para la una migración hacia nuevas tierras, viéndose obligados a dejar atrás todo aquello que habían construido: esquimales y lapones (por la reducción drástica de los hielos 
polares), mongoles (por el avance del desierto del Gobi), o kiribatianos (por la el aumento del nivel del mar y la contaminación salina de sus pozos).

Sin embargo, esto es solo el principio. La superficie terrestre se irá hundiendo cada vez más rápido y acabará siendo insuficiente para todos. Debemos prepararnos para un éxodo global. Los líderes del mundo, junto con los científicos más experimentados, se reúnen en la base secreta de operaciones especiales del Monte Pasabán. Deben poner en marcha la Operación ODS: 'Si logramos instaurar los 17 Objetivos de Desarrollo Sostenible en todos los países del mundo, lograremos revertir nuestro desastre’. Sin embargo, ¡hay un problema! Para poner en marcha este Plan de Emergencia, se necesitan 4 llaves-insignia, que fueron escondidas en la base secreta de la Isla de Pan, una isla desierta en lo más profundo del océano Pacífico. Pero ahora mismo, ¡la isla se está hundiendo por completo! Los expertos están reclutando a un grupo altamente capacitado de Aventureros, que estén dispuestos a viajar a la isla, resolver los acertijos que llevan a las 4 llaves-insignia, recuperarlas y traerlas de vuelta para salvar el mundo tal y como lo conocemos. ¡Todo antes de que se hunda la Isla! ¿Qué me dices? ¿Estás dispuesto a aceptar la misión?’

\subsubsection{Componentes del recurso}

Nuestro trabajo pretende contribuir a que el alumnado: i) adquiera conocimientos relacionados con medioambiente, sostenibilidad, bienestar y salud; ii) comprenda la interconexión existente entre todos estos factores; iii) conozca la existencia y significado de los ODS; y iv) comprenda cómo se relacionan estos con todas esas temáticas. Con la finalidad de adecuar el juego de mesa a estos objetivos didácticos, los componentes del mismo han sido rediseñados de la siguiente forma:

- 89 cartas, subdivididas a su vez en:

- 59 cartas ODS: Divididas 4 familias de cartas ODS (Agua, Tierra, Sostenibilidad y Bienestar; ver Anexo 1), han sustituido a las cartas de Tesoro. Hay 12 cartas asociadas a cada una de las familias (están relacionadas a su vez con las distintas llaves-insignia y con diferentes ODS; ver apartado 4.2.8. Cartas $O D S$ para mayor detalle). En este mazo de cartas encontramos además:

- 4 cartas camufladas de iSuben las aguas!: Indican que hay que subir el marcador del Nivel de Agua en una unidad. Han sustituido a las cartas de 'iLas aguas suben!'. 
- 4 cartas camufladas de Despegamos: Son cartas que permiten moverse volando por la isla y salir de la isla tras conseguir las llaves-insignia. Han sustituido a las cartas de 'Ascenso al Helicóptero'.

- 3 cartas camufladas de Flotadores: Son cartas que permiten reflotar losetas que han sido hundidas, independientemente de su posición en la isla. Han sustituido a las cartas de 'Sacos Terreros'.

- 24 cartas de Inundación: Son las cartas que indican las 'losetas Isla' que deben ir hundiéndose a lo largo del juego. Acorde a la temática de nuestro juego, muestran distintos escenarios, prácticas o situaciones con las que se espera que, cómo ciudadanos, estemos comprometidos socialmente (es decir, enseña un mundo que se implica con los ODS).

- 6 cartas de Aventurero: Definen el rol que toma cada jugador en el juego. Cada carta de Aventurero lleva información sobre tres aspectos: i) la habilidad especial del Aventurero en cuestión; ii) la secuencia de juego; y iii) las acciones (generales) posibles en él. Las cartas han sido rediseñadas, siendo el color de cada una de ellas indicativo del color de la ficha/peón del Aventurero en el juego (ver Anexos 2 y 3).

- 24 losetas Isla de doble cara: Cada loseta cuenta con dos caras. La cara con tonos de colores se muestra cuando la loseta está a flote, y la cara con tonos ocres y apagados se muestra cuando la loseta está hundida. Las losetas a color muestran los distintos escenarios, prácticas o situaciones con las que se espera que, cómo ciudadanos, estemos comprometidos socialmente (son los mismos escenarios que muestran las cartas de Inundación). El lado de color ocre de cada loseta muestra el escenario contrario, es decir, en qué se convierte el mundo si nuestra implicación en los ODS es nula.

- 6 peones de madera (fichas Aventurero): Son las fichas que representan a cada jugador.

- 4 figuras de Tesoro: En esta caso, los Tesoros son cada una de las llaves-insignia (Agua, Tierra, Sostenibilidad y Bienestar; ver Anexo 4) que deben recuperar los Aventureros en su misión.

- 1 Marcador de agua: Similar al del juego original pero con un nuevo diseño. Se ha modificado especialmente el último nivel del mismo, donde en lugar de 
aparecer una calavera con dos tibias cruzadas, ahora vemos un logotipo de un 'hombre al agua'. La finalidad de dicho cambio es que, en caso de perder, en lugar de aludir a la muerte de los jugadores, se haga alusión a que simplemente “caen al agua" al hundirse la isla por completo (ver Anexo 5).

- 1 Indicador de Nivel de Agua (ver Anexo 5).

Cabe destacar que, para el diseño de todos los componentes del recurso se ha seguido una paleta de colores que sirviera de unión entre todos ellos. De este modo, la llave-insignia, las cartas del mazo ODS, las cartas del mazo Inundación, y las losetas Isla que sean del mismo color (o se encuentre delimitadas por él) están relacionadas con la misma familia (azul para aludir a la familia ODS de Agua, verde para la de Tierra, rojo para la de Sostenibilidad, y naranja para la de Bienestar; ver Imagen 8).

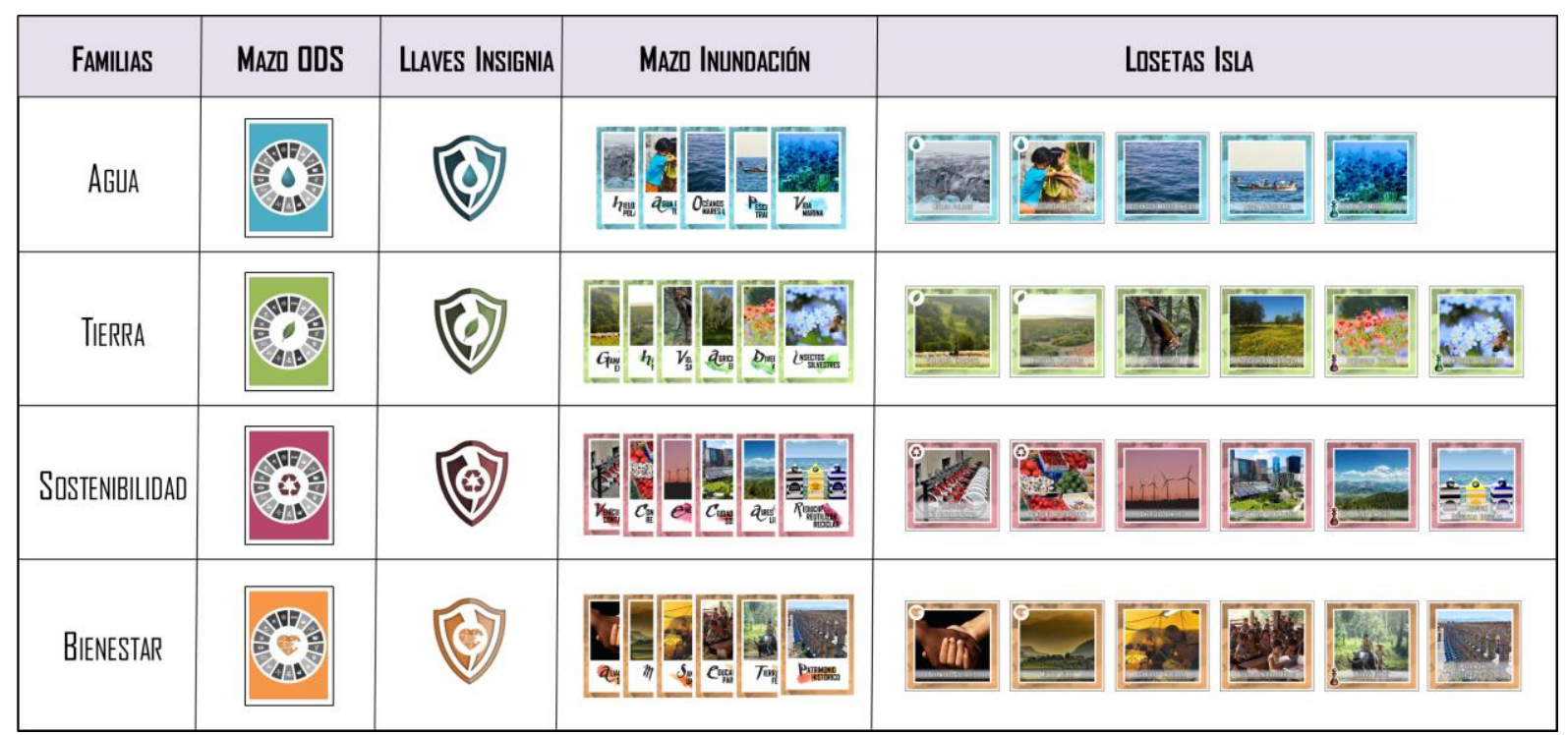

Imagen 8. Relación por el color entre los diferentes elementos del recurso elaborado y las cuatro familias de ODS diseñadas para el mismo.

Para el desarrollo del juego, y dado que han sido incluidos códigos QR (ver más detalles en apartado 4.2.8 Cartas $O D S$ ) para ayudar al alumnado en el proceso de enseñanza y aprendizaje durante la partida, es necesario contar con algún dispositivo móvil o tablets (con acceso a internet) que permita a los jugadores poder interactuar con dichos códigos durante el transcurso del juego. 


\subsubsection{Objetivos del recurso}

Para el alumnado, el objetivo del juego creado es similar al objetivo del juego de mesa original: deben salir en grupo de la isla, antes de que esta se hunda, con las 4 llaves insignias. Así habrán logrado salvar el mundo y a sus civilizaciones, al haberlo instaurado en todos los países los ODS. Para el docente, los objetivos didácticos generales a conseguir con dicho recurso por parte de su alumnado son: i) adquirir conocimientos relacionados con medioambiente, sostenibilidad, bienestar y salud; ii) conocer la existencia y significado de los ODS y iii) comprender la interconexión existente entre todos estos factores. Los objetivos didácticos específicos serían los estipulados en el currícullum de la asignatura de Ciencias de la Tierra y del Medio Ambiente de $2^{\circ}$ de Bachillerato y que son tratados en este recurso (ver apartado 5. Didáctica del recurso).

\subsubsection{Preparando el escenario del recurso}

La preparación del recurso sigue las mismas normas que las explicadas para el caso del juego original (ver apartado 4.1.4 Preparando el escenario del juego). Simplemente el mazo de cartas de Tesoro es sustituido por el mazo de cartas ODS y los cuatro tesoros son sustituidos por las 4 llaves-insignias. Las losetas Isla del juego han sido diseñadas especialmente para mostrar temáticas relacionadas con cada una de las cuatro familias del juego (Agua, Tierra, Salud y Bienestar). El haz de cada loseta muestra un escenario favorable de la misma, mientras que el envés (en tono ocre o apagado) exhibe un escenario cuando no se consiguen los ODS. De esta forma, en función de su relación con dichas familias diferenciamos las siguientes losetas (en paréntesis figura el nombre de la cara inversa de la loseta, la cara ocre):

- Familia Agua (azul): Océanos y mares limpios (vs. océanos y mares de plástico); agua para todos (vs. sin agua potable); hielos polares (vs. disminución de hielos polares); vida marina (vs. destrucción de la vida marina); pesca tradicional (vs. pesca intensiva).

- Familia Tierra (verde): Agricultura ecológica (vs. agricultura intensiva); ganadería extensiva (vs. agricultura intensiva); diversidad vegetal (vs. no plantas silvestres); insectos silvestres (vs. no insectos); hábitats naturales (vs. destrucción de hábitats); vida salvaje (vs. vida cautiva).

- Familia Sostenibilidad (roja): Aires limpios (vs. aires contaminados); ciudades sostenibles (vs. ciudades no sostenibles); vehículos no contaminantes (vs. 
vehículos contaminantes); energías limpias (vs. energías contaminantes); consumo responsable (vs. consumo excesivo); reducir, reutilizar y reciclar (vs. usar y tirar).

- Familia Bienestar (naranja): Tierra fértil (vs. tierra estéril); alianzas sociales (vs. no alianzas sociales); educación para todos (vs. trabajo infantil); patrimonio histórico y cultural (vs. destrucción de patrimonio); mundo rural (vs. vida urbana); sanidad universal (vs. sin acceso a sanidad).

Adicionalmente, existe una loseta extra, la 'pista de aterrizaje' (en tonos amarillos), que no está relacionada con ninguna de las familias anteriores, pero es necesaria para que los jugadores puedan salir de la Isla para concluir la misión (al igual que ocurre en el juego original). La Imagen 9 muestra cómo quedaría el escenario de juego del recurso antes de comenzar la partida. La Imagen 10 muestra la cara inversa (tonos ocres o grises) de todas las losetas Isla del recurso (es la cara que mostrarán las losetas Isla de la Imagen 9, a color, cuando se vayan hundiendo en el transcurso del juego). El Anexo 6 muestra con mayor detalle el diseño de las losetas Isla diseñadas.

Del mismo modo que en el juego original, en la isla encontramos: i) losetas asociados a los peones de los jugadores (fichas), que marcan las losetas de salida de cada jugador al inicio del juego (para más detalle ver Anexo 6, losetas que cuentan con un peón en su esquina inferior-izquierda); y ii) dos losetas asociadas a cada llave-insignia (el homólogo a los Tesoros del juego original; ver Imagen 11 y Anexo 6 para mayor detalle). El mazo Inundación ha sido rediseñado para el recurso tomando como escenarios los mismos que figuran en las losetas isla, ya que este mazo se encargará de indicar a los jugadores qué losetas deben ir hundiendo a lo largo de la partida. El Anexo 7 recoge las cartas diseñadas para el mazo de Inundación (tanto el envés, como las imágenes del haz de cada una).

En el juego original, recordamos que, el jugador debía conseguir 4 cartas de un mismo Tesoro y situarse en una de las losetas asociadas a dicho tesoro para conseguir recuperarlo. En nuestro caso, el jugador tendrá que conseguir 3 cartas de una misma familia de ODS (es decir, de Agua, Tierra, Sostenibilidad o Bienestar) para recuperar una llave-insignia y situarse en una de sus losetas asociadas. El proceso por el que un jugador, en colaboración con el equipo, puede conseguir cartas ODS queda explicado detalladamente en el apartado 4.2.8 Cartas ODS. 


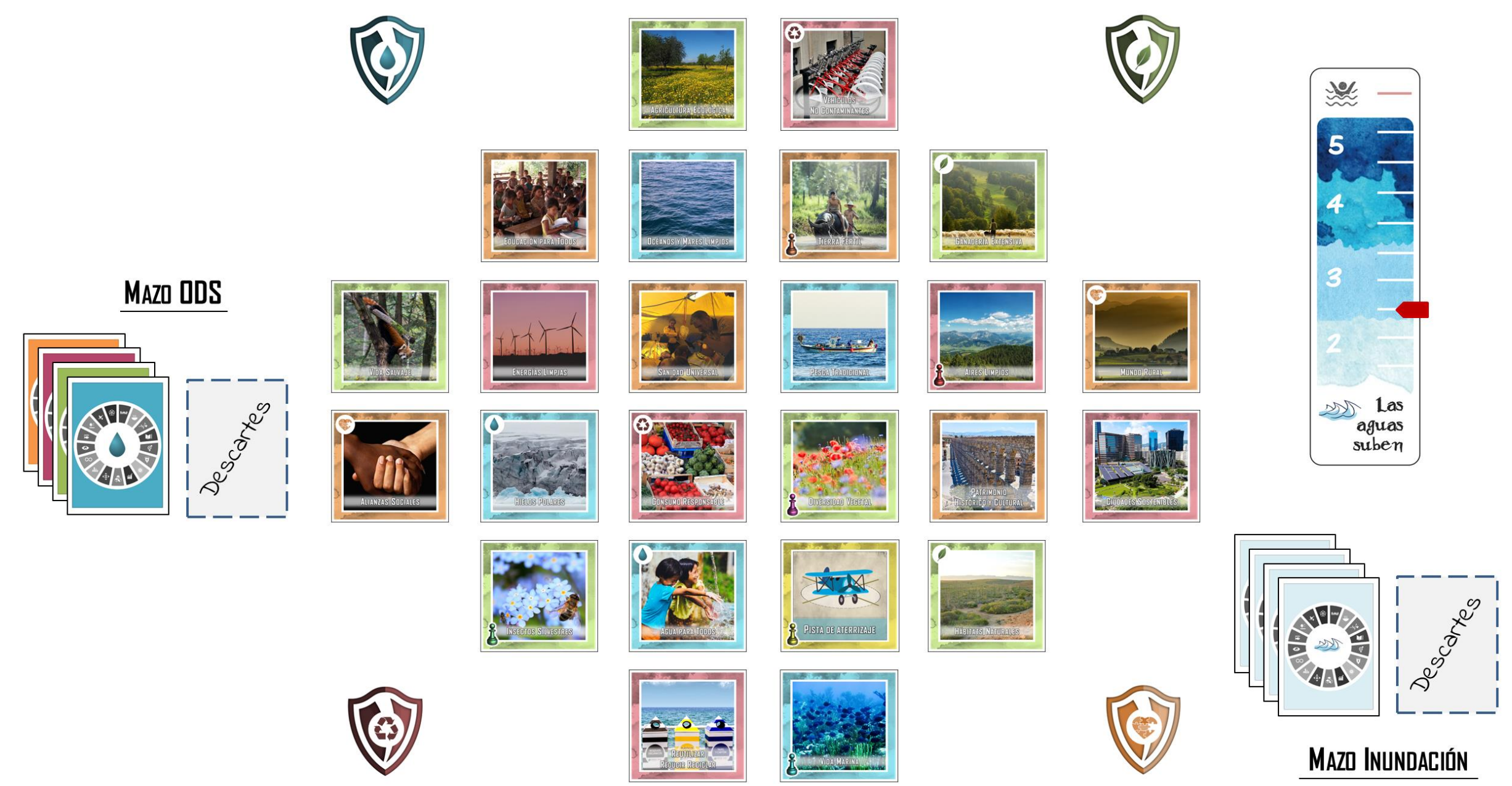

Imagen 9. Visualización del escenario de juego sobre la mesa antes de comenzar la partida. Las losetas muestran escenarios que tienen lugar cuando se consiguen los ODS. 


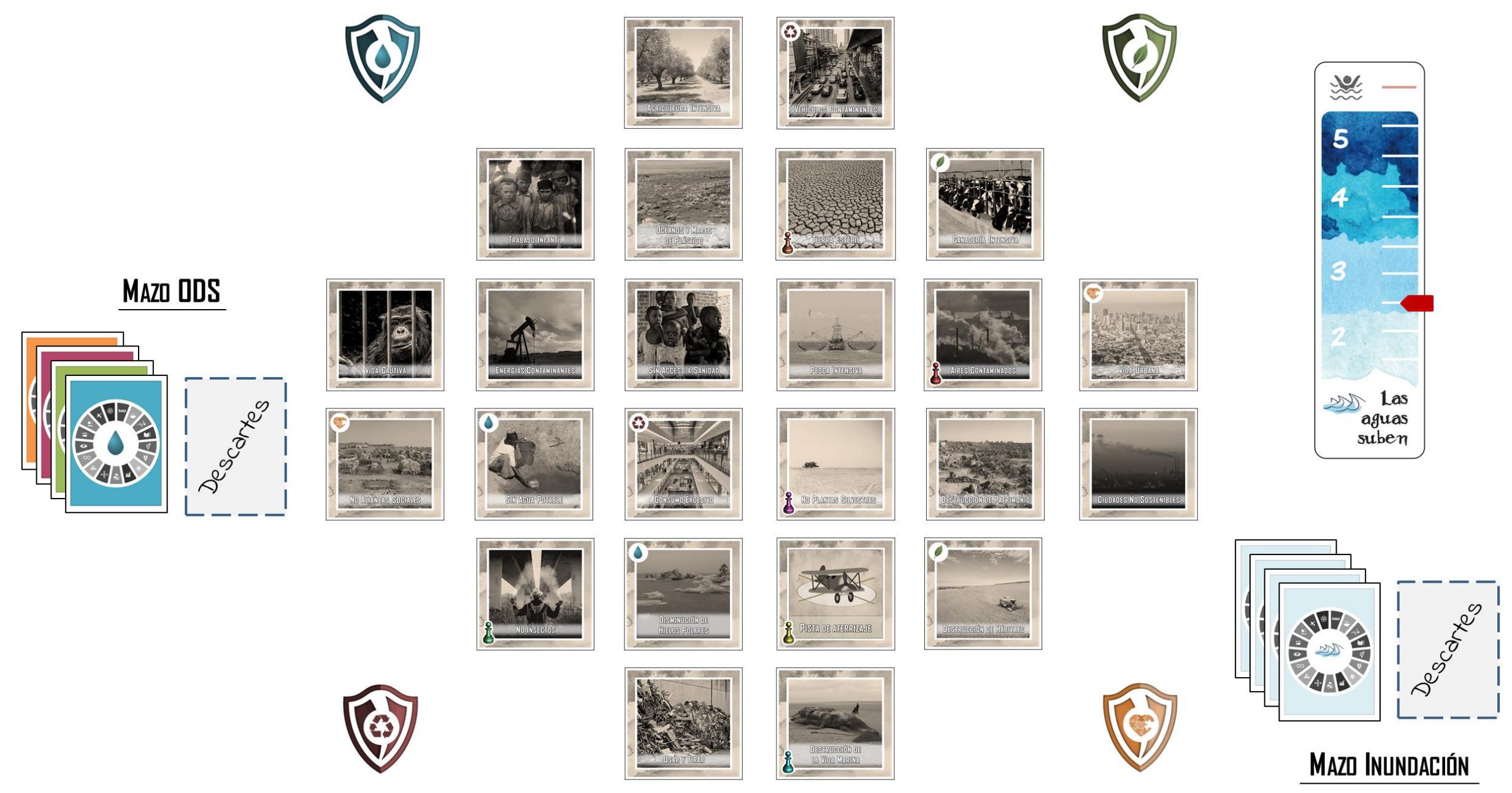

Imagen 10. Visualización del escenario de juego sobre la mesa en el caso de que todas las losetas Isla estuvieran hundidas. Muestra escenarios que tienen lugar cuando no se consiguen los ODS. 

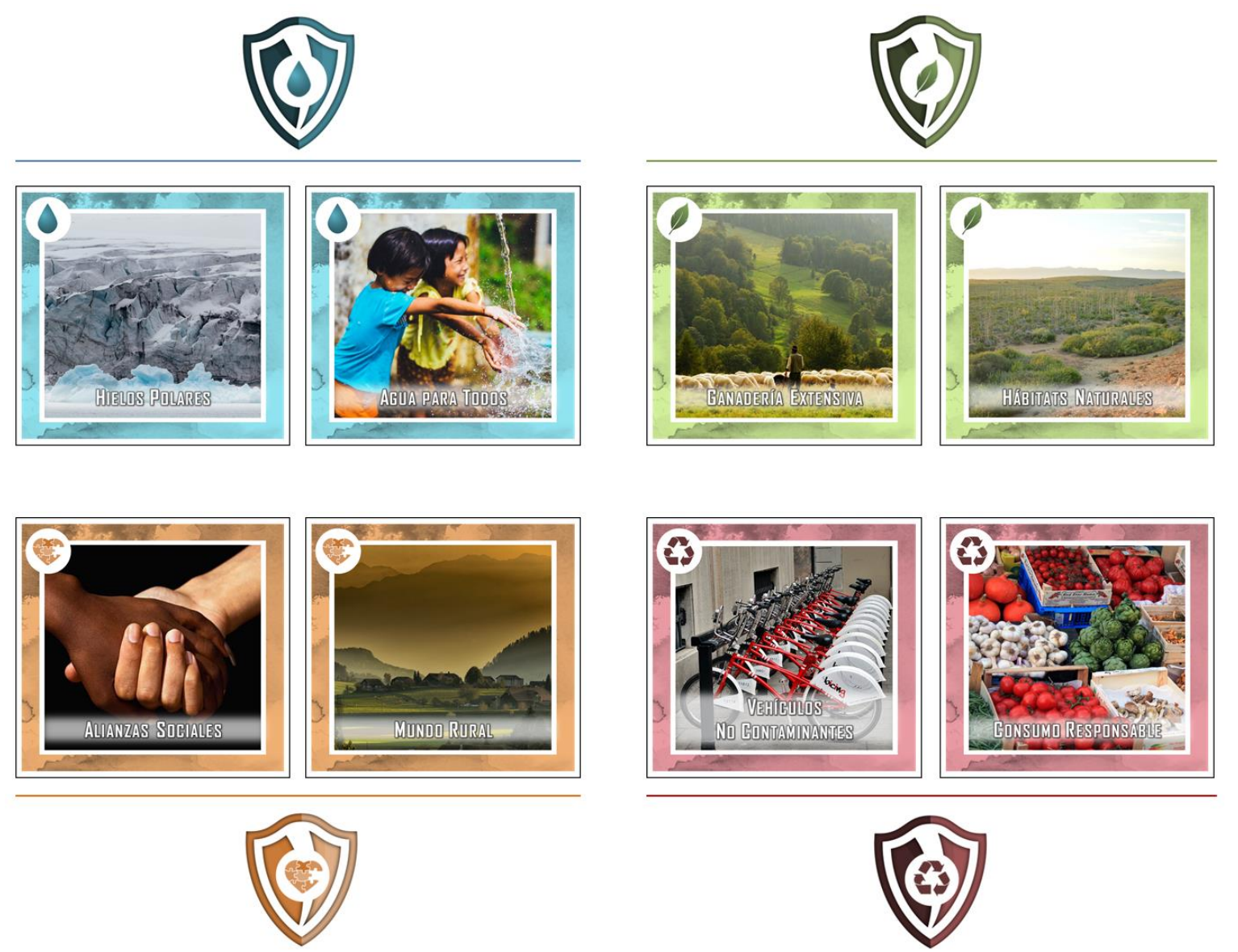

Imagen 11. Llaves-insignia (Tesoros) asociadas a su pareja de sus losetas en la isla.

\subsubsection{Desarrollo de juego didáctico}

Teniendo en cuenta las modificaciones realizadas, para el desarrollo de juego se siguen las mismas pautas que las comentadas en el juego original (ver apartados 4.1.5. Comienza el juego; 4.1.6 Secuencia de juego y tipos de acciones; y 4.1.9 ¿Ganar o perder?). En este caso, los jugadores habrán ganado el juego si consiguen salir en grupo de la isla con las 4 llaves-insignias antes de que la isla se hunda. Si completan la misión, habrán instaurado los ODS en todos los países del mundo y salvado así no solo a las civilizaciones más sensibles al Cambio Global, sino a toda la humanidad.

\subsubsection{Cartas especiales del recurso}

Del mismo modo que en el juego original, en el mazo de cartas ODS encontraremos tres tipos de cartas especiales camufladas (Imagen 12; ver Anexo 8 para mayor detalle):

- Despegamos: Sustituyen las cartas de Ascenso en Helicóptero del juego original.

- Flotadores: Sustituyen las cartas de Sacos Terreros del juego original. 
- Suben las Aguas: Sustituyen las cartas de ¡Las aguas suben! del juego original.

Los tres nuevos tipos de cartas especiales mantienen la función de las cartas del juego original de las que proceden (ver detalles de funciones en apartado 4.1.7. Cartas especiales).
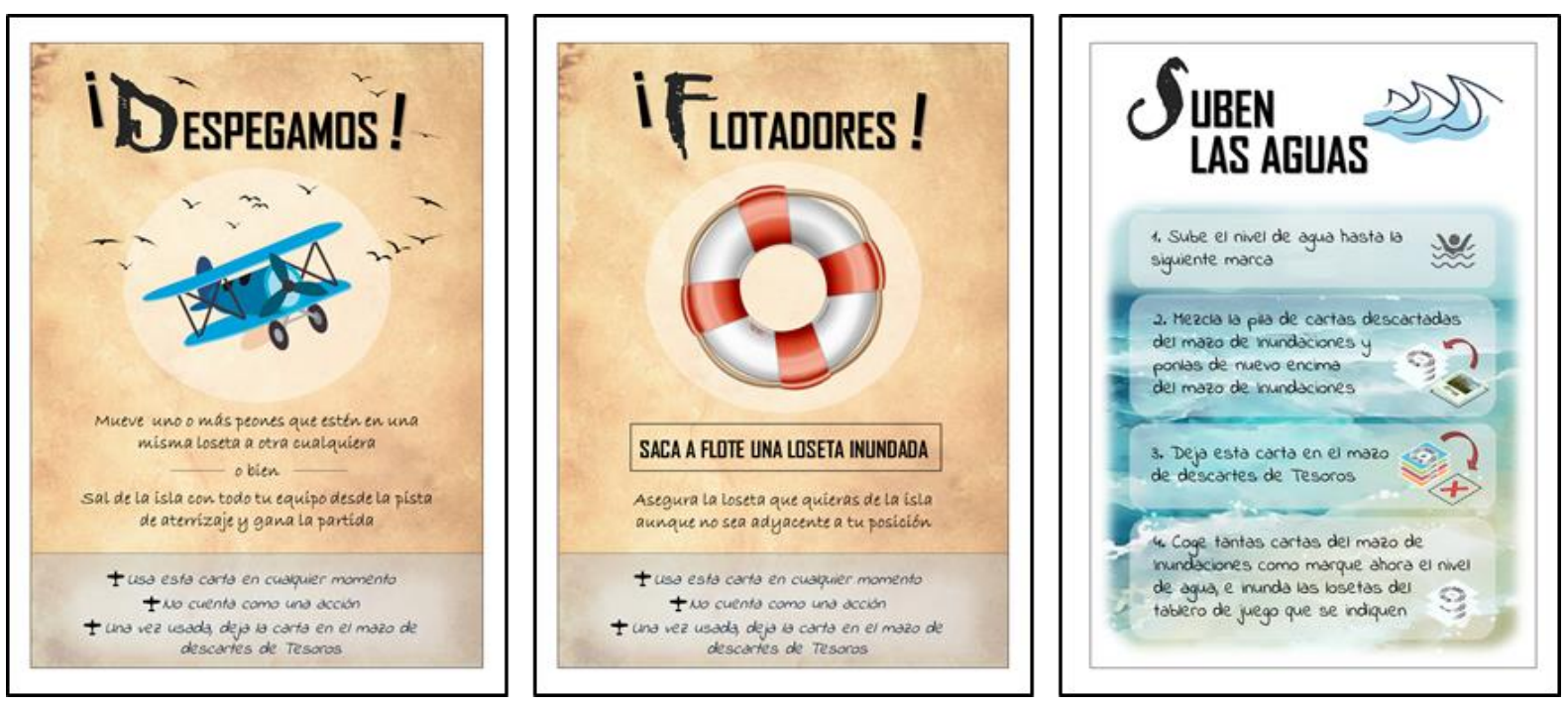

Imagen 12. Cartas especiales, rediseñadas para el recurso didáctico, que se encuentran dentro del mazo ODS: i) Despegamos; ii) Flotadores; y ii) Suben las aguas.

\subsubsection{Cartas de los Aventureros}

En el recurso creado se siguen manteniendo los 6 posibles roles de Aventurero que figuraban en el juego original (ver apartado 4.1.8. Habilidades especiales de los Aventureros), cada uno de ellos con su correspondiente habilidad. Sin embargo, con la finalidad de ligar dichos roles con la biodiversidad y el medio ambiente, se han rediseñado las cartas asignando a cada una de ellas un animal relacionado con el rol asignado (ver Anexo 2 y 3).

\subsubsection{Cartas ODS}

El mazo de cartas ODS es la base de este recurso didáctico, y sustituye al mazo de cartas Tesoro del juego original. Como se ha mencionado en apartados anteriores, el recurso cuenta con 4 familias de cartas ODS dentro de este mazo: Agua (azul), Tierra (verde), Sostenibilidad (rojo) y Bienestar (naranja) (Anexo 1). Obtener cartas ODS es lo que permitirá a los jugadores conseguir cada una de las llaves-insignia, ya que cada familia de cartas ODS está asociada a una llave-insignia determinada (ver Imagen 8). ¿Cómo puede obtener un jugador cartas ODS? Únicamente resolviendo las cuestiones que encontrará en el haz de cada una de ellas. Cuando un jugador coge una carta del mazo ODS, esta debe ser resuelta entre 
todos los jugadores del equipo. Si logran resolverla, esta quedará en poder del jugador que la robó del mazo, situándola sobre la mesa por el lado del envés (es decir, por el lado en el que se ve la familia ODS a la que pertenece) para que todos los jugadores puedan verla. Cuando un jugador tenga en su poder 3 cartas de una misma familia ODS, podrá recuperar la llaveinsignia asociada a dicha familia, situándose sobre alguna de las losetas de la isla que lo permitan (ver Imagen 11). Una vez haya conseguido la llave-insignia para el equipo, el jugador descartará las 3 cartas ODS que ha empleado para conseguir dicha llave-insignia sobre el mazo de descartes de cartas ODS (marcado en Imagen 9 y 10).

Las preguntas a resolver en cada una de las familias ODS, han sido definidas a partir de los Objetivos de Desarrollo Sostenible de Naciones Unidas (Imagen 13). A partir de ellos, y teniendo en cuenta las temáticas objeto de la asignatura de CTMA de $2^{\circ}$ de Bachillerato, se hizo una subdivisión en grupos de las mismas:

- Valoración y preocupación por el medio ambiente y su biodiversidad: Objetivos 6 (Agua limpia y saneamiento), 13 (Acción por el clima), 14 (Vida submarina), y 15 (Vida de ecosistemas terrestres). Este grupo dio lugar a dos familias ODS: Agua (trabajando los objetivos 6 y 14) y Tierra (trabajando los objetivos 13 y $15)$.

- Impacto de las actividades humanas y sostenibilidad: Objetivos 7 (Energía asequible y no contaminante), 11 (Ciudades y comunidades sostenibles), y 12 (Producción y consumo responsable). Son trabajados dentro de la familia ODS de Sostenibilidad.

- Salud: Objetivo 3 (Salud y bienestar). Se trabaja dentro de la familia ODS de Bienestar.

- Desarrollo e implicación social: Objetivos 1 (Fin de la pobreza), 2 (Hambre cero), 4 (Educación de Calidad), 5 (Igualdad de género), 8 (Trabajo decente y crecimiento económico), 9 (Industria, innovación e infraestructuras), 10 (Reducción de las desigualdades), 16 (Paz, justicia e instituciones sólidas), 17 (Alianzas para lograr los objetivos). Estos objetivos, que guardan mayor relación con temas de implicación social y empáticos, no fueron trabajados como tal dentro del mazo de familias ODS, aunque por su naturaleza son temas que están profundamente relacionados con los objetivos ODS que se trabajan mediante preguntas dentro de las cuatro familias de cartas ODS. Además, la problemática social que motiva la misión de los jugadores, y los escenarios que muestran las 
losetas Isla, buscan trabajar todos estos temas, creando conciencia en el alumnado, no mediante la búsqueda de información, sino mediante la formación de su pensamiento crítico y empático hacia la sociedad y el mundo. Así, el alumnado trabajará estos objetivos de una forma indirecta, pero muy activa, dado que todos ellos son el fundamento de su misión como jugadores.
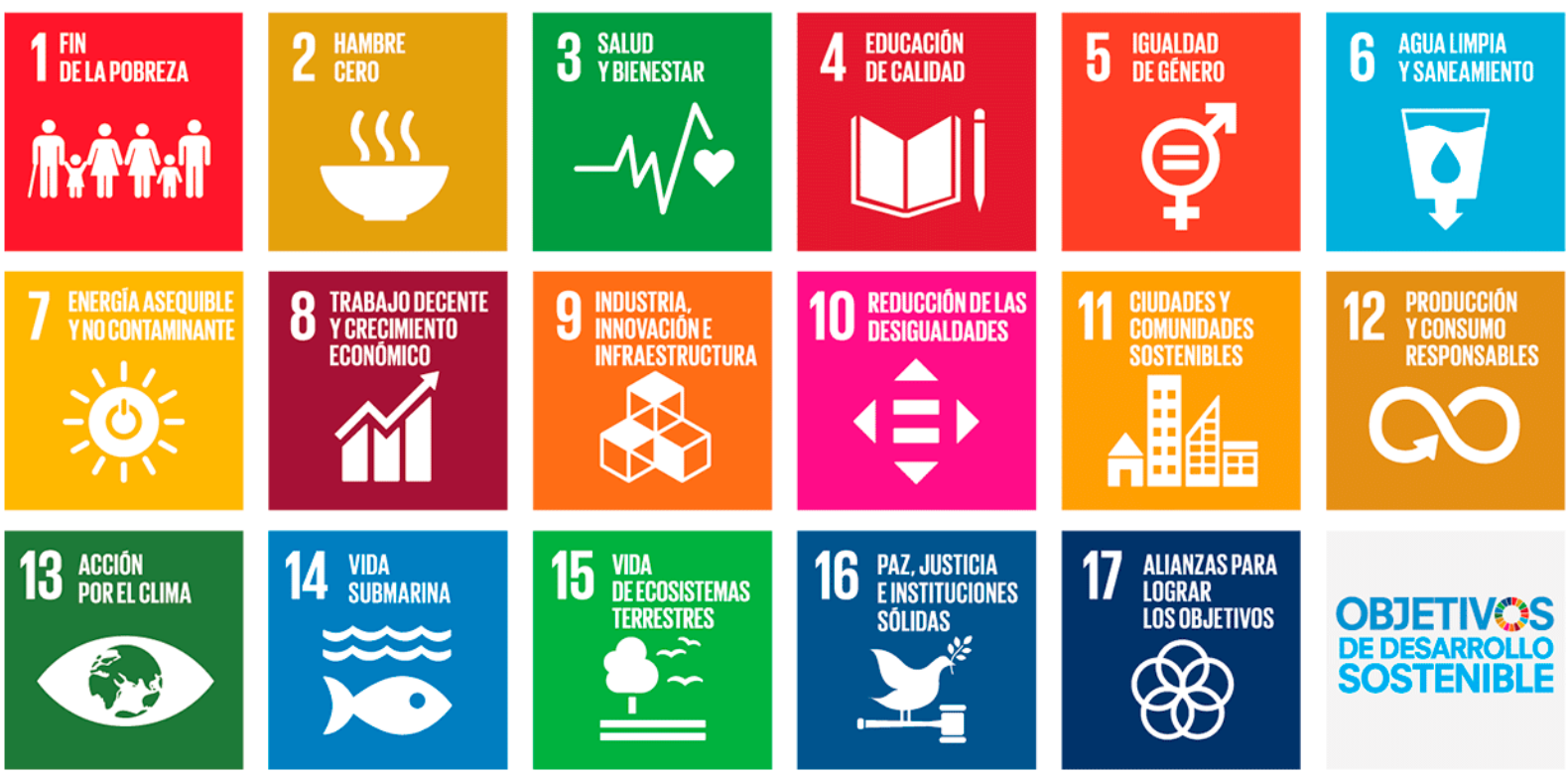

OBJETIVGS DEDESARROLLO SOSTENIBLE

Imagen 13. Los 17 Objetivos de Desarrollo Sostenible para 2030 definidos por Naciones Unidas (Fuente: United Nations website)

Para el diseño de las preguntas que deben resolverse en las cartas ODS se tomaron como referente los atributos o características que según Ouariachi et al. (2020) debe cumplir un 'serious game' para potenciar el aprendizaje y compromiso del alumnado: i) retos alcanzables; ii) desafiantes (que requieran esfuerzo, en este caso cognitivo); iii) basados en la realidad; iv) que potencien el intercambio de opiniones por parte de los participantes; y v) que produzcan 'sentimientos' en los participantes (generalmente, a modo de concienciación). Al mismo tiempo, para la elaboración de las preguntas se utilizaron distintas estructuras, con la finalidad de hacer el juego más atractivo a los participantes. De esta forma, encontramos preguntas de tipo: i) verdadero y falso; ii) abiertas de desarrollo y reflexión; iii) completar espacios; iv) buscar relaciones a modo 'une con flechas'; v) interpretación de gráficos e imágenes; vi) acertijos o crucigramas; vii) elección múltiple; y viii) pequeños cálculos. Con la intención de contextualizar las preguntas en ambientes cercanos, muchas de ellas están basadas en experiencias o impresiones propias del alumnado, o en casos dentro de España. El 
Anexo 9 recoge el conjunto de preguntas asociadas a cada una de las familias ODS que han sido diseñadas para trabajar los objetivos didácticos asociados al recurso (ver apartado 5 . Didáctica del recurso para más información)

Para guiar el proceso de enseñanza y aprendizaje del alumnado durante el transcurso del juego, se han incluido códigos QR en la mayor parte de las cartas de preguntas. Estos códigos dan acceso a videos cortos, divulgativos, de la plataforma web YouTube o a artículos virtuales que cuentan con información suficiente para resolver las cuestiones que se plantean. A su vez, el profesorado encargado de la asignatura deberá hacer de 'guía de juego' y marcar la dinámica y tiempos del mismo, según las características del alumnado con el que se trabaje. Una ventaja de este recurso es que, si el profesorado quisiera trabajar algún objetivo ODS o tema de una forma determinada en su clase, podrá crear nuevas preguntas e incluirlas como nuevas cartas ODS en el juego.

Por último, cabe mencionar que para la elaboración de las cartas y preguntas ODS, así como para la selección de la información contenida en los códigos QR, se ha hecho especial hincapié en qué la información sea visualmente atractiva para el alumnado, con la intención de captar su atención lo máximo posible. Se pretende así que, la utilización de este recurso en las aulas, sea entendida por ellos verdaderamente como 'un juego', y no como otra 'clase teórica'.

\section{Didáctica del recurso}

\subsection{Objetivos didácticos}

El Real Decreto 1105/2014 presenta la asignatura de Ciencias de la Tierra y del Medio Ambiente de $2^{\circ}$ de Bachiller como la materia cuyo 'eje principal el uso que hacemos los humanos de los recursos que nos ofrece nuestro planeta, un planeta finito que "utilizamos" como si fuese ilimitado. [...] La humanidad se enfrenta a importantes retos en el siglo XXI [...]. Es necesaria una reflexión científica, aplicando modelos teóricos y análisis científicos, para proporcionar una visión que permita encontrar un equilibrio entre el aprovechamiento de los recursos y la sostenibilidad, así como comprender de modo global y sistémico la realidad que nos rodea y valorar el entorno y los problemas relacionados con la actividad humana, para lo que es necesario valorar los riesgos y plantear medidas que corrijan o mitiguen el riesgo'.

A su vez, la Orden del 14 de Julio de 2016 de la Junta de Andalucía al definir los aspectos generales de esta materia menciona que 'su papel formativo se basa en infundir en 
los alumnos y las alumnas hábitos y actitudes personales congruentes con los valores ecológicos, valorando la compatibilidad de la utilización de los recursos naturales con la conservación del medio ambiente y el desarrollo social y económico, promoviendo con ello una reflexión científica sobre el funcionamiento del planeta, encaminada a mitigar los impactos de la actividad humana sobre el medio y a una reducción de los riesgos naturales'.

El recurso aquí planteado ha sido elaborado en base a estos aspectos, fundamentando los mismos en el conocimiento de los ODS por parte de su alumnado. La Tabla 3 recoge los objetivos generales de etapa del Real Decreto de 1105/2014, y los objetivos generales de la materia de la Orden del 14 de Julio de 2016, que son trabajados con el recurso didáctico elaborado.

Tabla 3. Objetivos generales de etapa (Real Decrero 1105/2014) y de materia (Orden del 14 de Julio de 2016 de la Junta de Andalucía) que son trabajados con el recurso elaborado.

\section{OBJETIVOS GENERALES DE ETAPA (BACHILLERATO)}

Real Decreto 1105/2014 (BOE)

a) Ejercer la ciudadanía democrática, desde una perspectiva global, y adquirir una conciencia cívica responsable, inspirada por los valores de la Constitución española así como por los derechos humanos, que fomente la corresponsabilidad en la construcción de una sociedad justa y equitativa.

e) Dominar, tanto en su expresión oral como escrita, la lengua castellana y, en su caso, la lengua cooficial de su Comunidad Autónoma.

g) Utilizar con solvencia y responsabilidad las tecnologías de la información y la comunicación.

i) Acceder a los conocimientos científicos y tecnológicos fundamentales y dominar las habilidades básicas propias de la modalidad elegida.

j) Comprender los elementos y procedimientos fundamentales de la investigación y de los métodos científicos. Conocer y valorar de forma crítica la contribución de la ciencia y la tecnología en el cambio de las condiciones de vida, así como afianzar la sensibilidad y el respeto hacia el medio ambiente.

k) Afianzar el espíritu emprendedor con actitudes de creatividad, flexibilidad, iniciativa, trabajo en equipo, confianza en uno mismo y sentido crítico.

\section{OBJETIVOS GENERALES DE LA MATERIA (CTMA)}

Orden del 14 de Julio de 2016 (BOJA)

1. Comprender el funcionamiento de la Tierra y de los sistemas terrestres y sus interacciones, como fundamento para la interpretación de las repercusiones globales de algunos hechos aparentemente locales y viceversa. 
3. Conocer las posibilidades de utilización de los recursos naturales, incluyendo sus aplicaciones, y reconocer la existencia sus límites, valorando la necesidad de adaptar el uso a la capacidad de renovación.

5. Analizar las causas que dan lugar a riesgos naturales, conocer los impactos derivados de la explotación de los recursos y considerar diversas medidas de prevención y corrección.

7. Conocer y valorar la diversidad del patrimonio natural andaluz como un recurso sostenible, esencial en el devenir socioeconómico futuro de nuestra comunidad.

9. Utilizar las tecnologías de la información y la comunicación para realizar simulaciones, tratar datos y extraer y utilizar información de diferentes fuentes, evaluar su contenido, fundamentar los trabajos y realizar informes.

10. Promover actitudes favorables hacia el respeto y la protección del medio ambiente, desarrollando la capacidad de valorar las actuaciones sobre el entorno y tomar libremente iniciativas en su defensa.

Al tratarse de un juego práctico y colaborativo, será el alumnado quien construirá su propio aprendizaje mediante la búsqueda y resolución de problemas de distinta índole, y siempre trabajando en equipo.

\subsection{Contenidos, criterios de evaluación y estándares de aprendizaje evaluables}

A continuación se especifican los contenidos y criterios de evaluación asociados a ellos (según la Orden del 14 de Julio de 2014 de la Junta de Andalucía), así como sus estándares de aprendizaje evaluables (según el Real Decreto de 1105/2014), que quedarían recogidos dentro del recurso didáctico que planteamos en esta memoria (Tabla 4).

Tabla 4. Criterios de evaluación y estándares de aprendizaje evaluables que pueden ser trabajados, total o parcialmente, con el recurso elaborado.

CRITERIOS DE EVALUACIÓN
ESTÁNDARES DE APRENDIZAJE EVALUABLES

\section{Bloque 2. Los subsistemas terrestres fluidos, dinámica.}

9. Identificar los riesgos climáticos, valorando los factores que contribuyen a favorecerlos y los factores que contribuyen a paliar sus efectos. CMCT, CSC.

\section{Bloque 3. La contaminación atmosférica.}

1. Argumentar el origen de la contaminación atmosférica, sus repercusiones sociales y sanitarias. CMCT, CSC.
9.2. Propone medidas para evitar o disminuir los efectos de los riesgos climáticos.

1.2. Asocia los contaminantes con su origen, reconociendo las consecuencias sociales, ambientales y sanitarias que producen. 
2. Proponer medidas que favorecen la disminución de la contaminación atmosférica y del efecto invernadero. CMCT, CSC, SIEP, CAA.

3. Relacionar la contaminación atmosférica con sus efectos biológicos. CMCT, CD.

\section{Bloque 4. Contaminación de las aguas.}

3. Valorar las repercusiones que tiene para la humanizad la contaminación del agua, proponiendo medidas que la eviten o disminuyan. CSC, CD.

5. Conocer y valorar medidas de ahorro de agua, domésticas, industriales y agrícolas. $\mathrm{CD}, \mathrm{CSC}$.

\section{Bloque 5. La geosfera y riesgos geológicos.}

7. Identificar medidas de uso eficiente determinando sus beneficios. CMCT, CSC, CD.

\section{Bloque 6. Circulación de materia y energía en la biosfera.}

3. Comprender los mecanismos naturales de autorregulación de los ecosistemas y valorar la repercusión de la acción humana sobre los ecosistemas. CMCT, CSC.

4. Distinguir la importancia de la biodiversidad y reconocer las actividades que tienen efectos negativos sobre ella. CMCT, CSC, CAA.

6. Valorar el suelo como recurso frágil y escaso. CSC.

10. Analizar y valorar la evolución de los recursos pesqueros. CSC

11. Valorar la conservación de las zonas litorales por su elevado valor ecológico. CMCT, CSC.

13. Valorar la riqueza en biodiversidad de Andalucía. CMCT, CSC.
2.1. Describe medidas que previenen o atenúan la contaminación atmosférica y el efecto invernadero.

3.2. Explica los efectos biológicos producidos por la contaminación atmosférica.

3.1. Describe el proceso de eutrofización de las aguas valorando las consecuencias del mismo. 3.2. Propone actitudes y acciones, individuales, estatales e intergubernamentales que minimicen las repercusiones ambientales de la contaminación del agua.

7.1. Valora el uso eficiente de la energía y de los recursos.

3.3 Argumenta la repercusión de la acción humana sobre los ecosistemas.

4.1 Relaciona las distintas actividades humanas con las repercusiones en la dinámica del ecosistema.

4.2 Argumenta la importancia de la biodiversidad y los riesgos que supone su disminución.

4.3 Relaciona las acciones humanas con su influencia en la biodiversidad del ecosistema.

6.1. Valora el suelo como recurso frágil y escaso.

10.1. Valora el sistema litoral como fuente de recursos y biodiversidad.

10.2. Relaciona la sobreexplotación de los recursos pesqueros con impactos en las zonas litorales.

11.1. Establece la importancia de la conservación de las zonas litorales. 


\section{Bloque 7. La gestión y desarrollo sostenible.}

1. Establecer diferencias entre el desarrollo incontrolado, el conservacionismo y el desarrollo sostenible. CMCT, CSC.

3. Determinar el origen de los residuos, las consecuencias de su producción valorando la gestión de los mismos. CMCT, CSC.

6. Valorar la protección de los espacios naturales. CEC, CSC.
1.1. Distingue diferentes modelos uso de los recursos diseñando otros sostenibles.

1.2. Argumenta las diferencias que existen entre el desarrollismo incontrolado, el conservacionismo y el desarrollo sostenible.

3.2. Relaciona el consumo de algunos productos y el deterioro del medio.

3.3. Expone políticas ambientales adecuadas a la defensa del medio.

6.1. Argumenta la necesidad de protección de los espacios naturales y sus consecuencias.

\subsection{Competencias claves}

Atendiendo a los criterios de evaluación, especificados en el apartado anterior (5.2. Contenidos, criterios de evaluación y estándares de aprendizaje evaluables), que quedan englobados dentro del recurso didáctico, las competencias claves trabajadas por él serían:

1. Competencia matemática y competencias básicas en ciencias y tecnología (CMCT): El recurso trabaja temáticas ambientales, científicas y tecnológicas de distinta índole con sus preguntas, y al estar encuadrado dentro de la asignatura de CTMA de $2^{\circ}$ de Bachillerato, es claramente la competencia más trabajada con el recurso. La competencia matemática es trabajada sobretodo en las preguntas de interpretación gráfica y realización de cálculos.

2. Competencia digital (CD): El uso de distintas fuentes de información virtual, el empleo de códigos QR y de dispositivos electrónicos trabaja estas competencias.

3. Aprender a aprender (CAA): La utilización de distintas fuentes de información mediante códigos QR familiariza a los participantes a usar esas misma fuentes para resolver sus dudas en determinados temas. Esto contribuye a que puedan ser usadas por ellos mismos en otros ámbitos académicos para aprender nuevos conceptos o aclararlos. Potencian la investigación para conseguir información.

4. Competencias sociales y cívicas (CSC): Son trabajadas debido a que el recurso se fundamenta en los ODS, tratando así temáticas sociales, ambientales y cívicas y acercándolas al alumanado. 
5. Sentido de la iniciativa y espíritu emprendedor (SIEP): Se trabaja especialmente en las preguntas que piden a los participantes el diseño de medidas o mejoras para solucionar distintos temas o paliar determinados efectos en el medio.

6. Conciencia y expresiones culturales (CEC): El recurso trabaja la importancia del patrimonio natural y cultural, especialmente a escala nacional, lo que está estrechamente relacionado con esta competencia.

Adicionalmente, y a pesar de no ser una competencia que queda incluida en los criterios de evaluación tratados con el recurso (ver apartado 5.2. Contenidos, criterios de evaluación y estándares de aprendizaje evaluables), la 'Competencia en comunicación lingüística (CCL)' es también trabajada aquí debido al carácter colaborativo del recurso. Los participantes deben intercambiar opiniones entre ellos, y saber comunicar finalmente su conclusión para dar respuesta a las preguntas que se les plantean en el 'juego’.

\subsection{Estrategias metodológicas y modelos de pensamiento}

El recurso didáctico que aquí se presenta, al estar encuadrado dentro del 'aprendizaje basados en juegos' potencia la metodología activa de la enseñanza, junto con el aprendizaje colaborativo/cooperativo del alumnado. Es recomendable, que para la utilización de este recurso, el profesorado sea quien forme los equipos de jugadores, de tal forma que divida la clase en grupos heterogéneos de 4 alumnos cada uno. El profesorado actuará como guía del juego, orientando al alumnado en el caso de necesitarlo. Opcionalmente, en el caso de querer usar este recurso como un método de evaluación, cada participante/alumno deberá tomar anotaciones de los logros que el equipo vaya consiguiendo resolver durante el juego, para más tarde realizar un informe de Aventurero, más elaborado donde, se exponga las investigaciones y conclusiones que han realizado a lo largo de su 'aventura de juego'. Este 'informe de Aventurero' podrá ser usado como 'producto final', para el proceso de evaluación individual de cada alumno.

Atendiendo a la dinámica de 'juego' expuesta en esta memoria, y al tratarse de un recurso de tipo 'serious game' fundamentado en los juegos de mesa colaborativos, los modelos de pensamiento principalmente trabajados con dicho recurso serían: el reflexivo, el analítico, el lógico, y el crítico. 


\subsection{Evaluación}

Al tratarse de un juego colaborativo, este recurso pude ser usado como una 'actividad' dentro de una unidad didáctica de final de curso en la asignatura de CTMA de $2^{\circ}$ de Bachillerato, ya que aúna distintos conceptos del conjunto de la asignatura y pretende ayudar al alumnado a contextualizar los distintos temas que han sido trabajados durante todo el curso académico, al mismo tiempo que potenciar su pensamiento crítico y su compromiso social y medioambiental.

Sin embargo, tal y como se ha comentado en el apartado 5.4. Estrategias metodológicas y modelos de pensamiento, el profesorado puede emplear dicho recurso como un método de evaluación. En este caso, deberá indicarse al alumnado participante que durante el transcurso del juego deberán tomar, individualmente, pequeños apuntes de los logros (cuestiones resueltas), que vayan consiguiendo superar como grupo. A partir de ellos, deberán posteriormente al 'juego', elaborar un 'informe de Aventurero', imaginando que deben entregarlo a la ONU al regresar de su aventura en la Isla para informarles de sus descubrimientos en ella. El profesorado deberá dar unas pautas al alumnado sobre la estructura que puede tener dicho informe y donde deberá figurar el nombre del alumnado y el rol de Aventurero que ha tomado en la misión del juego.

De esta forma, en el caso de usar el recurso didáctico de esta memoria como elemento de evaluación, los instrumentos y la metodología propuesta para evaluar la adquisición de competencias y criterios por parte del alumnado quedan recogidos en la Tabla 5.

La Tabla 6 muestra la rúbrica sugerida para realizar la evaluación a través de la observación directa, donde el profesorado analizará no solo la participación del alumnado durante el 'juego', sino también el trabajo en equipo y expresión a la hora de transmitir sus investigaciones y conocimientos. La Tabla 7 muestra la rúbrica sugerida para realizar la evaluación del informe de Aventurero, dado que todos los criterios de evaluación (o estándares) pueden ser evaluados de la misma forma, se recomienda utilizar esta rúbrica para evaluar cada uno de los criterios especificado en el apartado 5.2. Contenidos, criterios de evaluación y estándares de aprendizaje evaluables.

Dado que un equipo durante una partida no contesta todas las preguntas del 'juego', el profesorado, usando como guía una copia del Anexo 9, deberá ir realizando un seguimiento de aquellas cartas que son resueltas por el equipo, para poder realizar posteriormente la evaluación de los criterios del apartado 5.2 de esta memoria que puedan ser evaluados con la 
resolución de esas cuestiones. El Anexo 10 muestra la relación entre las actividades o preguntas del recurso (Anexo 9) y los criterios de evaluación asociados al mismo.

Tabla 5. Instrumentos de evaluación propuestos para el profesorado en el caso de usar el recurso didáctico que aquí se presenta para la evaluación del alumnado.

\begin{tabular}{|c|c|c|}
\hline INSTRUMENTOS DE EVALUACIÓN* & RÚBRICAS ASOCIADAS & Porcentaje \\
\hline $\begin{array}{l}\text { Observación directa } \\
\qquad \begin{array}{l}\text { El profesor actúa como } \\
\text { observador del juego, y } \\
\text { evalúa la participación y } \\
\text { trabajo en equipo de los } \\
\text { participantes }\end{array}\end{array}$ & Tabla 6 & $30 \%$ \\
\hline $\begin{array}{l}\text { Informe de Aventurero } \\
\qquad \begin{array}{l}\text { Cada alumno debe realizar un } \\
\text { informe final de la 'misión', } \\
\text { donde se especifiquen los } \\
\text { descubrimientos y logros que } \\
\text { han llevado a cabo durante la } \\
\text { misma. Este elemento actúa } \\
\text { como 'producto final'. }\end{array}\end{array}$ & Tabla 7 & $70 \%$ \\
\hline
\end{tabular}

* Los instrumentos de evaluación deben contemplar siempre la adquisición de conocimientos de acuerdo a los criterios de evaluación o estándares de aprendizaje evaluables asociados a este recurso (ver apartado 5.2. Contenidos, criterios de evaluación y estándares de aprendizaje evaluables para más detalle)

Tabla 6. Rúbrica sugerida para la evaluación por observación directa.

\begin{tabular}{|c|c|c|c|c|c|c|c|c|c|c|c|c|c|c|c|c|}
\hline NOMBRE DE EQUIPO: & & & & & & & & & & & & & & & & \\
\hline INTEGRANTES: & & & & & & & & & & & & & & & & \\
\hline ÍTEMS & & LUI & MNC & & & LUI & INC & & & UN & IN & & & UI & IN & \\
\hline Participa de manera activa & 1 & 2 & 3 & 4 & 1 & 2 & 3 & 4 & 1 & 2 & 3 & 4 & 1 & 2 & 3 & 4 \\
\hline $\begin{array}{l}\text { Escucha las opiniones de sus } \\
\text { compañeros }\end{array}$ & 1 & 2 & 3 & 4 & 1 & 2 & 3 & 4 & 1 & 2 & 3 & 4 & 1 & 2 & 3 & 4 \\
\hline $\begin{array}{l}\text { Utiliza adecuadamente } \\
\text { vocabulario científico en la } \\
\text { expresión de ideas }\end{array}$ & 1 & 2 & 3 & 4 & 1 & 2 & 3 & 4 & 1 & 2 & 3 & 4 & 1 & 2 & 3 & 4 \\
\hline Utiliza TICs & 1 & 2 & 3 & 4 & 1 & 2 & 3 & 4 & 1 & 2 & 3 & 4 & 1 & 2 & 3 & 4 \\
\hline Respeta las normas del juego & 1 & 2 & 3 & 4 & 1 & 2 & 3 & 4 & 1 & 2 & 3 & 4 & 1 & 2 & 3 & 4 \\
\hline
\end{tabular}

Baremo: 1 [no cumple el ítem evaluable]; 2 [cumple mínimamente el ítem evaluable]; 3 [cumple adecuadamente el ítem evaluable]; 4[cumple muy satisfactoriamente el ítem evaluable]. 
Tabla 7. Rúbrica sugerida para la evaluación de los criterios de evaluación asociados a este recurso didáctico (ver apartado 5.2. Contenidos, criterios de evaluación y estándares de aprendizaje evaluables) mediante el informe de Aventurero y la observación directa.

\begin{tabular}{|c|c|c|c|}
\hline \multicolumn{4}{|c|}{ Nombre de Equipo: } \\
\hline \multicolumn{4}{|c|}{ Alumno: } \\
\hline \multicolumn{4}{|c|}{ Criterio/s de evaluación (número/s): } \\
\hline \multicolumn{4}{|c|}{ Competencia/s clave trabajadas: } \\
\hline \multicolumn{4}{|c|}{ Estandar/es de aprendizaje evaluable (número/s): } \\
\hline \multicolumn{4}{|c|}{$\begin{array}{l}\text { Nivel de desempeño } \\
\end{array}$} \\
\hline $\begin{array}{c}\text { Insuficiente } \\
(1 / 4)\end{array}$ & $\begin{array}{c}\text { Suficiente } \\
(5 / 6)\end{array}$ & $\begin{array}{c}\text { Notable } \\
(7 / 8)\end{array}$ & $\begin{array}{c}\text { Sobresaliente } \\
(9 / 10)\end{array}$ \\
\hline $\begin{array}{l}\text { El alumno no ha } \\
\text { logrado cumplir lo } \\
\text { indicado en el } \\
\text { criterio de } \\
\text { evaluación }\end{array}$ & $\begin{array}{l}\text { El alumno ha } \\
\text { logrado } \\
\text { parcialmente } \\
\text { cumplir lo indicado } \\
\text { en el criterio de } \\
\text { evaluación }\end{array}$ & $\begin{array}{l}\text { El alumno ha } \\
\text { logrado cumplir } \\
\text { adecuadamente lo } \\
\text { indicado en el } \\
\text { criterio de } \\
\text { evaluación }\end{array}$ & $\begin{array}{l}\text { El alumno ha } \\
\text { logrado cumplir } \\
\text { muy } \\
\text { satisfactoriamente lo } \\
\text { indicado en el } \\
\text { criterio de } \\
\text { evaluación }\end{array}$ \\
\hline
\end{tabular}

Nota adicional: En este caso hemos dado la misma importancia a todos los criterios de evaluación especificados en el apartado 5.2. Contenidos, criterios de evaluación y estándares de aprendizaje evaluables. Sin embargo, el profesorado puede optar por dividir previamente esos criterios de evaluación en Básicos, Óptimos y Deseables, en función de su adecuación a la Taxonomía de Bloom (revisada por Anderson y Krathwohl, 2001). Atendiendo a esta, los criterios de evaluación relacionados con "Recordar" y "Comprender" son clasificados como "Básicos"; los criterios relacionados con "Aplicar" y "Analizar" son clasificados como "Óptimos"; y los criterios relacionados con "Evaluar" y "Crear" son clasificados como "Deseables" (ver Tabla 8 y Fig. 1). Una vez se han clasificado así los criterios, a cada uno se le asigna un porcentaje de importancia para su evaluación en función de si son Básicos (70\%), Óptimos (20\%) o Deseables (10\%), teniendo en cuenta el conjunto de criterios básicos, óptimos y deseables de toda la programación del curso (con todas las unidades didácticas). A partir del cómputo global del curso (que es el que evalúa el 100\% de los conocimientos adquiridos por cada alumno, a partir de los criterios de evaluación), establecemos el porcentaje de calificación que deben llevarse los criterios asociados a este recurso didáctico. De esta manera podremos evaluar estos criterios de evaluación, en relación a todo el curso académico. 
Tabla 8. Clasificación de los Criterios de Evaluación trabajados con el recurso que aquí se presenta, según la Taxonomía de Bloom.

\section{Criterios de evaluación}

Bloque 2. Los subsistemas terrestres fluidos, dinámica.

9. Identificar los riesgos climáticos, valorando los factores que contribuyen a favorecerlos y los factores que contribuyen a paliar sus efectos. CMCT, CSC.

\section{Bloque 3. La contaminación atmosférica.}

1. Argumentar el origen de la contaminación atmosférica, sus repercusiones sociales y sanitarias. CMCT, CSC.

2. Proponer medidas que favorecen la disminución de la contaminación atmosférica y del efecto invernadero. CMCT, CSC, SIEP, CAA.

3. Relacionar la contaminación atmosférica con sus efectos biológicos. CMCT, CD.

\section{Bloque 4. Contaminación de las aguas.}

3. Valorar las repercusiones que tiene para la humanizad la contaminación del agua, proponiendo medidas que la eviten o disminuyan. CSC, CD.

5. Conocer y valorar medidas de ahorro de agua, domésticas, industriales y agrícolas. CD, CSC.

\section{Bloque 5. La geosfera y riesgos geológicos.}

7. Identificar medidas de uso eficiente determinando sus beneficios. CMCT, CSC, CD.

8. Valorar los factores responsables del incremento de la desertización en Andalucía. CMCT, CSC, CD.

Bloque 6. Circulación de materia y energía en la biosfera.

3. Comprender los mecanismos naturales de autorregulación de los ecosistemas y valorar la repercusión de la acción humana sobre los ecosistemas. CMCT, CSC.

4. Distinguir la importancia de la biodiversidad y reconocer las actividades que tienen efectos negativos sobre ella. CMCT, CSC, CAA.

6. Valorar el suelo como recurso frágil y escaso. CSC.

10. Analizar y valorar la evolución de los recursos pesqueros. CSC

11. Valorar la conservación de las zonas litorales por su elevado valor ecológico. CMCT, CSC.

13. Valorar la riqueza en biodiversidad de Andalucía. CMCT, CSC.

\begin{tabular}{cc}
$\begin{array}{c}\text { Verbos taxonomía } \\
\text { de Bloom }\end{array}$ & $\begin{array}{c}\text { Clasificación } \\
\text { Crit. Eval. }\end{array}$ \\
\hline
\end{tabular}

RECORDAR Básico

COMPRENDER Básico

CREAR Deseable

RECORDAR Básico

CREAR Deseable

ANALIZAR Óptimo

RECORDAR Básico

ANALIZAR Óptimo

ANALIZAR Óptimo

RECORDAR Básico

$\begin{array}{ll}\text { ANALIZAR } & \text { Óptimo } \\ \text { ANALIZAR } & \text { Óptimo } \\ \text { ANALIZAR } & \text { Óptimo }\end{array}$

ANALIZAR Óptimo 


\section{Bloque 7. La gestión y desarrollo sostenible.}

1. Establecer diferencias entre el desarrollo incontrolado,

RECORDAR

Básico

el conservacionismo y el desarrollo sostenible. CMCT,

CSC.

3. Determinar el origen de los residuos, las consecuencias de su producción valorando la gestión de los mismos.

CMCT, CSC.

6. Valorar la protección de los espacios naturales. CEC, CSC.

ANALIZAR Óptimo

ANALIZAR Óptimo

Fig. 1. Clasificación porcentual de los Criterios de Evaluación trabajados con el recurso que aquí se presenta según la Taxonomía de Bloom (mostrada en la Tabla 8).

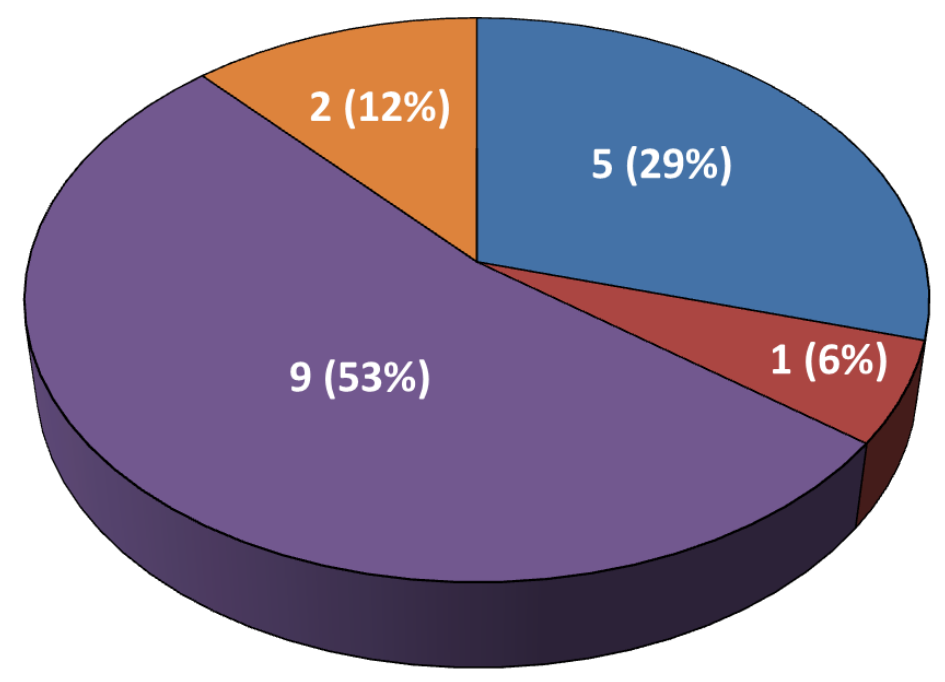

$\square$ RECORDAR $\square$ COMPRENDER $\square$ ANALIZAR $\square$ CREAR

\subsection{Otros usos del recurso: Temáticas transversales en la ESO}

Como se ha comentado a lo largo de esta memoria, por su temática en torno a los ODS, donde mejor queda encuadrada la utilización de este recurso como elemento docente es en la asignatura de CTMA de $2^{\circ}$ de Bachillerato. Por los temas y valores que se trabajan en él, hubiera resultado idóneo haber podido encuadrarlo dentro de la etapa de secundaria, sin embargo, esa opción fue descartada al no encontrar criterios y estándares evaluables suficientemente acordes con el conocimiento de los ODS. La Enseñanza Secundaria Obligatoria (ESO), aunque en la asignatura de Biología y Geología $\left(1^{\circ}, 3^{\circ}\right.$ y $4^{\circ}$ curso $)$ trabaja objetivos que tienen que ver con el medio ambiente, la conservación de la biodiversidad y la salud pública, lo hace de una manera mucho más secundaria que la trabajada en este recurso. 
Sin embargo, atendiendo al artículo 3 de la Orden del 14 de Julio de 2016 de la Junta de Andalucía, queda patente cómo el recurso que aquí presentamos engloba algunas de las temáticas transversales que deben ser trabajadas a lo largo de la etapa de secundaria. Principalmente:

'l) La toma de conciencia sobre temas y problemas que afectan a todas las personas en un mundo globalizado, entre los que se considerarán la salud, la pobreza en el mundo, la emigración y la desigualdad entre las personas, pueblos y naciones, así como los principios básicos que rigen el funcionamiento del medio físico y natural y las repercusiones que sobre el mismo tienen las actividades humanas, el agotamiento de los recursos naturales, la superpoblación, la contaminación o el calentamiento de la Tierra, todo ello, con objeto de fomentar la contribución activa en la defensa, conservación y mejora de nuestro entorno como elemento determinante de la calidad de vida'. Todos estos elementos quedan encuadrados dentro de la valoración, conocimiento y puesta en marcha de los ODS.

Aunque también:

'g) El desarrollo de las habilidades básicas para la comunicación interpersonal, la capacidad de escucha activa, la empatía, la racionalidad y el acuerdo a través del diálogo'. El recurso desarrollado está definido como un juego colaborativo. Esta temática representa una de sus bases sin la que es imposible conseguir éxito en el mismo.

De esta forma, el recurso elaborado puede ser un elemento recomendado dentro de la etapa de educación secundaria para que el docente trabaje las temáticas transversales expuestas anteriormente con su alumnado (preferiblemente para el curso de $4^{\circ}$ ESO por ser más acorde al nivel de las preguntas).

\section{Reflexión final}

Este recurso didáctico ha sido desarrollado para contribuir a la formación y conocimiento del alumnado de centros de secundaria y bachillerato en las problemáticas medioambientales y sociales actuales, a través de los Objetivos de Desarrollo Sostenible y la puesta en valor de los mismos. Cabe mencionar que a pesar de estar basado en los ODS de la ONU, ha sido difícil encontrar un espacio en el currícullum de secundaria y bachillerato para la formación de los mismo. Situación algo paradójica, ya que hablamos de retos sociales y medioambientales de carácter internacional que por tanto deberían estar considerados dentro del currícullum de las distintas etapas educativas. Para cumplir estos objetivos, debemos primero educar en los mismos y ponerlos así en valor en la sociedad actual. 
Con todo esto, esperamos que dicho recurso sirva para ayudar en la educación en estos temas y pueda ser puesta en marcha en las aulas de centros nacionales para probar su eficiencia. 


\section{Referencias}

Anderson, L.W., y D. Krathwohl (2001) A Taxonomy for Learning, Teaching and Assessing: a Revision of Bloom's Taxonomy of Educational Objectives. Longman: New York.

Aparicio-Chofré, L., y de Paredes-Gallardo, C. (2018) La introducción de los Objetivos de Desarrollo Sostenible (ODS) en el aula. En: Montagud M.D (Ed.) VII Jornadas de Innovación Docente en la educación superior - IDES (pp. 3-10). Valencia: Universidad de València.

Baaden, M., Delalande, O., Ferey, N., Pasquali, S., WaldispuÈhl, J., y Taly, A. (2018) Ten simple rules to create a serious game, illustrated with examples from structural biology. PLoS Comput Biol, 14(3):e1005955. doi: https://doi.org/10.1371/journal

Cheong, C., Filippou, J., y Cheong, F. (2014). "Towards the gamification of learning: investigating student perceptions of game elements", Journal of Information Systems Education, 2(53), 233-244.

Contreras-Espinosa, R. S. (2016). Juegos digitales y gamificación aplicados en el ámbito de la educación. RIED: Revista Iberoamericana de Educación a Distancia, 19(2), 27-33.

Corner, A., Roberts, O., Chiari, S., Völler, S., Mayrhuber, E. S., Mandl, S., y Monson, K. (2015). How do young people engage with climate change? The role of knowledge, values, message framing, and trusted communicators. Wiley Interdisciplinary Reviews: Climate Change, 6(5), 523-534.

Díaz-Barriga-Arceo, F. (2006). Enseñanza situada: Vínculo entre la escuela y la vida. México : McGraw-Hill Interamericana.

Dieste, B., Coma, T., y Blasco-Serrano, A. C. (2019). Inclusión de los Objetivos de Desarrollo Sostenible en el Currículum de Educación Primaria y Secundaria en Escuelas Rurales de Zaragoza. Revista Internacional De Educación Para La Justicia Social, 8(1). doi: https://doi.org/10.15366/riejs2019.8.1.006

Emblen-Perry, K. (2018). Enhancing student engagement in business sustainability through games. International Journal of Sustainability in Higher Education, 19(5), 858-876.

Esteve-Gilbert, J. M. (2008). El repte de l'escola del segle XXI. Escola catalana, 43, 26-28. Fundación de la Innovación Bankinter (2011). La educación del s. XXI : Una apuesta de futuro, resumen ejecutivo. Future Trends Forum. Madrid : Fundación de la Innovación Bankinter. [Disponible en https://bit.ly/2Assq27]

Gimeno-Sacristán, J. (1999). La educación que tenemos, la educación que queremos. En : F. Ibernón, L Bartolome, R. Flecha, J. Gimeno-Sacristán, H. Giroux, D. Macedo, P. Mc 
Laren, T. S. Popkewitz, L. Rigal, M. Subirats, y I. Tortajada (Eds.), La educación en el siglo XXI. Los restos del futuro inmediato (pp. 29-51). Barcelona : Editorial GRAÓ.

Gómez-Trigueros, I. M. (2018). Gamificación y tecnologías como recursos y estrategias innovadores para la enseñanza y aprendizaje de la historia. Educação \& Formação, 3(8), 3-16.

Hayes, L., González D., y Álvarez, C. (2017). The personal Learning Environment - A symbol of the changing landscape of education in the twenty first century. Revista de divulgación de experiencias pedagógicas MAMAKUNA, 4, 54-63.

Higgins, E., Grant, H., y Shah, J. (1999). Self regulation and quality of life: Emotional and nonemotional life experiences. En: D. Kahneman, E. Diener, y N. Schwarz (Eds.), Well-being: The foundations of hedonic psychology, (pp. 244-266). Nueva York: Russell Sage Foundation.

Kirriemuir, J., y McFarlane, A. (2004). Literature review in games and learning. [Disponible en https://telearn.archives-ouvertes.fr/file/index/docid/190453/filename/kirriemuir-j-2 004-r8.pdf]

Mittal, R. (2018). Analysis of serious game in Biology. Master Thesis. Massachusetts: Northeastern University.

Mitchell, A., y Savill-Smith, C. (2004). The use of computer and video games for learning: A review of the literature. Londres: Learning and Skills Development Agency.

Monroe, M. C., Oxarart, A., \& Plate, R. R. (2013). A role for environmental education in climate change for secondary science educators. Applied Environmental Education \& Communication, 12(1), 4-18.

Organización de las Naciones Unidas (2017) Educación para los Objetivos de Desarrollo Sostenible: Objetivos de aprendizaje. Paris: Organización de Naciones Unidas. Disponible en: https://josechuferreras.files.wordpress.com/2017/11/educacion-paralos-ods.pdf

Ouariachi, T., Li, C. Y., y Elving, W. J. (2020). Gamification Approaches for Education and Engagement on Pro-Environmental Behaviors: Searching for Best Practices. Sustainability, 12(11), 4565. doi: https://doi.org/10.3390/su12114565

Ouariachi, T., Olvera-Lobo, M. D., y Gutiérrez-Pérez, J. (2017). Evaluación de juegos online para la enseñanza y aprendizaje del cambio climático. Enseñanza de las ciencias: revista de investigación y experiencias didácticas, 35(1), 193-214. 
Perrotta, C., Featherstone, G., Aston, H., y Houghton, E. (2013). Gamebased Learning: Latest Evidence and Future Directions. NFER Research Programme: Innovation in Education. Slough: NFER

Ramírez, J. L. (2014). Gamificación : mecánicas de juegos en tu vida personal y profesional. Madrid : RC Libros.

Rodríguez-Palmero, M. L. (2011). La teoría del aprendizaje significativo : una revisión aplicable a la escuela actual. Revista Electrònica d'Investigació i Innovació Educativa i Socioeducativa, 3, 29-50.

Rosefsky-Saavedra, A., y Opfer, V. D. (2012). Learning 21st-century skills requires 21stcentury teaching. Phi Delta Kappan, 94(2), 8-13.

Sánchez-Carracedo, F., Segalàs-Coral, J., Cabré-Garcia, J. M., Climent-Vilaró, J., LópezÁlvarez, D., Martín-Escofet, C., y Vidal-López, E. M. (2017). El proyecto EDINSOST: inclusión de los ODS en la educación superior. Revista española de desarrollo y cooperación, 41, 67-81.

Schmidt, M., Radchuk, O., y Meinhart, C. (2014). A serious game for public engagement in synthetic biology. En: Göbel S. y Wiemeyer J. (eds) International Conference on Serious Games: Lecture Notes in Computer Science (pp. 77-85). Cham: Springer.

Sosa-Espinosa, A., Gielen, E., Palencia-Jiménez, J. S., Pérez-Alonso, Y., Moreno-Navarro, M. S., Temes-Córdovez, R. R., Miralles-García, J. L., y Trénor-Galindo, M. M. (2018). El aprendizaje lúdico como estrategia didáctica: El territorio en Juego. En: INRED 2018. IV Congreso Nacional de Innovación Educativa y Docencia en Red (pp. 1493-1503). Valencia: Editorial Universitat Politècnica de València.

Wu, J. S., y Lee, J. J. (2015). Climate change games as tools for education and engagement. Nature Climate Change, 5(5), 413-418.

$\underline{\text { Webs }}$

Blog Juan Carlos Moir :

http ://jcmoir.blogspot.com/2017/07/caracteristicas-del-perfil-del.html

ESD Expert Net :

https ://www.esd-expert.net/files/ESD-Expert/pdf/Materialien/Broschuere ES-SDG-

Barrierefrei-web.pdf

United Nations website:

https://www.un.org/sustainabledevelopment/es/ 


\section{$\underline{\text { Legislativas }}$}

- Orden de 14 de julio de 2016, por la que se desarrolla el currículo correspondiente a la Educación Secundaria Obligatoria en la Comunidad Autónoma de Andalucía, se regulan

- Real Decreto 1105/2014, de 26 de diciembre, por el que se establece el currículo básico de la Educación Secundaria Obligatoria y del Bachillerato.

\section{Otras fuentes legislativas consideradas (no citadas directamente en el documento)}

- Decreto 111/2016, de 14 de junio, por el que se establece la ordenación y el currículo de la Educación Secundaria Obligatoria en la Comunidad Autónoma de Andalucía.

- $\quad$ Ley Orgánica 2/2006, de 3 de mayo, de Educación.

- Ley Orgánica 8/2013, de 9 de diciembre, para la Mejora de la Calidad Educativa.

- Orden ECD/65/2015, de 21 de enero, por la que se describen las relaciones entre las competencias, los contenidos y los criterios de evaluación de la educación primaria, la educación secundaria obligatoria y el bachillerato determinados aspectos de la atención a la diversidad y se establece la ordenación de la evaluación del proceso de aprendizaje del alumnado. 


\section{Anexos}

Anexo 1. Diseño del envés de las distintas familias de las cartas ODS del juego.

\section{AELA}
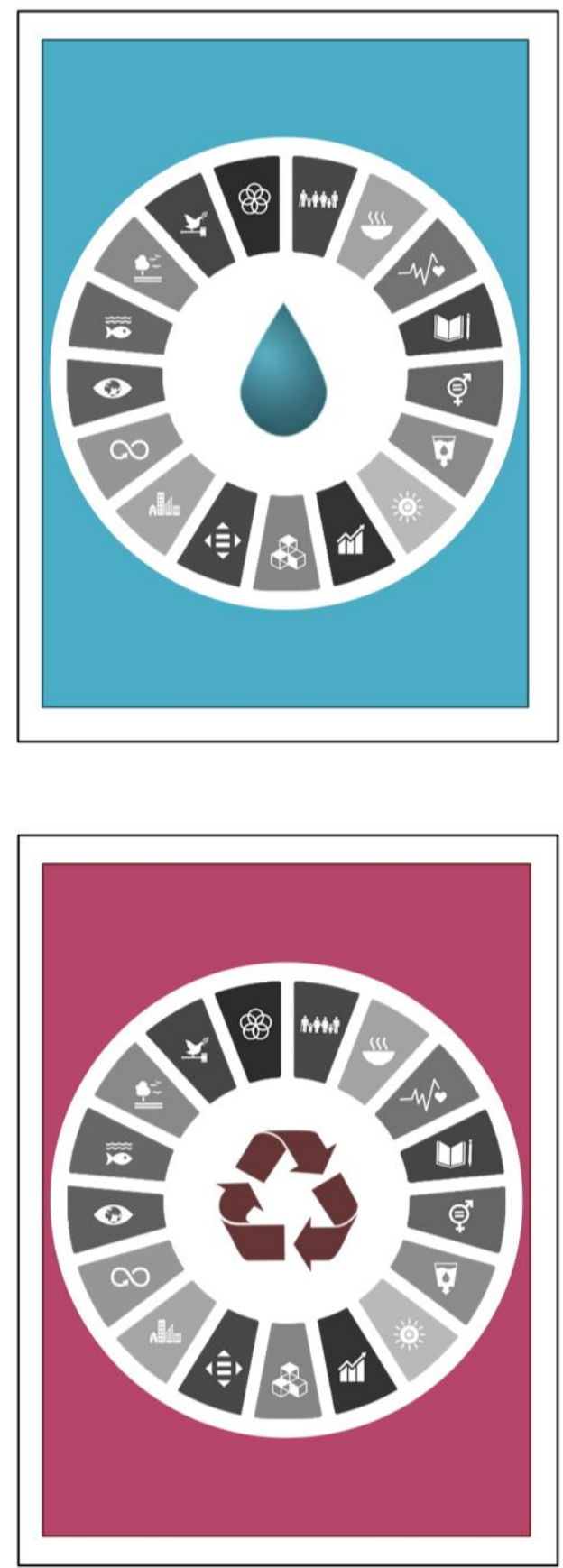

SDSTENIBILIDAD
TIERRA
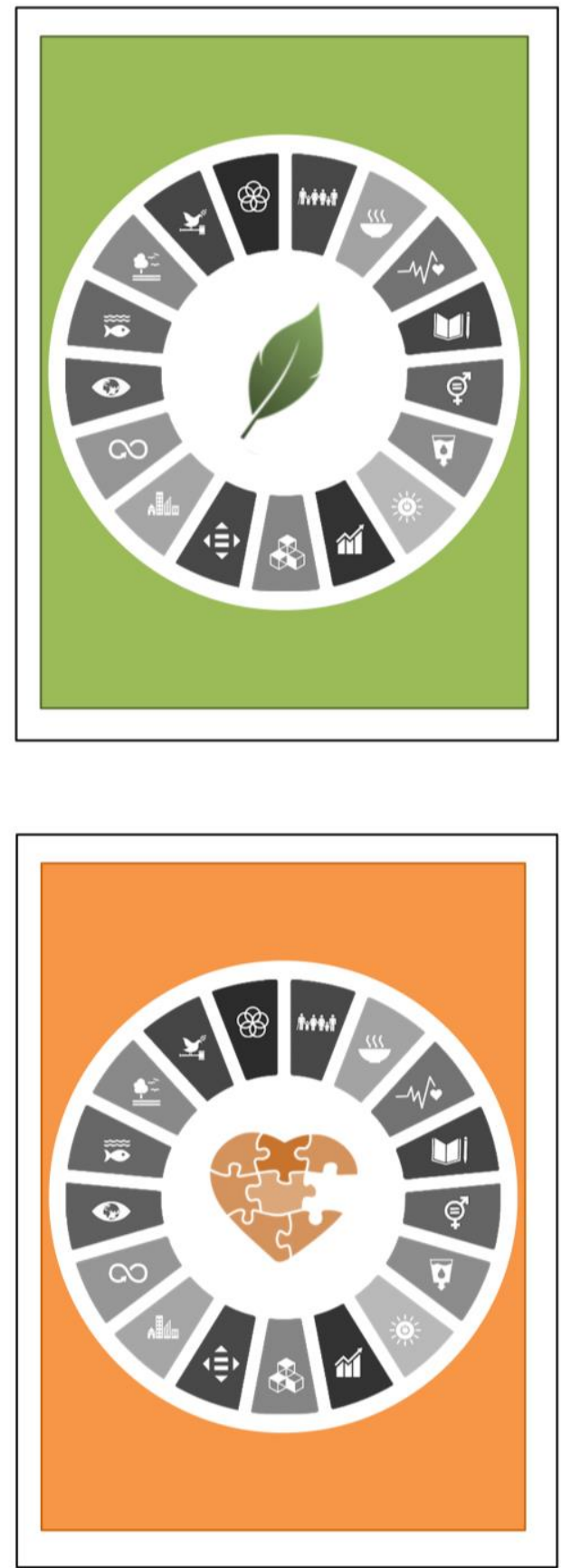

BIENESTAR 
Anexo 2. Diseño del envés de cada una de las cartas Aventurero del juego.

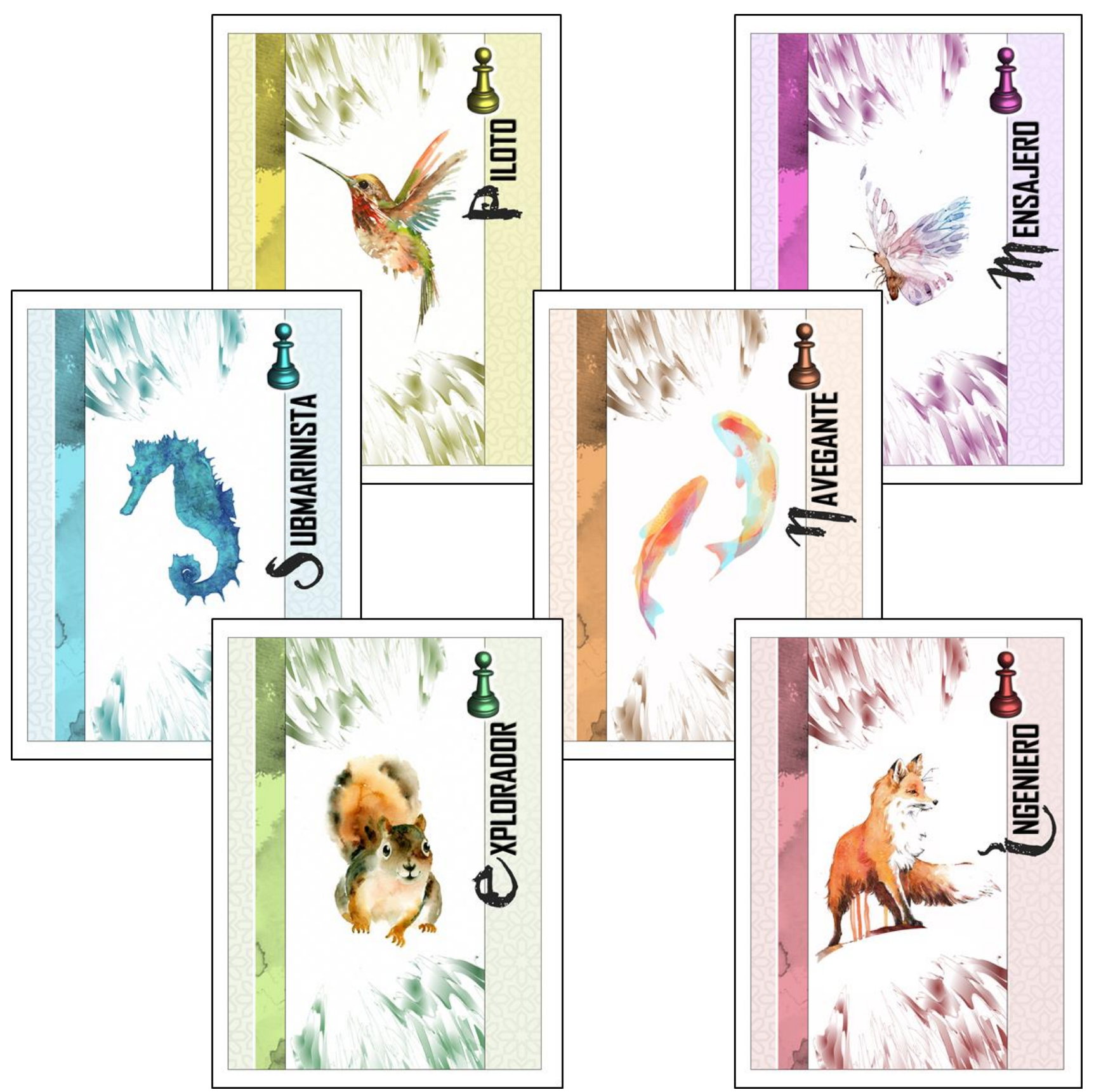


Anexo 3. Diseño del haz de cada una de las cartas Aventurero del juego.

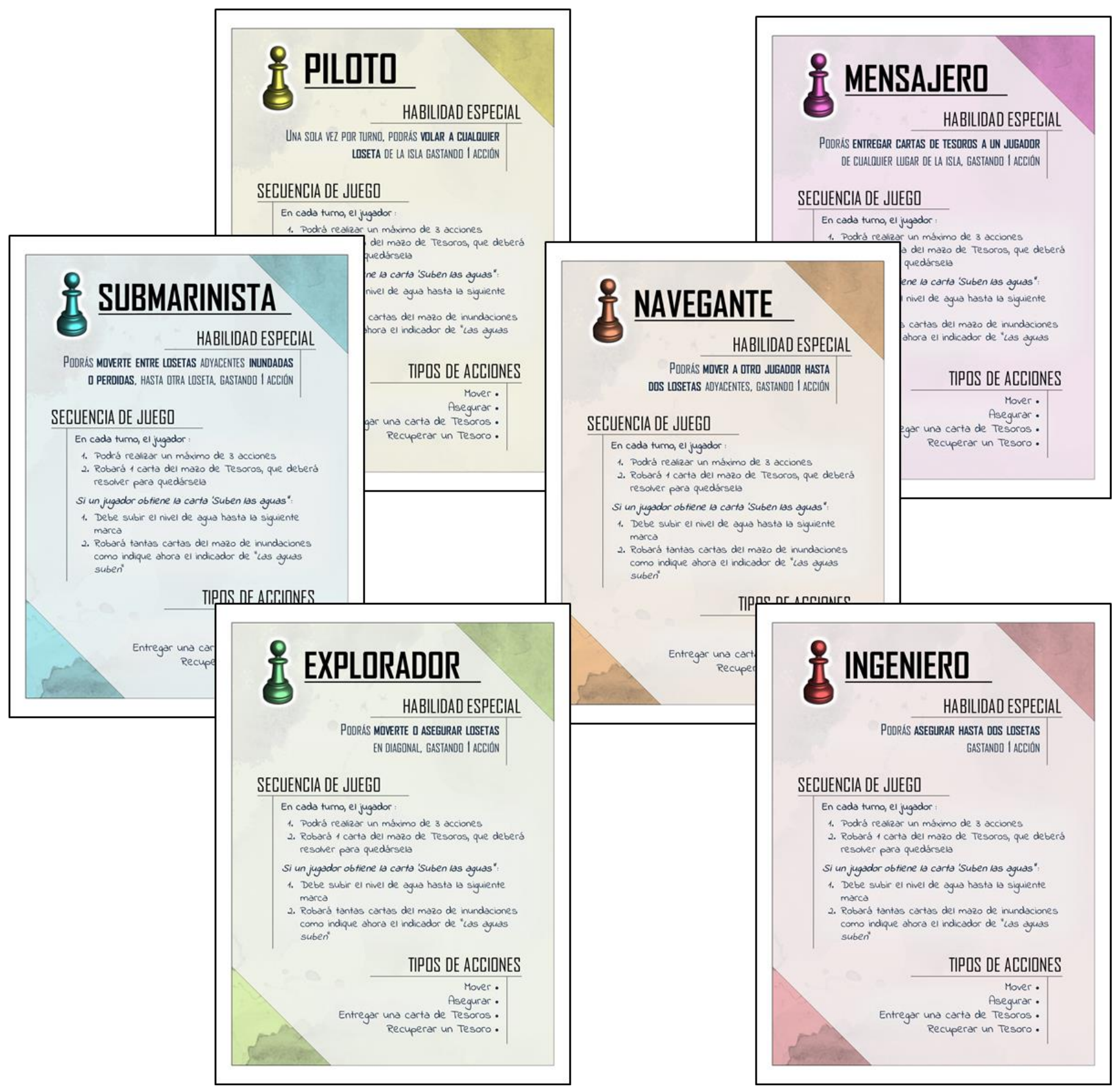


Anexo 4. Llaves-insignia (Tesoros) asociadas a cada una de las familias de cartas del juego.

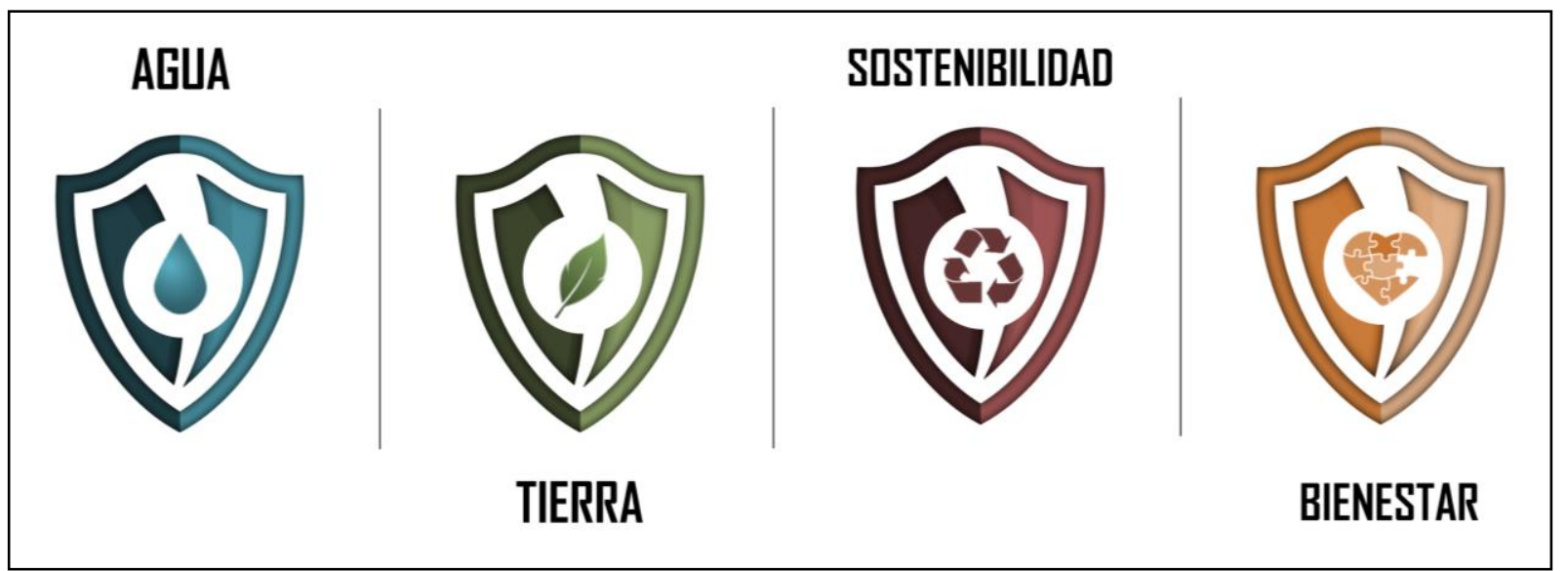

Anexo 5. Diseño del marcador e indicador de agua del recurso elaborado. El indicador de agua ha sido simulado con una flecha roja, que en el juego real debe ser un indicador "a modo de clip" que permita su movilidad sobre el marcador.

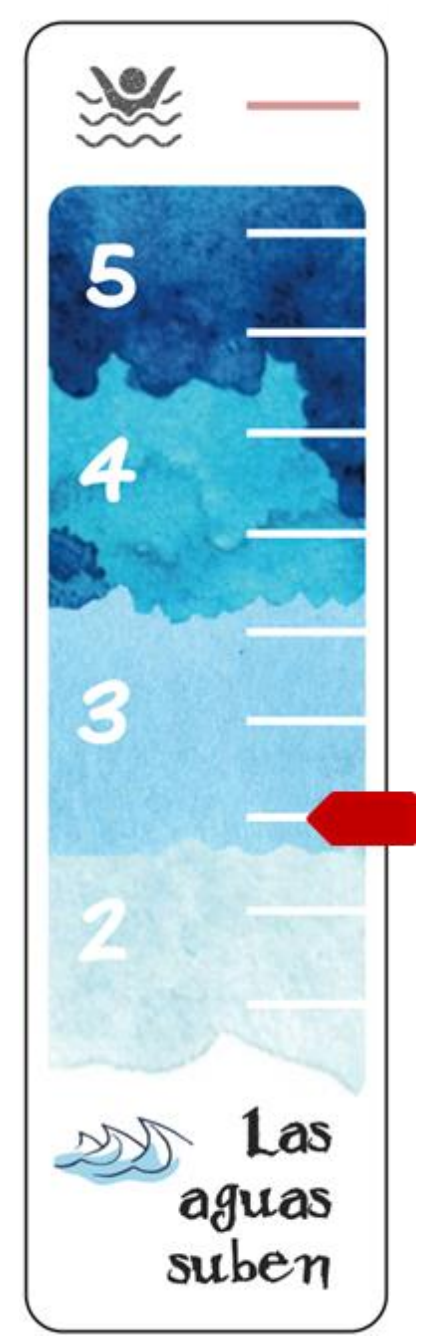


Anexo 6. Detalle de las losetas Isla diseñadas para el recurso que aquí se presenta. El color de cada loseta hace referencia a la familia de cartas con la cual guarda relación (azul = Agua; verde $=$ Tierra , roja $=$ Sostenibilidad , naranja $=$ Bienestar $)$. El color amarillo ha sido empleado únicamente para la loseta 'Pista de aterrizaje'. A color se muestra la loseta cuando esta se encuentra a flote (haz; izquierda), y en tonos ocres-grisáceos se muestra la loseta cuando se encuentra hundida (envés; derecha).
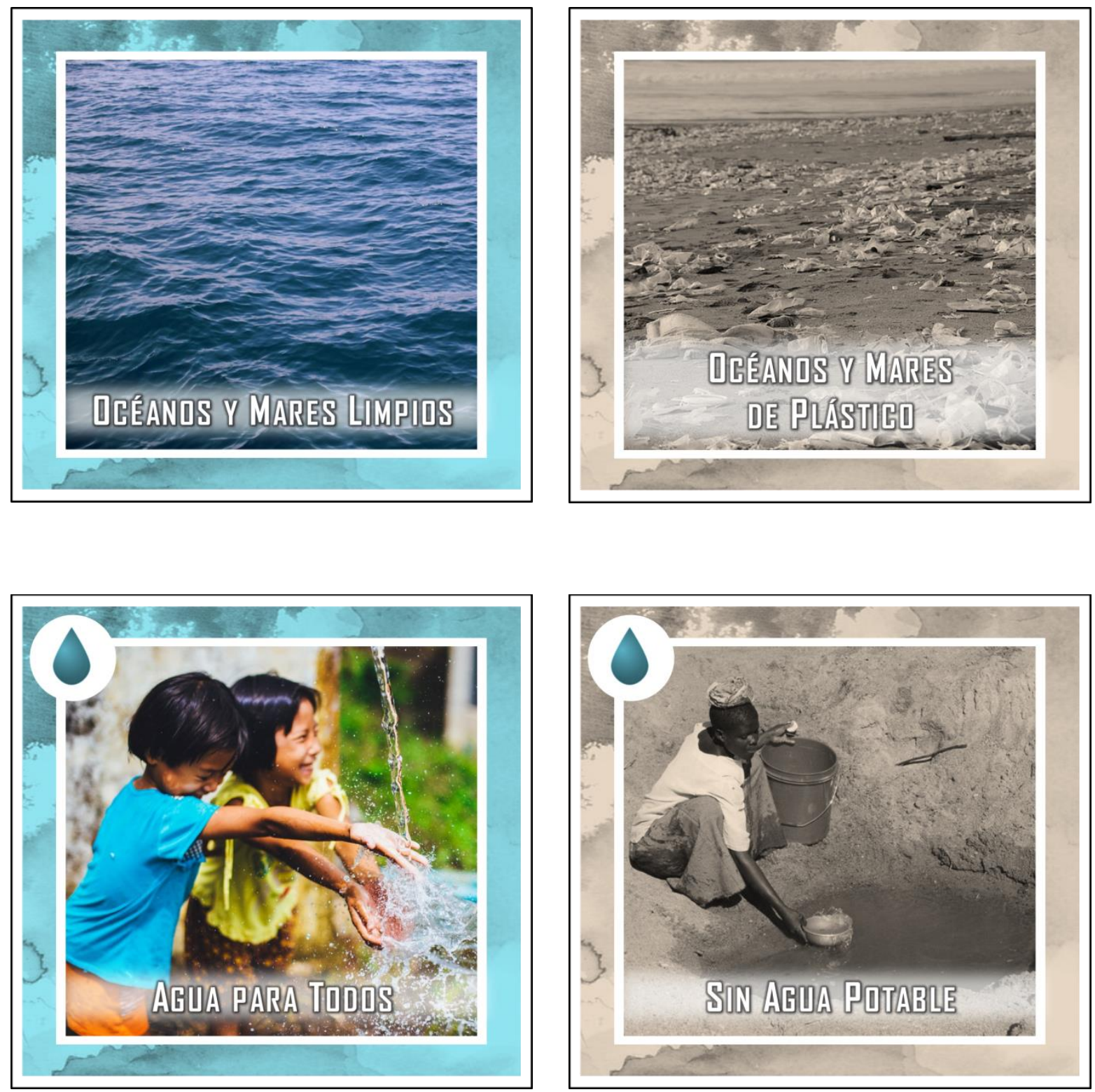

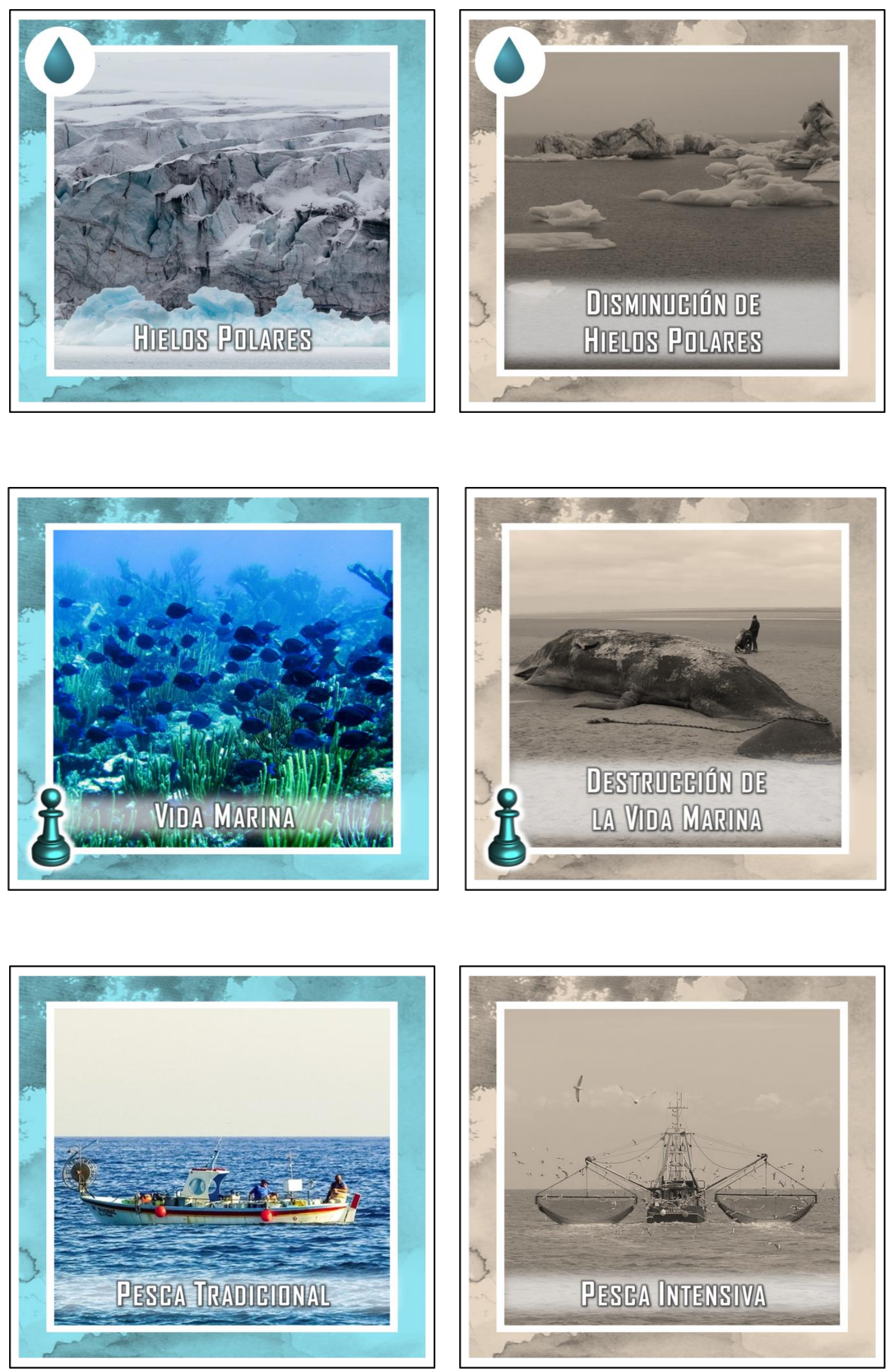

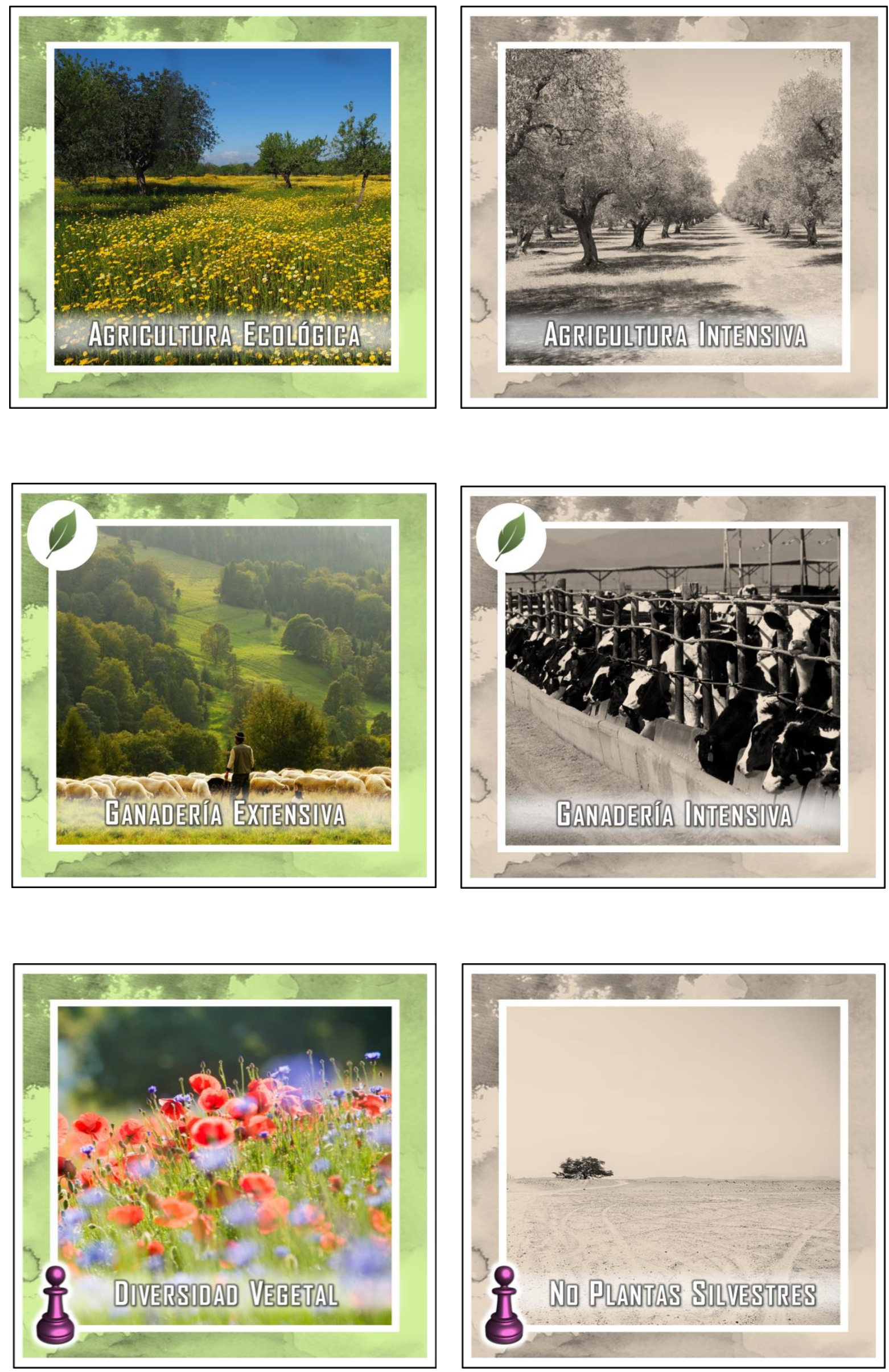

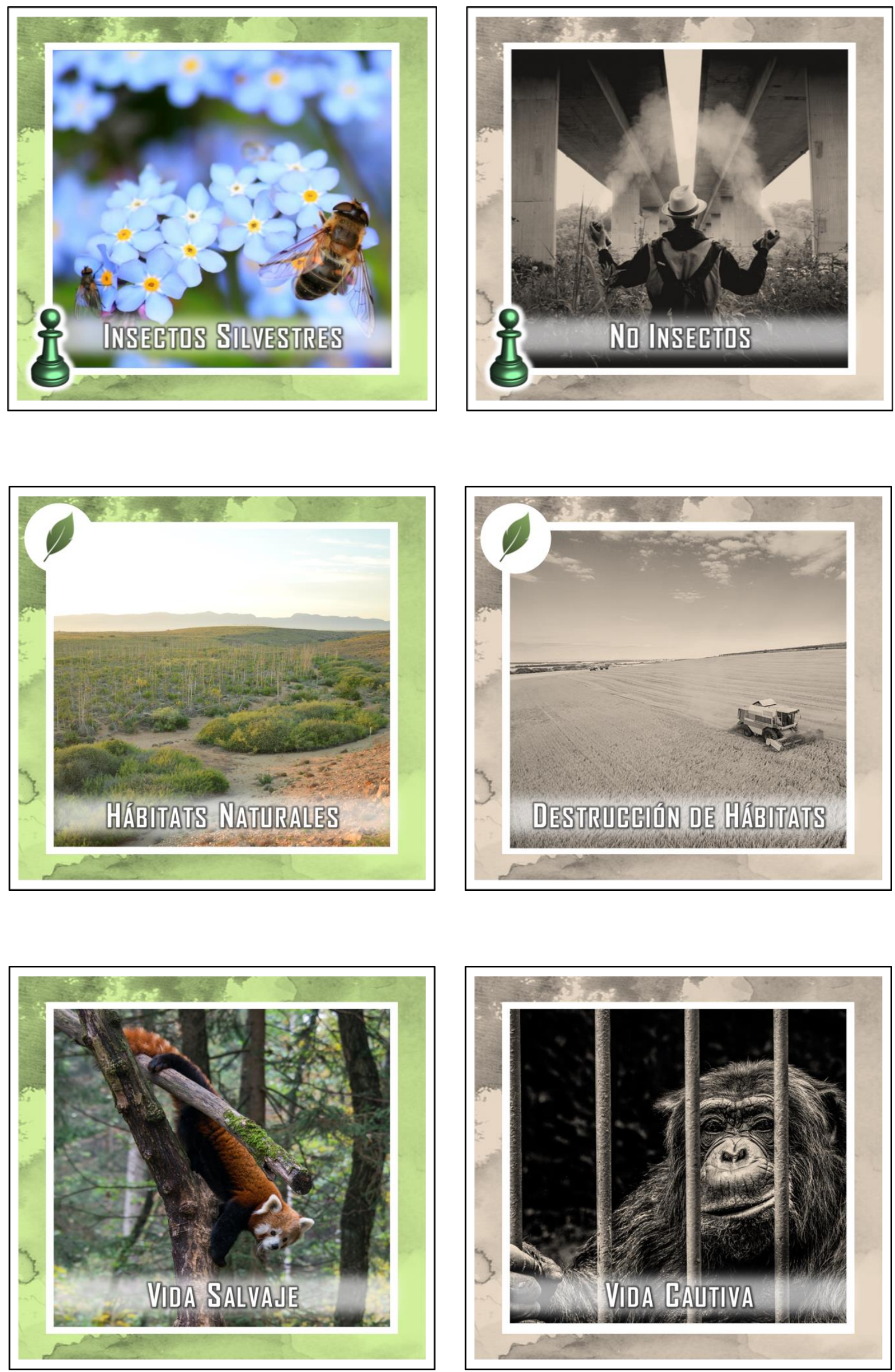

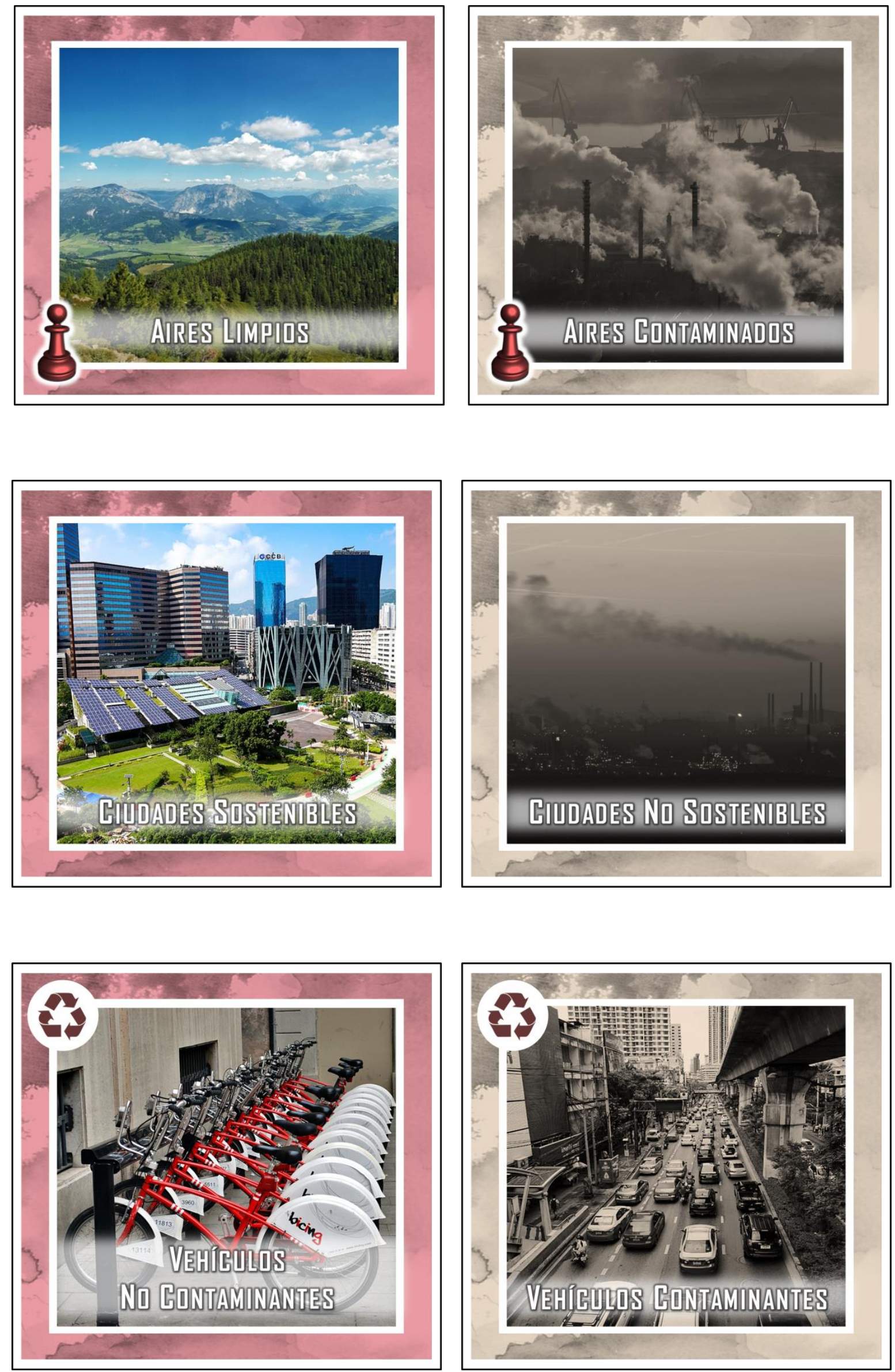

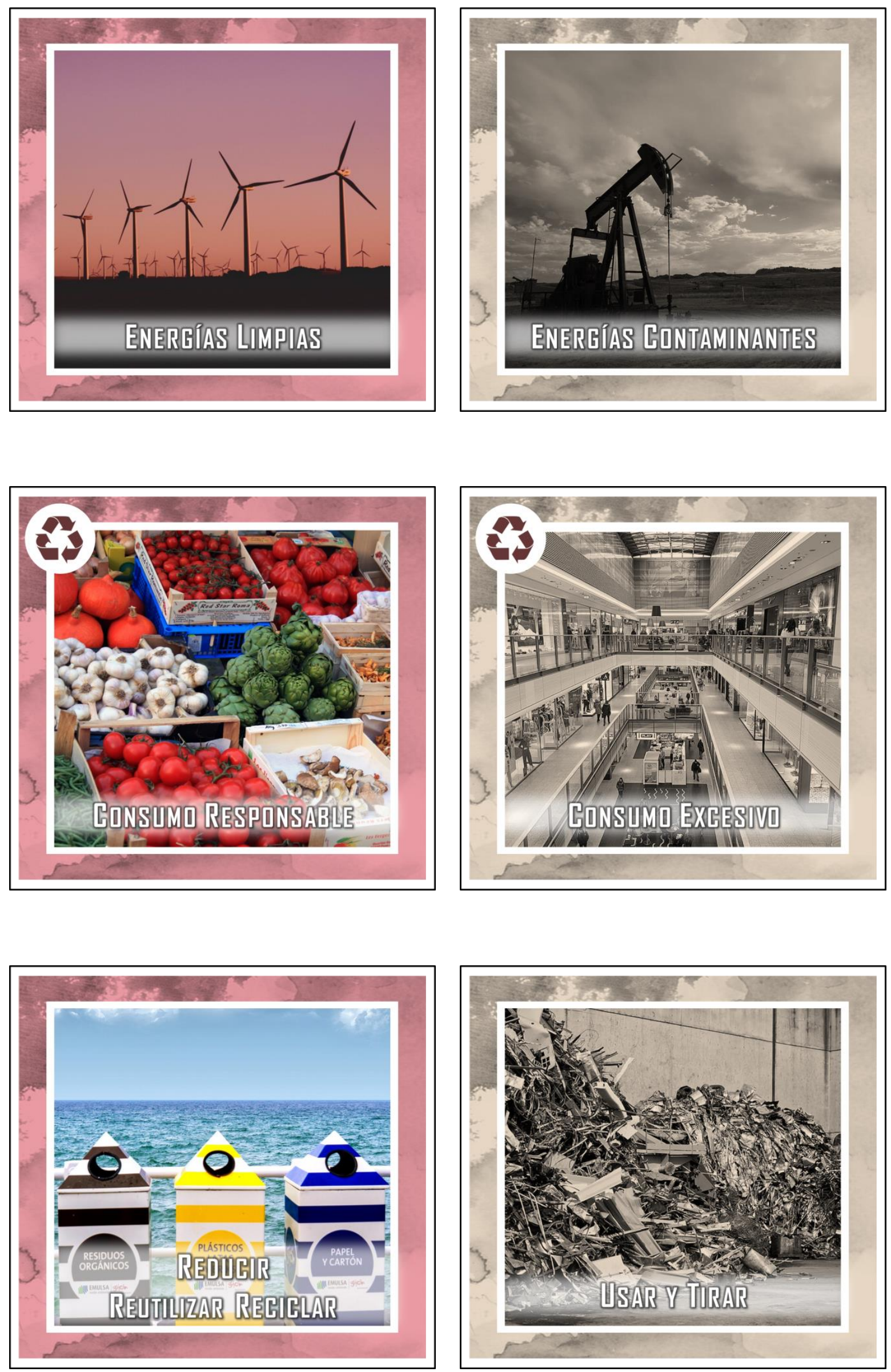

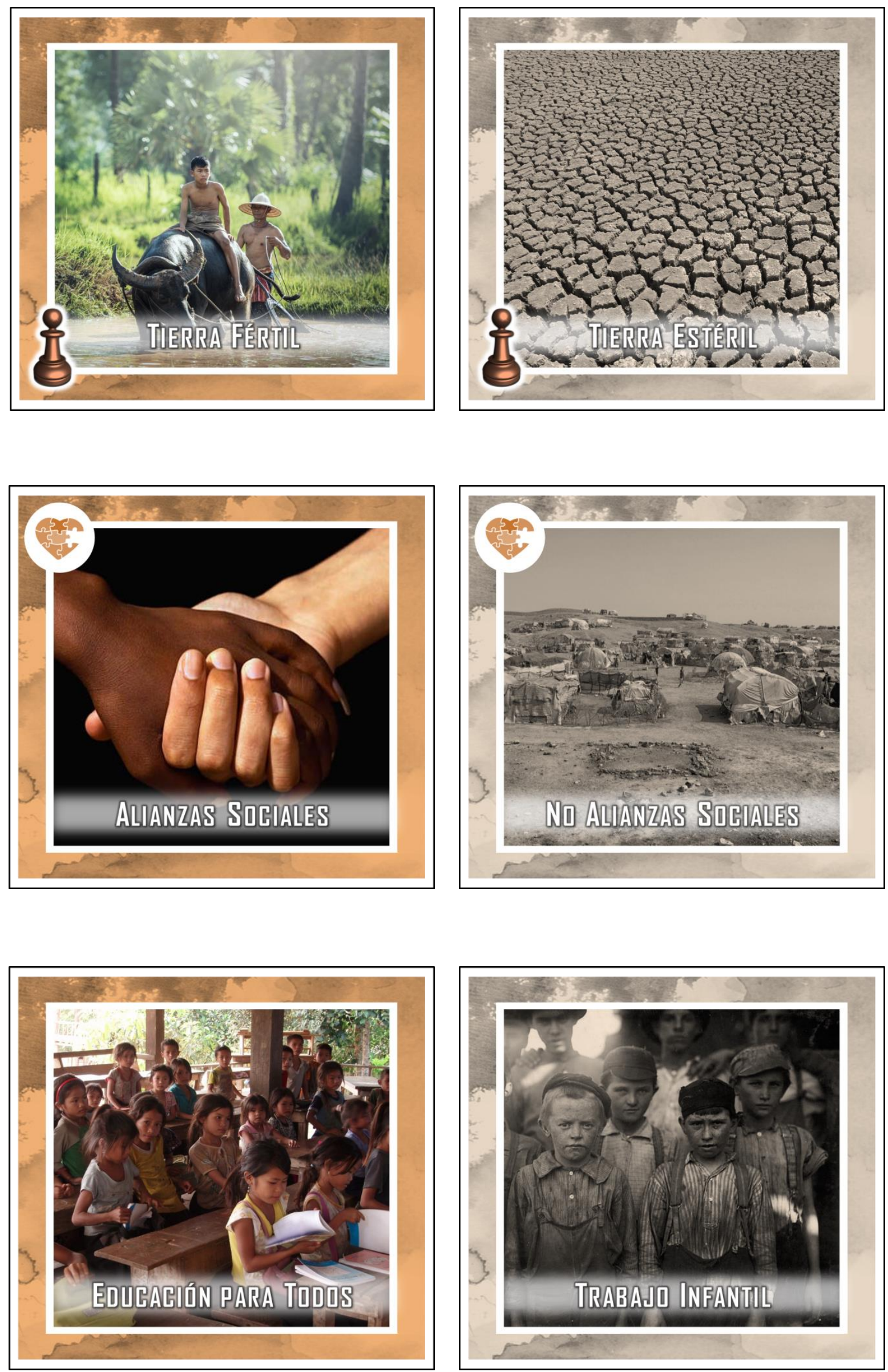

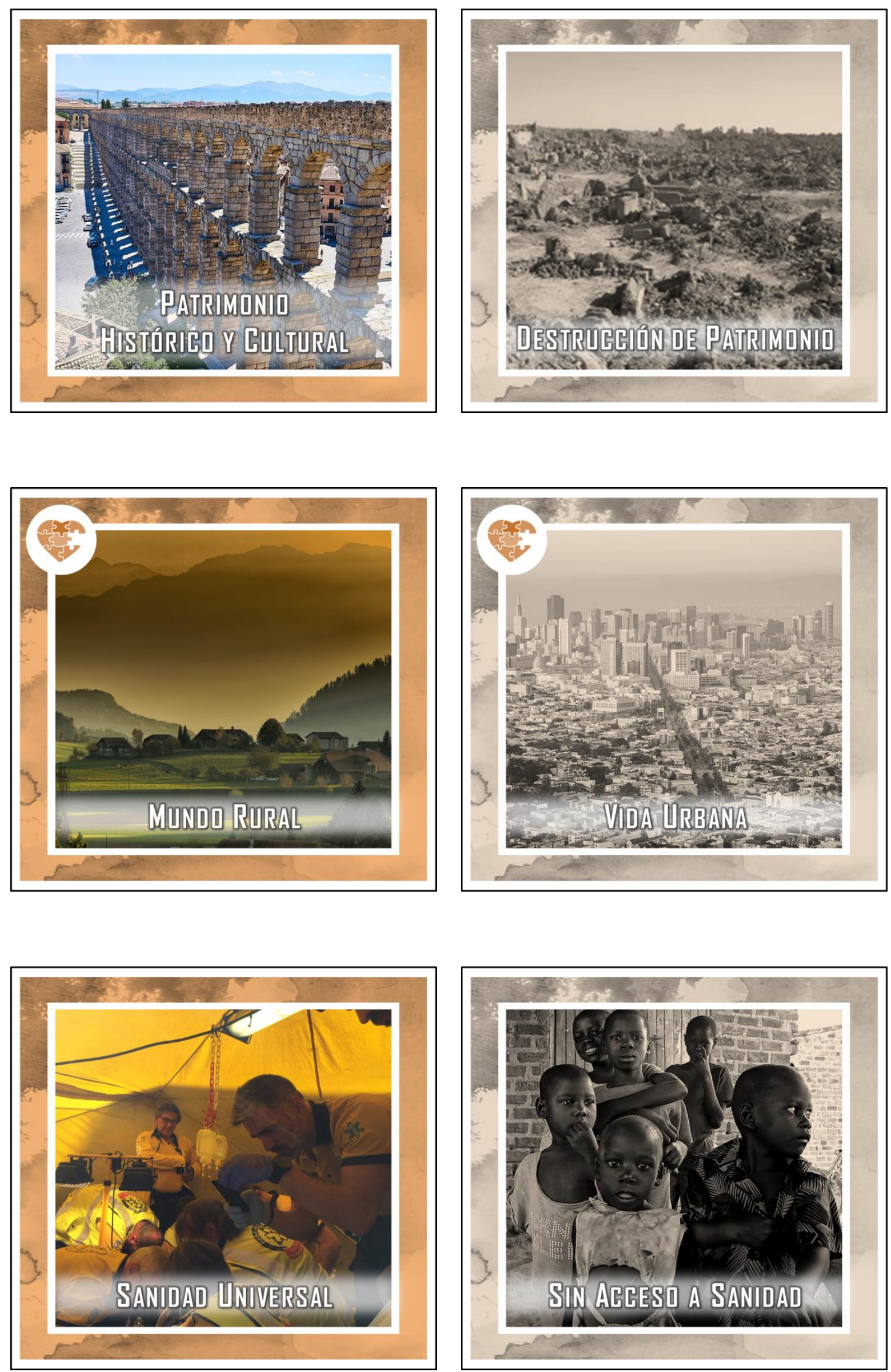

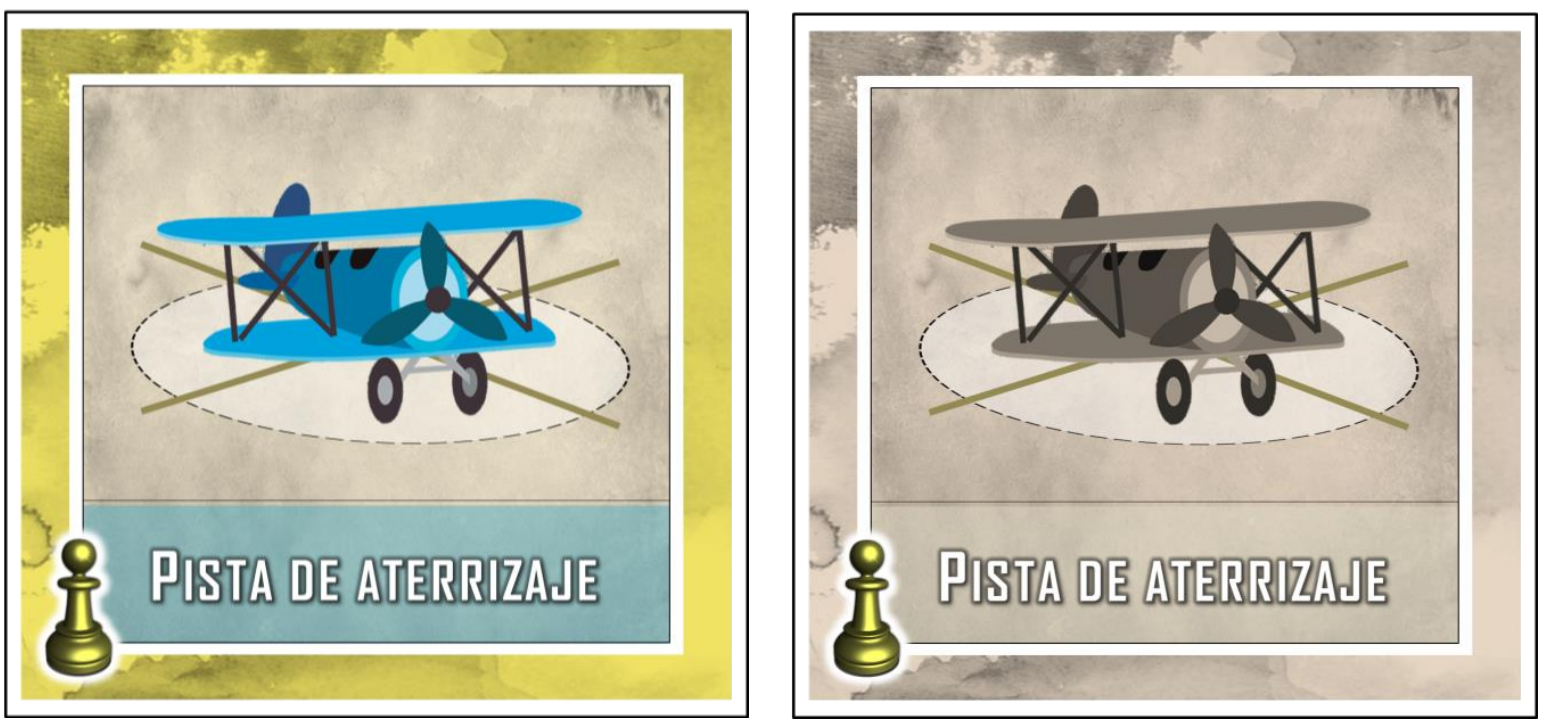
Anexo 7. Detalle de las cartas del mazo Inundación. Se muestra el diseño del envés (primera carta) y el diseño de haz de cada una de ellas (resto de cartas). Los escenarios que figuran en el haz de las cartas son los mismos que se encuentran en las losetas Islas.
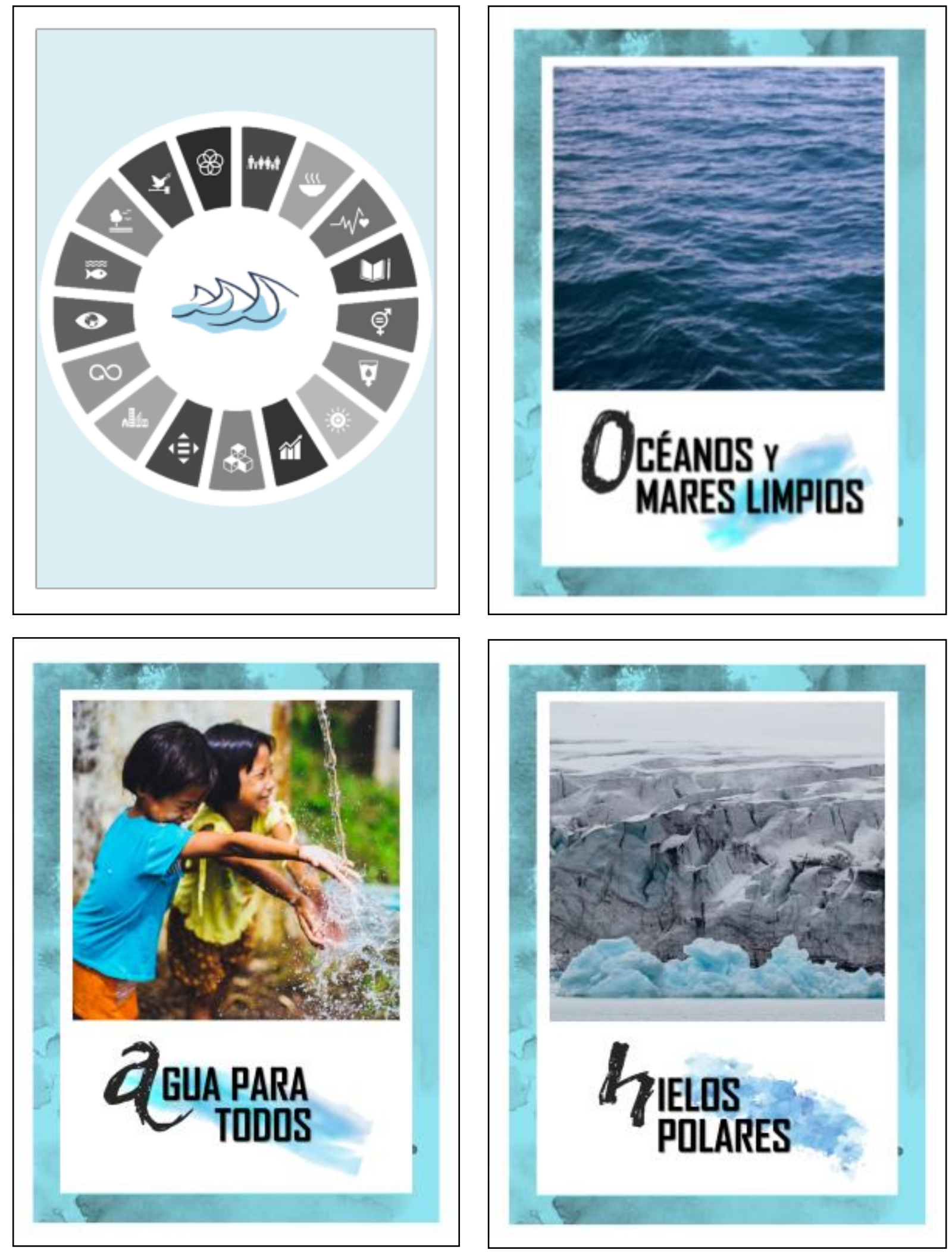

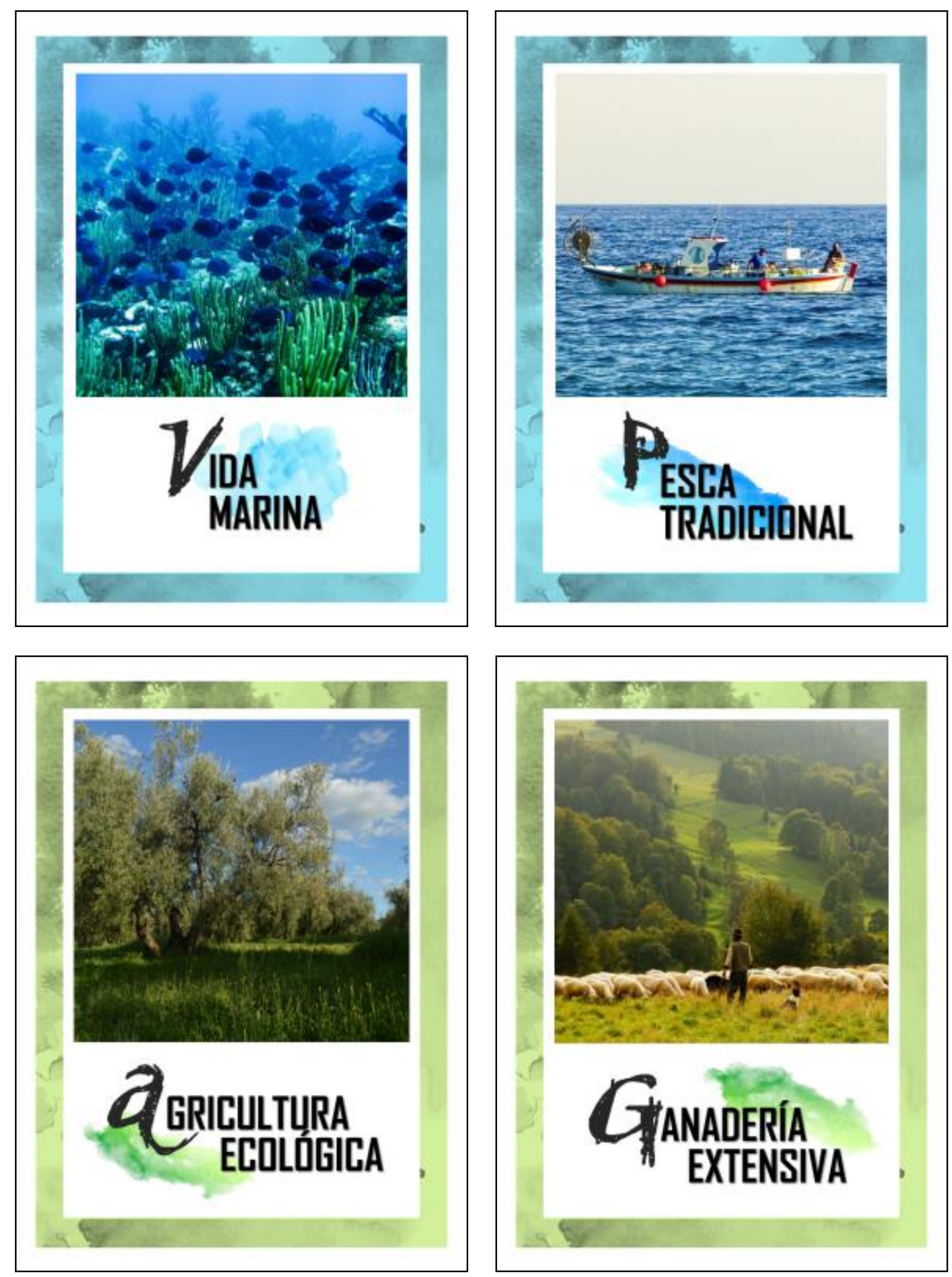

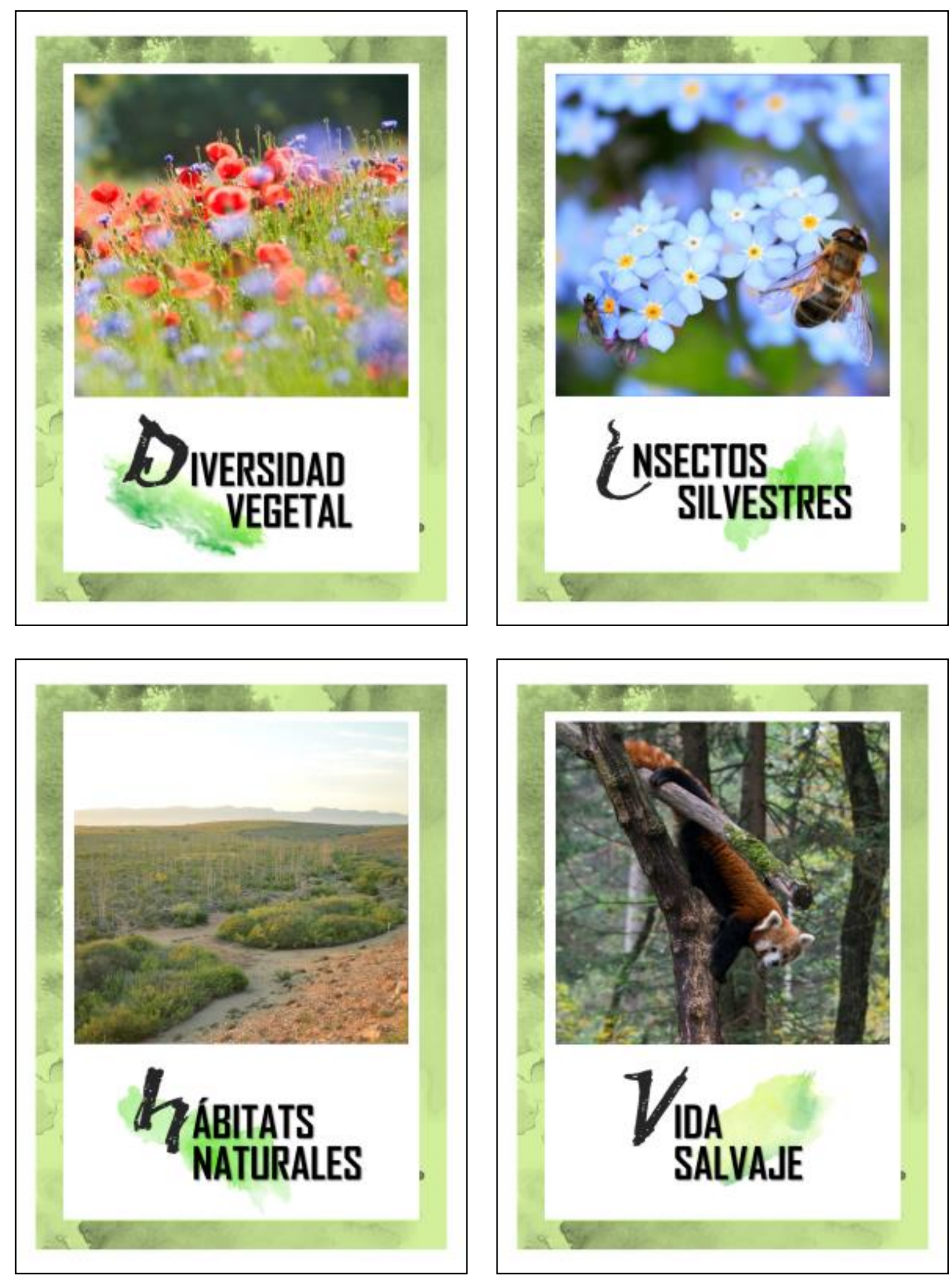

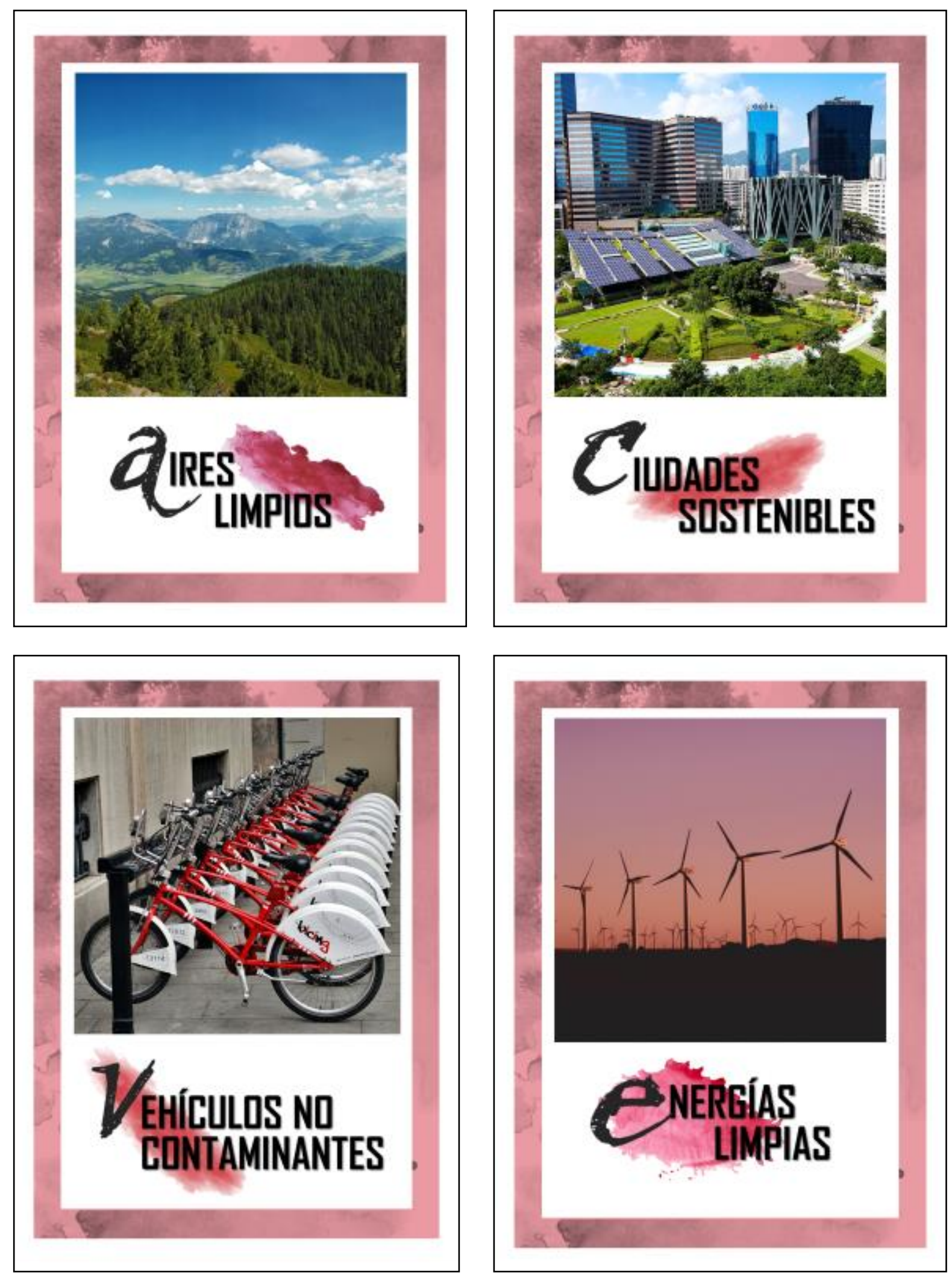

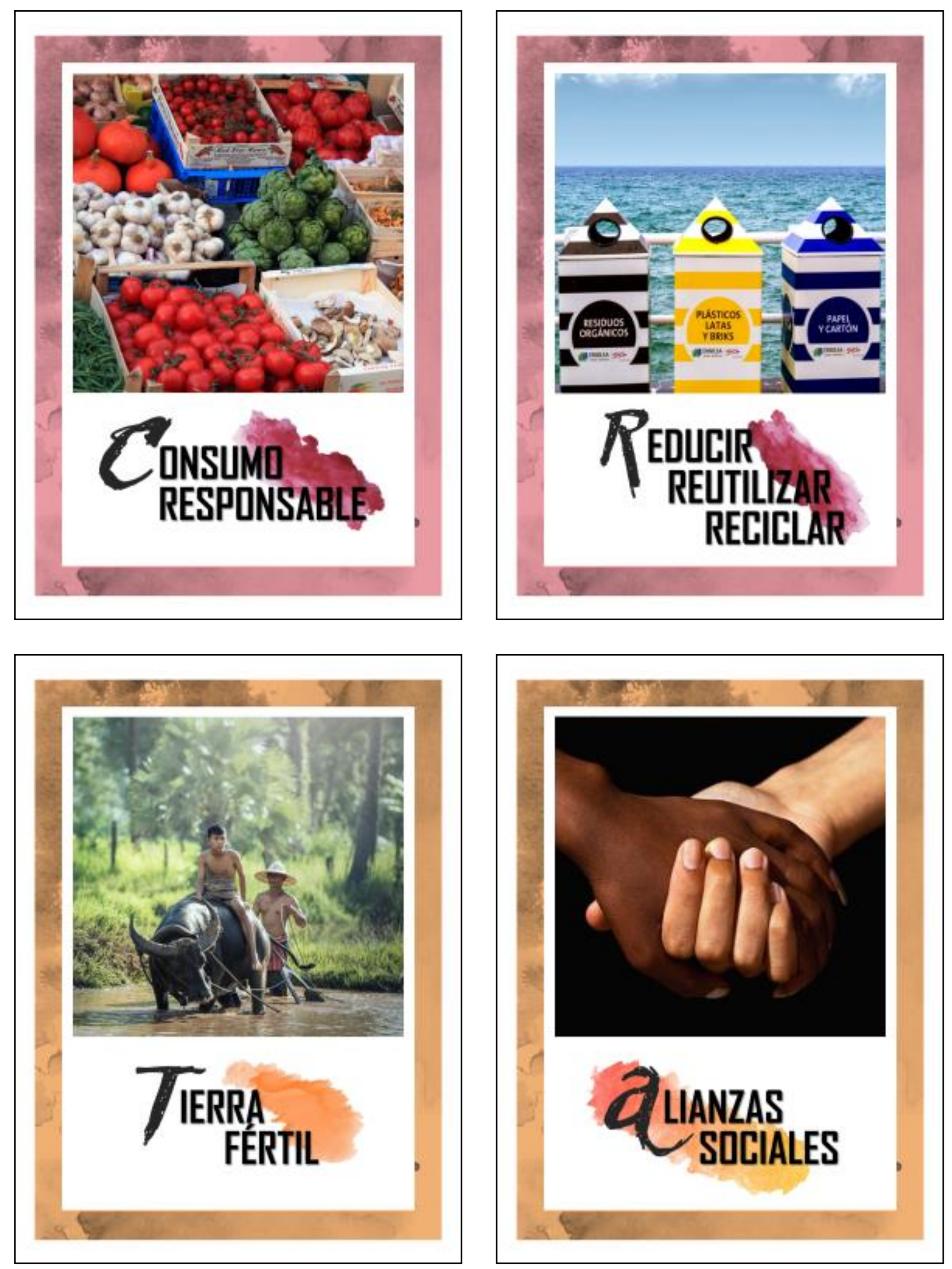

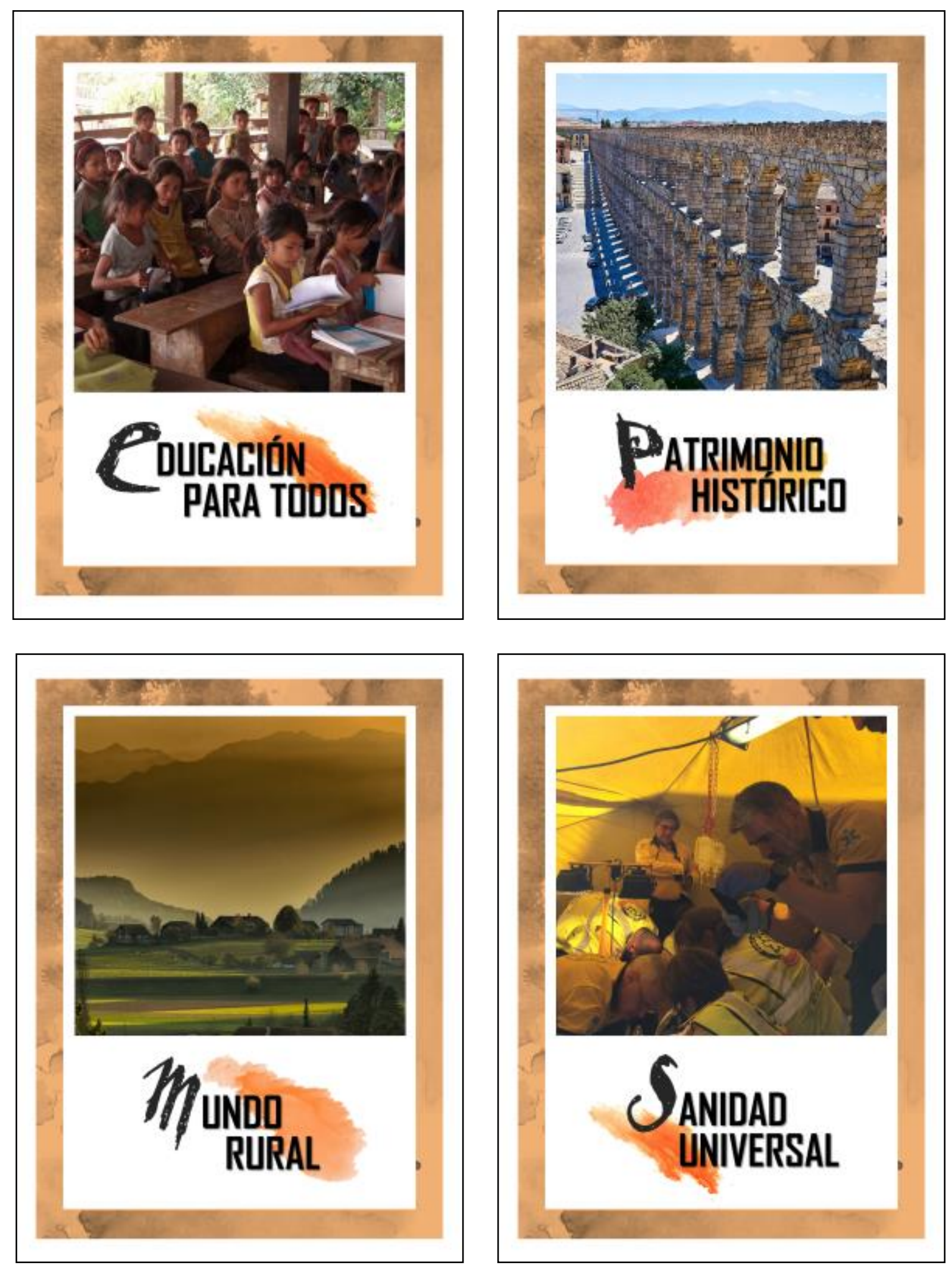


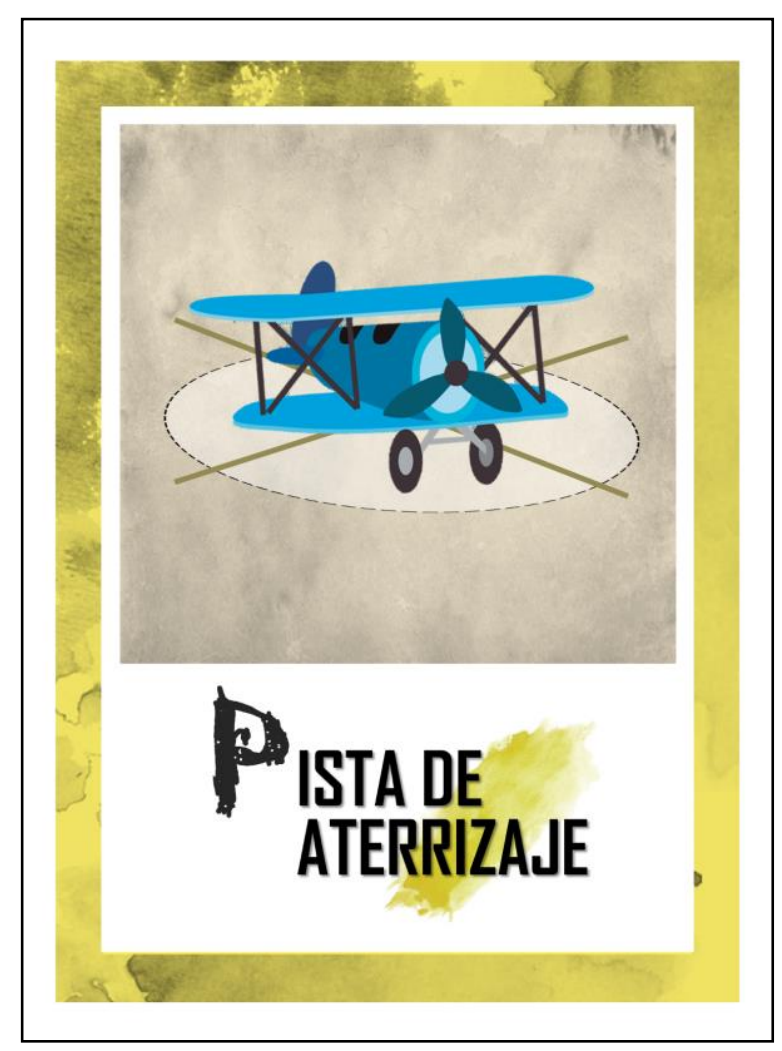


Anexo 8. Detalle de las cartas especiales diseñadas para el recurso.
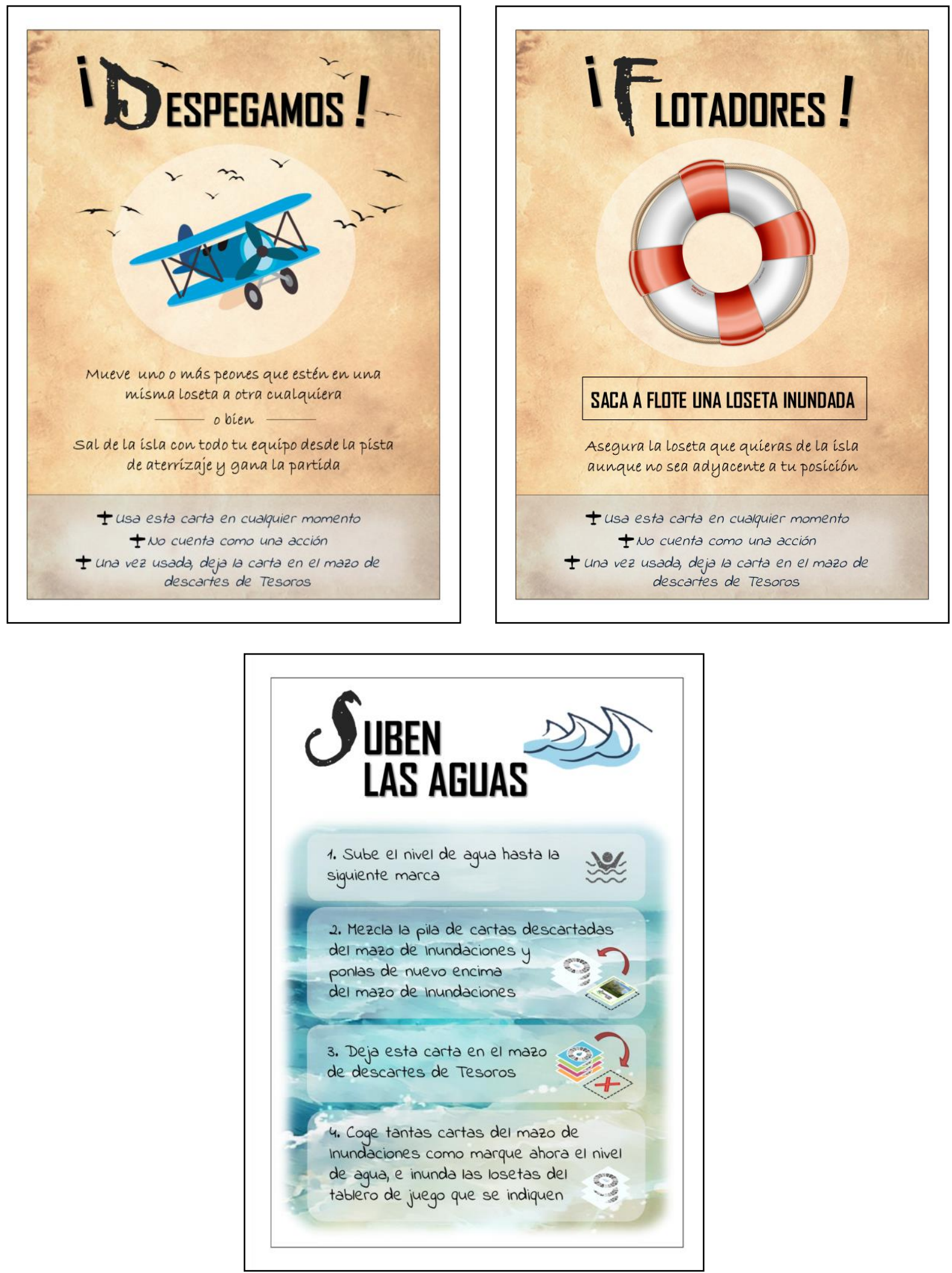
Anexo 9. Diseño del haz de las cartas del mazo ODS. El color de cada una hace referencia a la familia de cartas a la que pertenece $($ azul = Agua $;$ verde $=$ Tierra $;$ roja $=$ Sostenibilidad; naranja $=$ Bienestar $)$. El nombre, número y logotipo que titula cada carta hace referencia al ODS que se trabaja en ella.
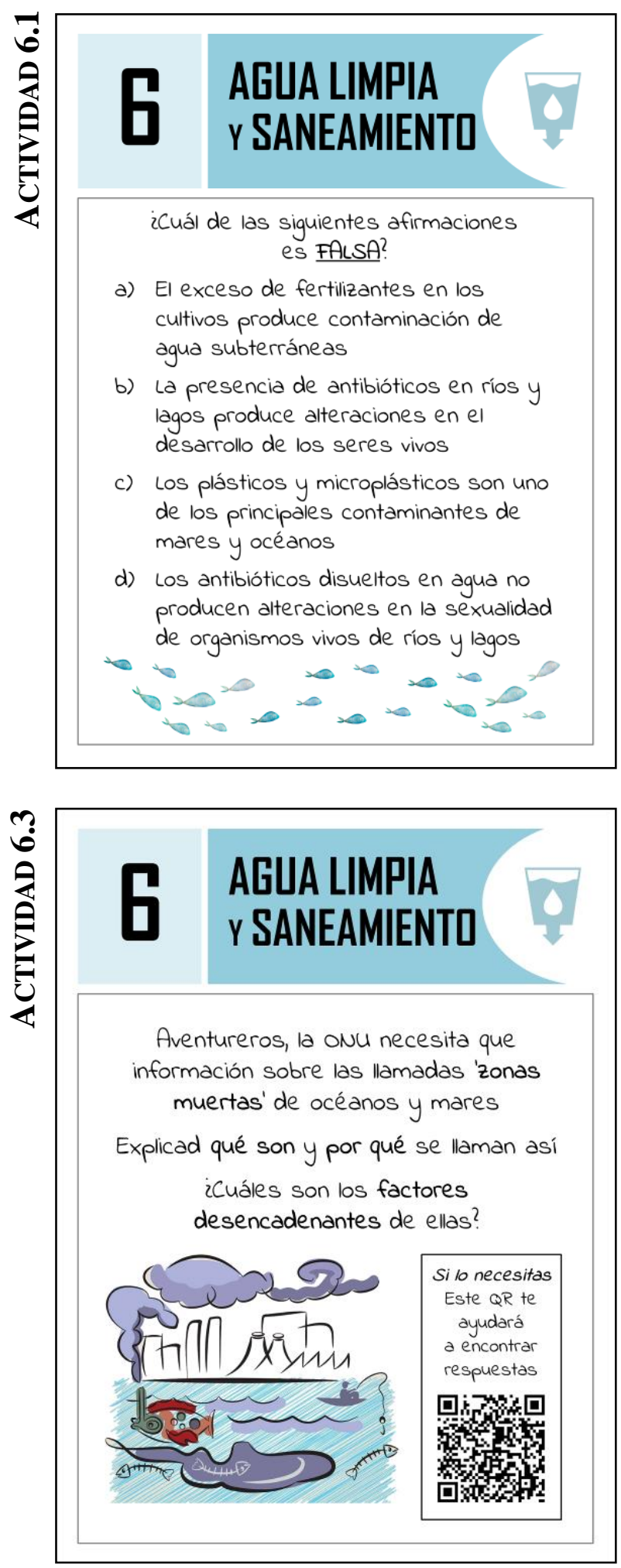

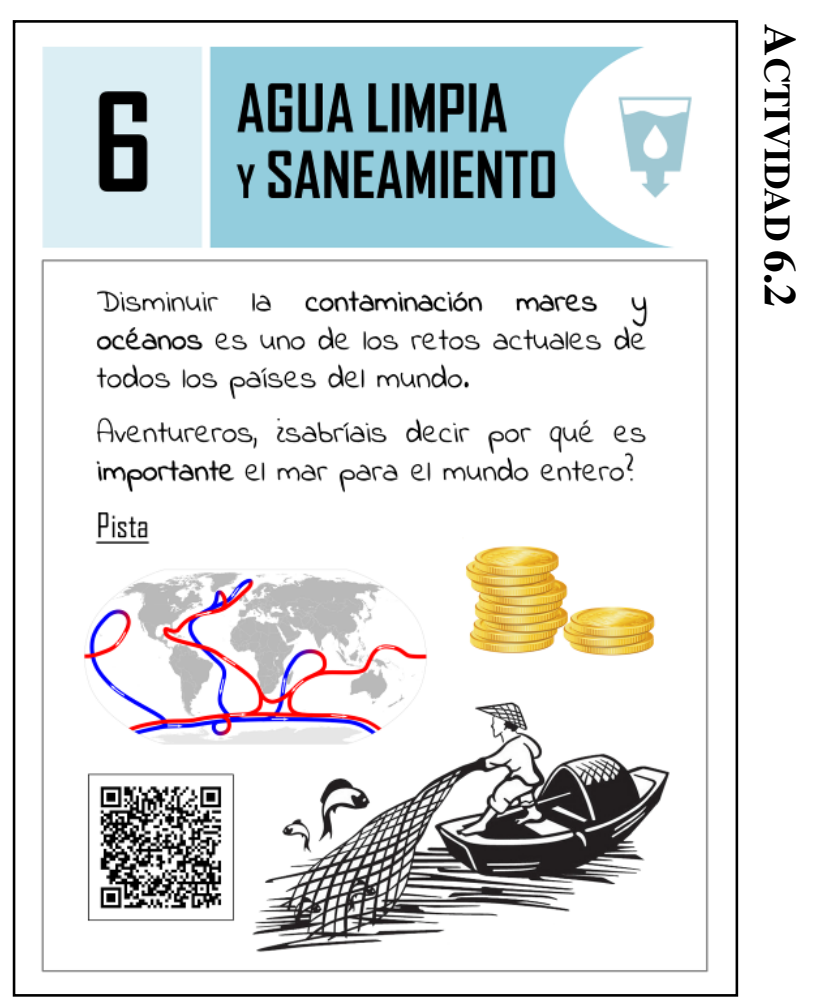

B AELA LIMPIA
Y SANEAMIENTI

En España se realizan seguimientos de la contaminación de playas anualmente ¿Adivináis de qué tipo son el 70\% de los residuos que se encuentran en las playas?

Como expertos, qué recomendaciones daríais para ayudar a disminuir la contaminación de nuestras playas, mares y océanos

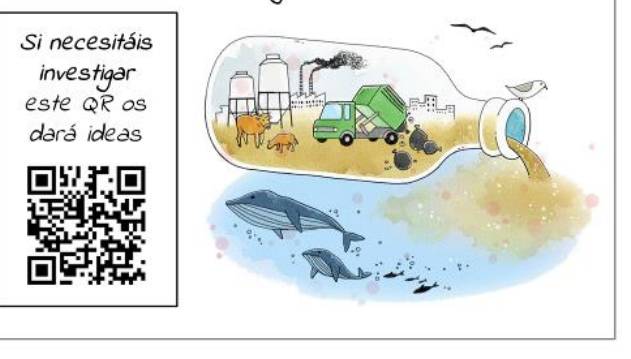



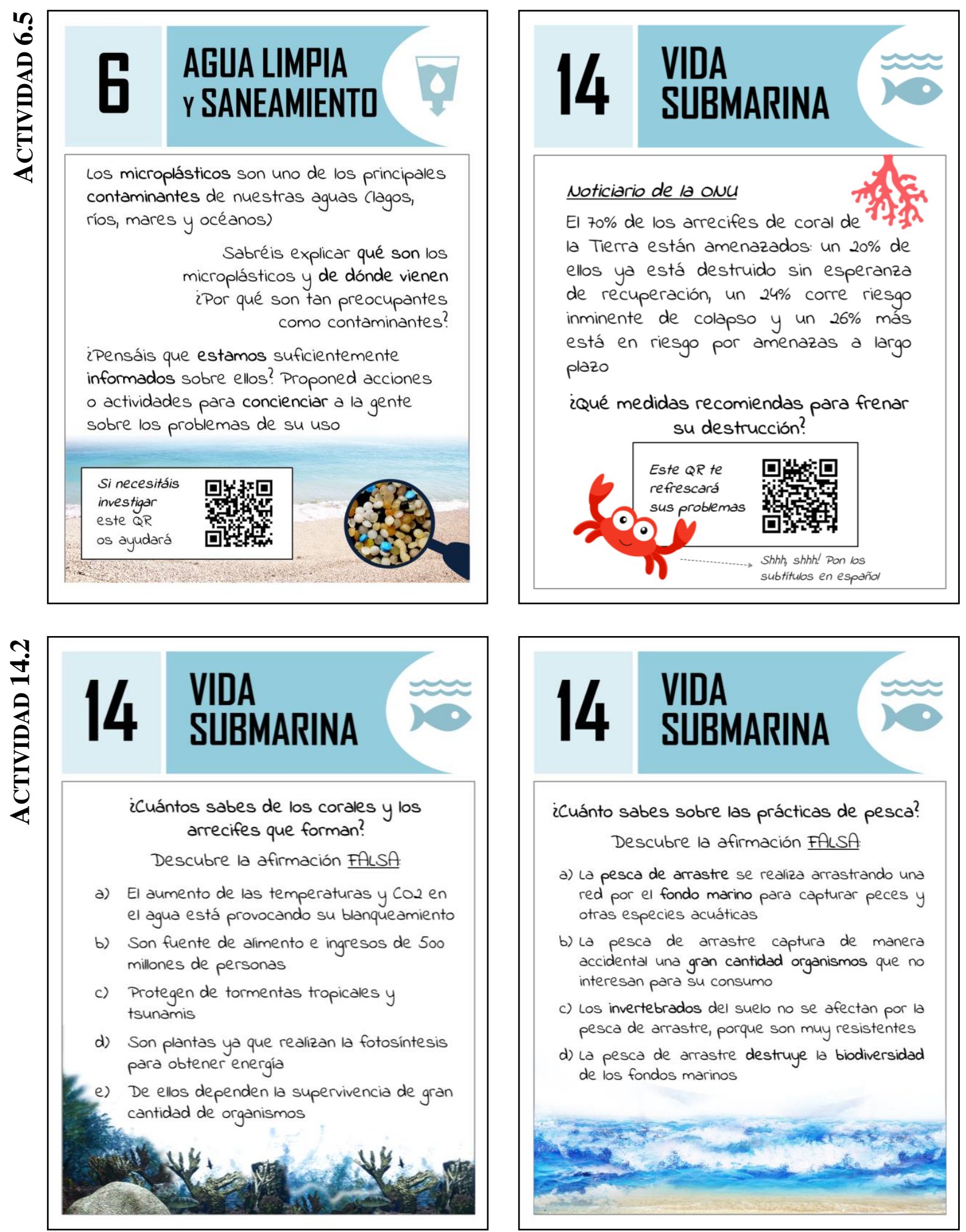

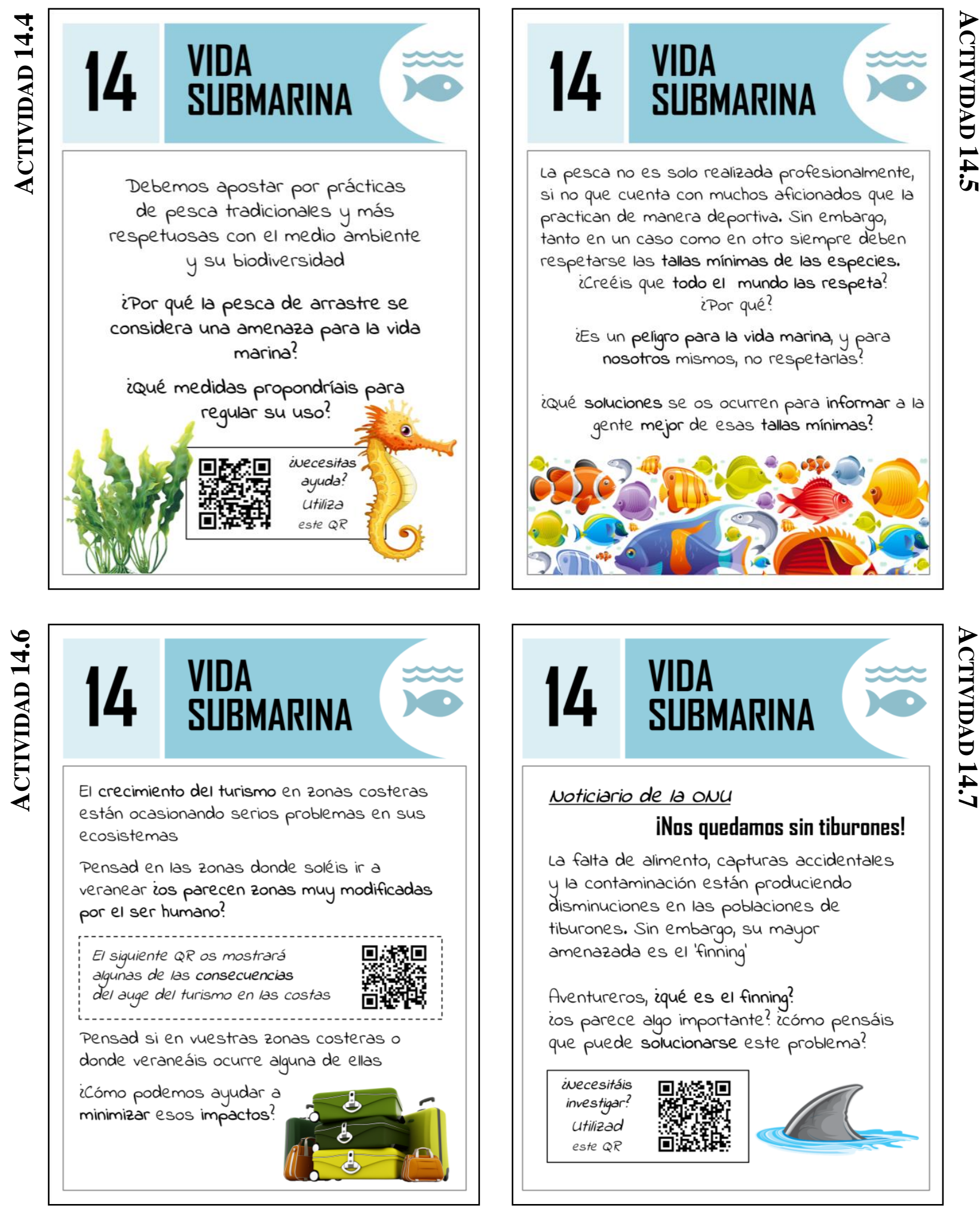

si no que cuenta con muchos aficionados que la practican de manera deportiva. Sin embargo, tanto en un caso como en otro siempre deben respetarse las tallas minimas de las especies.

¿creéis que todo el mundo las respeta? ¿Por qué?

iEs un peligro para la vida marina, y para nosotros mismos, no respetarlas?

¿Qué soluciones se os ocurren para informar a la gente mejor de esas tallas mínimas?
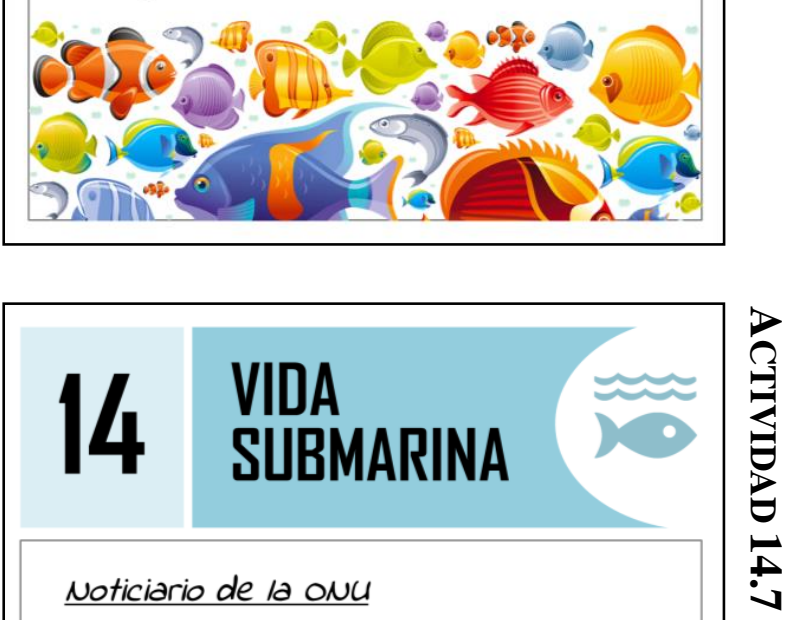

iNos quedamos sin tiburones!

La falta de alimento, capturas accidentales

y la contaminación están produciendo disminuciones en las poblaciones de tiburones. Sin embargo, su mayor amenazada es el 'finning'

Aventureros, iqué es el finning?

ios parece algo importante? icómo pensáis que puede solucionarse este problema?

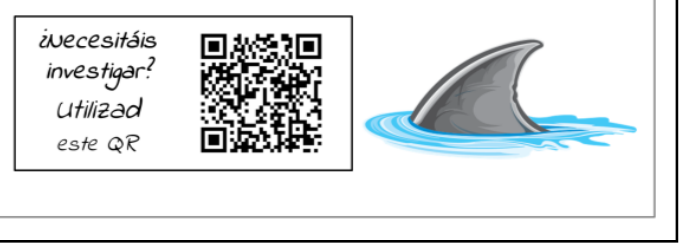



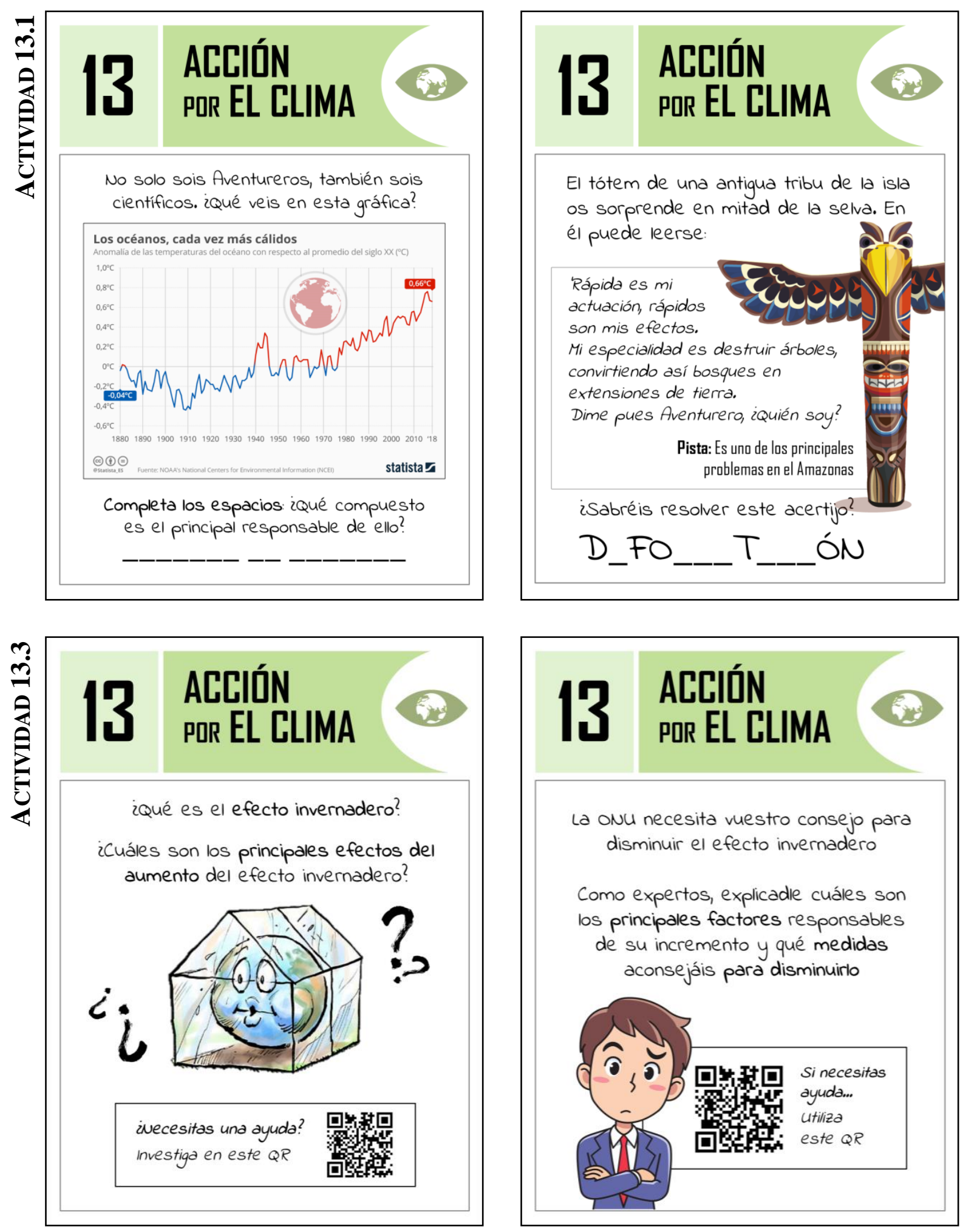

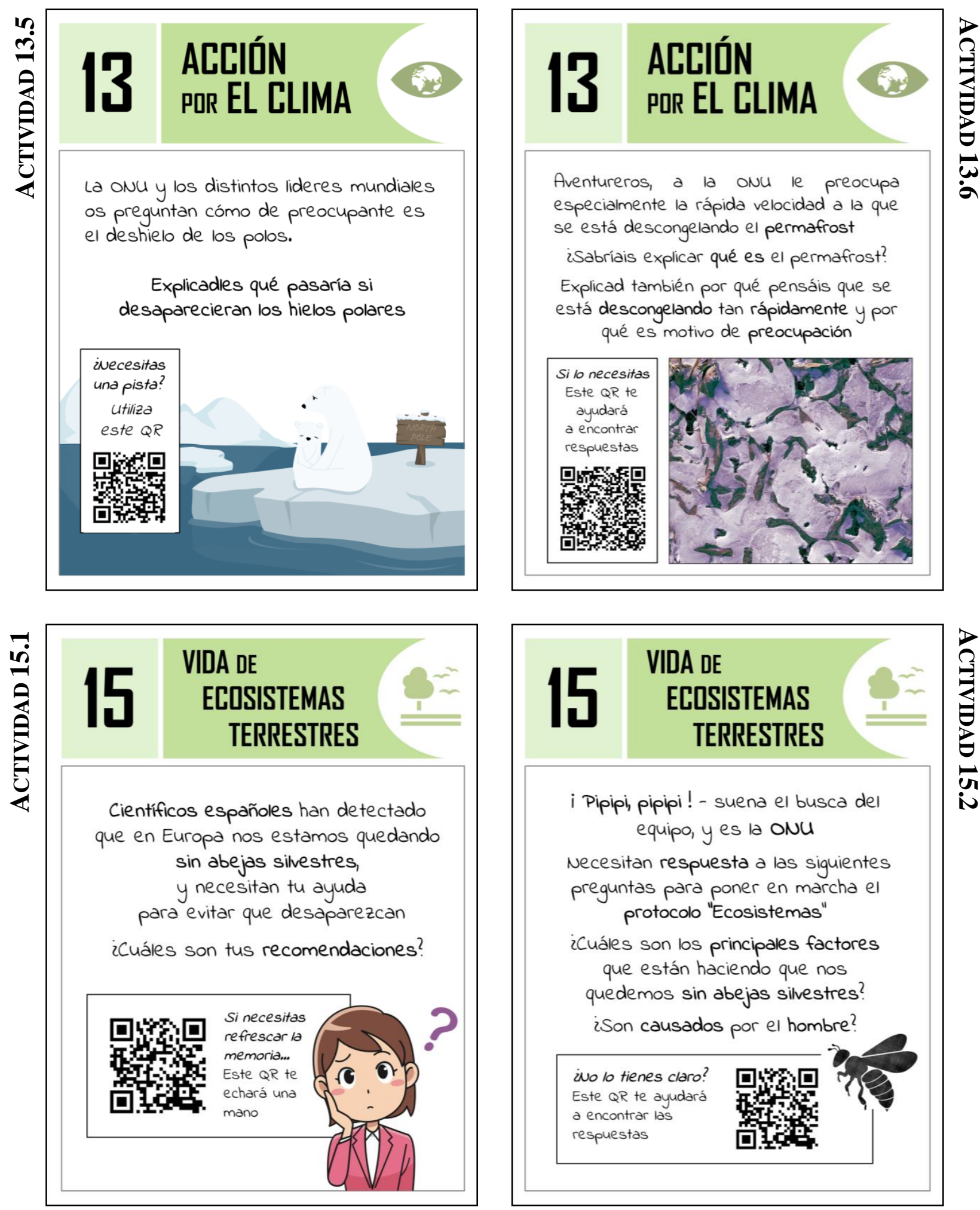

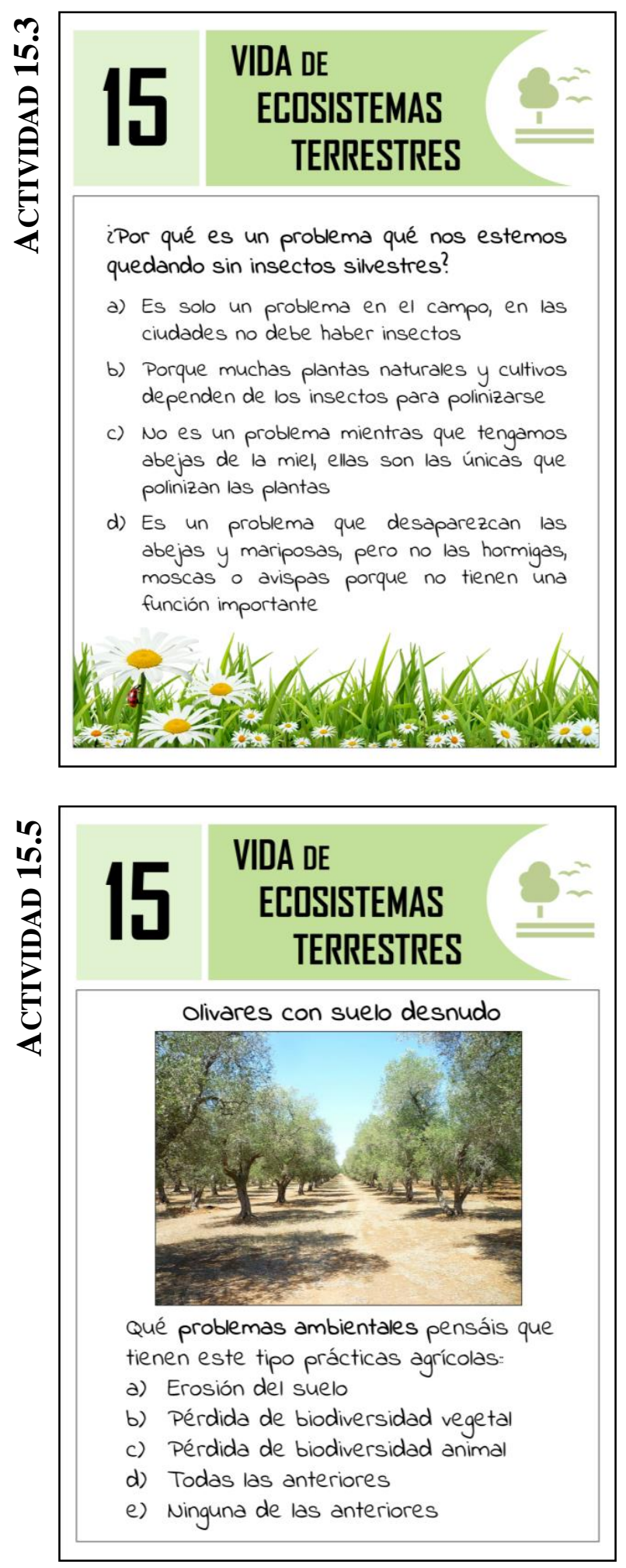

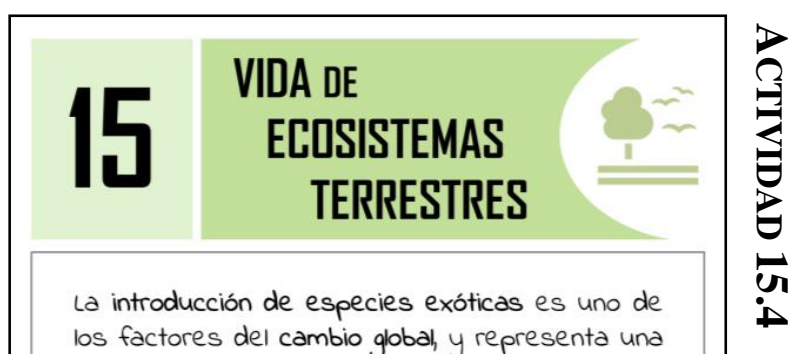
amenaza para cambio global, y representa una se introducen.

pero...esto no todo el mundo lo entiende bien.

iSabríais explicar cuales son los principales problemas que desencadena la introducción de especies exóticas en un lugar?
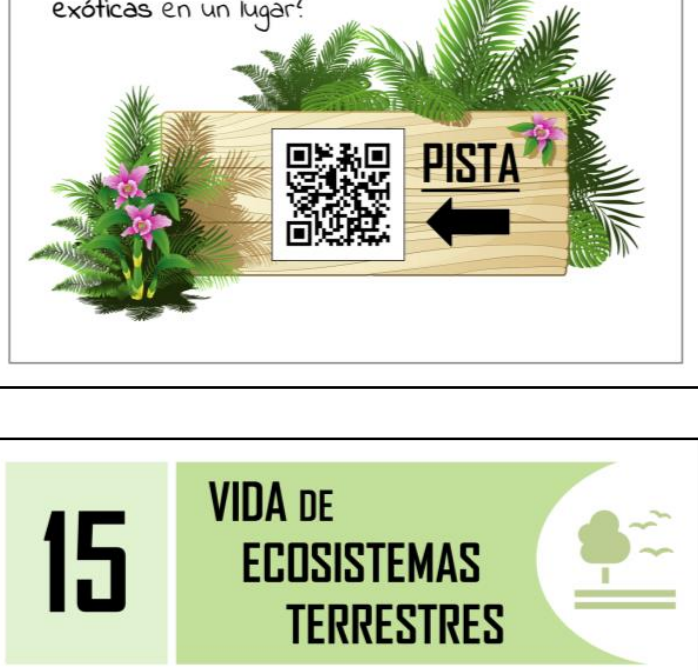

España cuenta con una gran biodiversidad (animal y vegetal). Sin embargo, varias de nuestras especies se encuentran seriamente amenazadas, generalmente a causa del ser humano. El linde ibérico es uno de los casos más conocidos.

isabriais decir otras tres especies (animales o vegetales) que se encuentren amenazadas en España?

¿A qué pensáis que se debe?

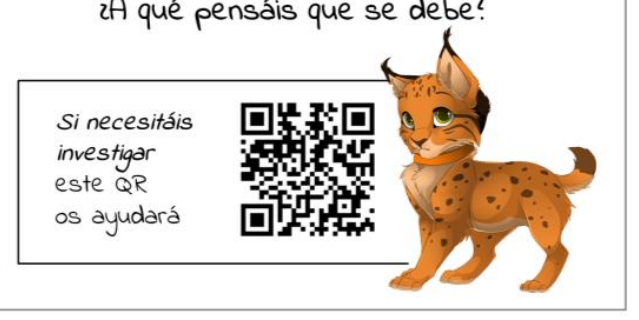



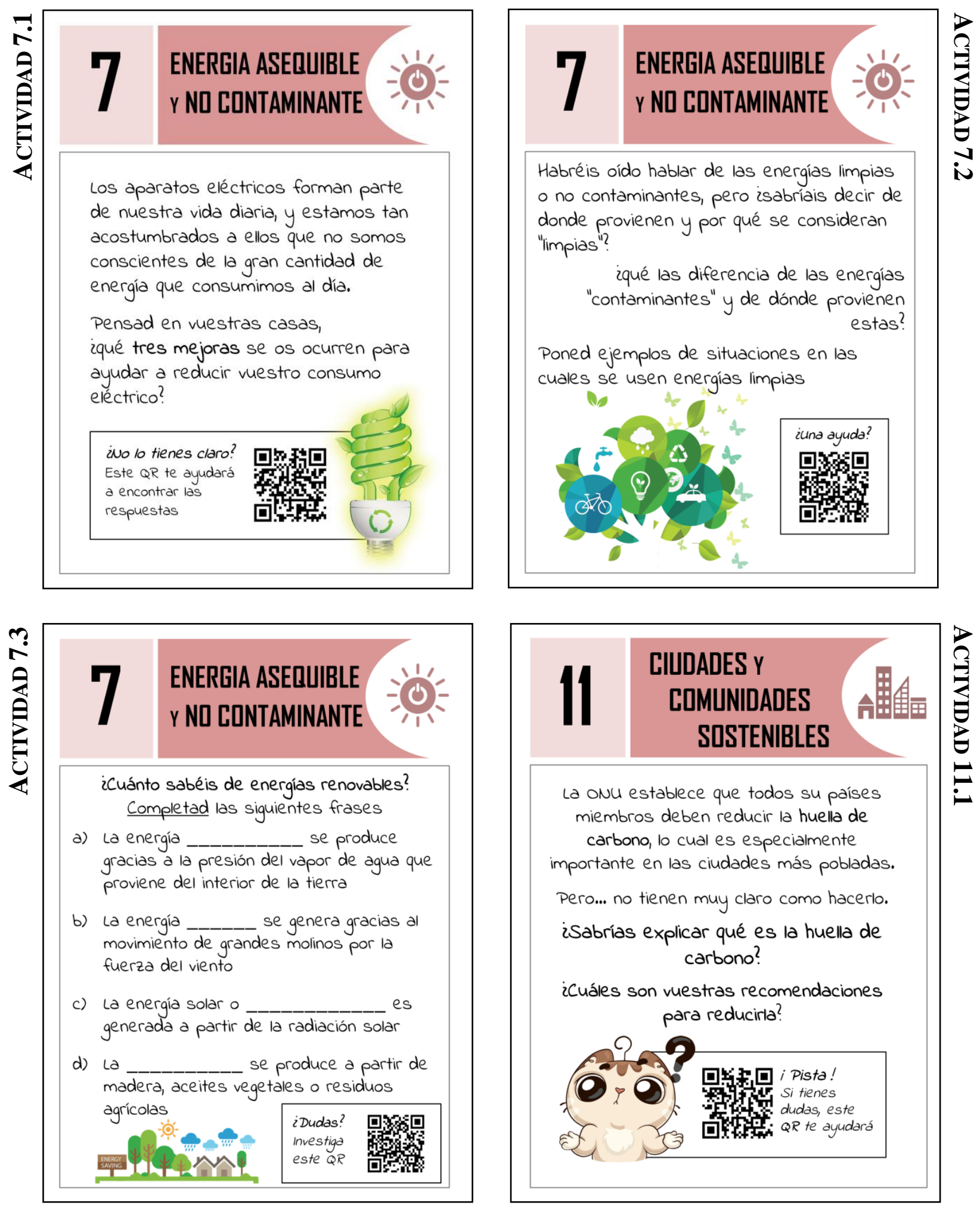

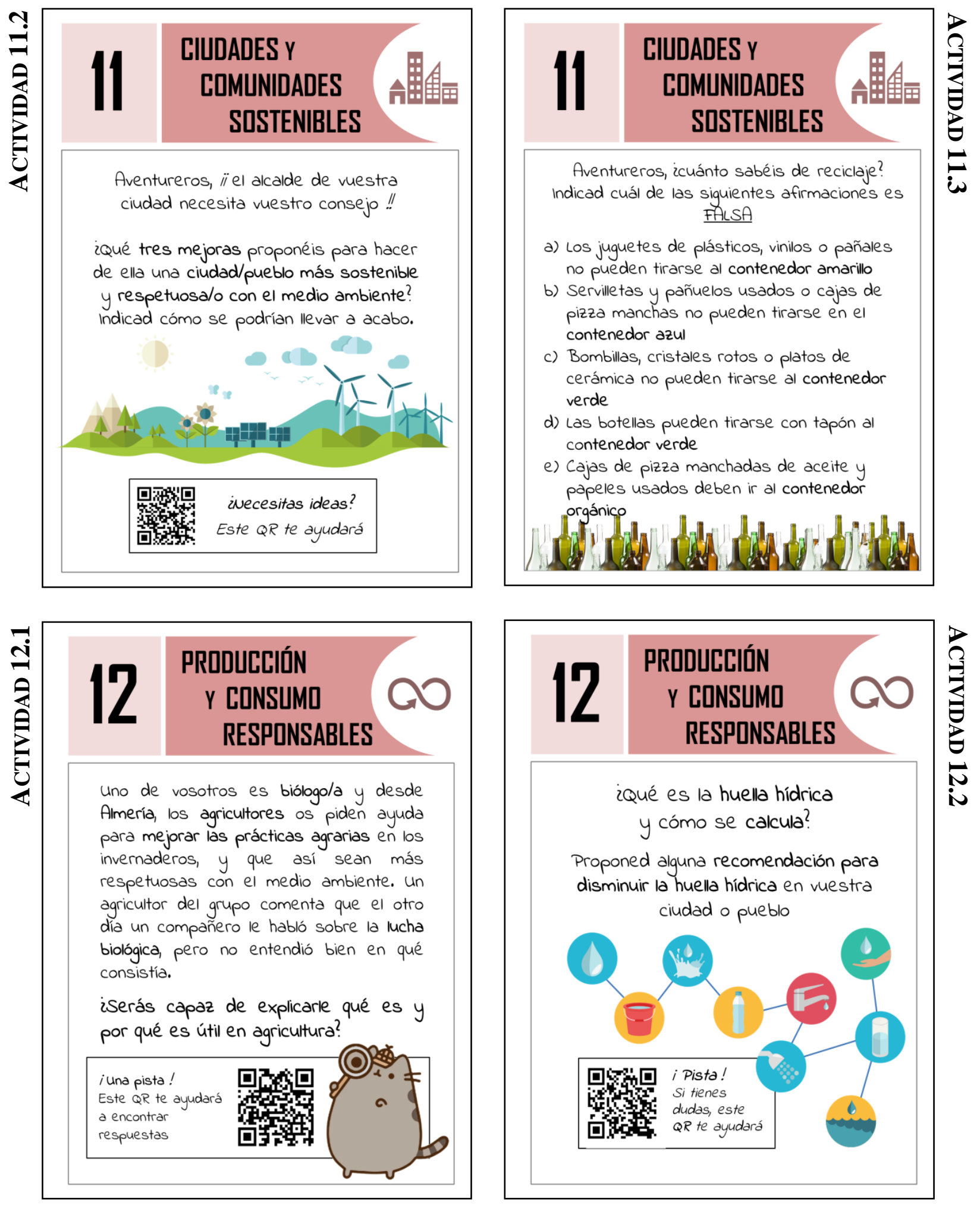

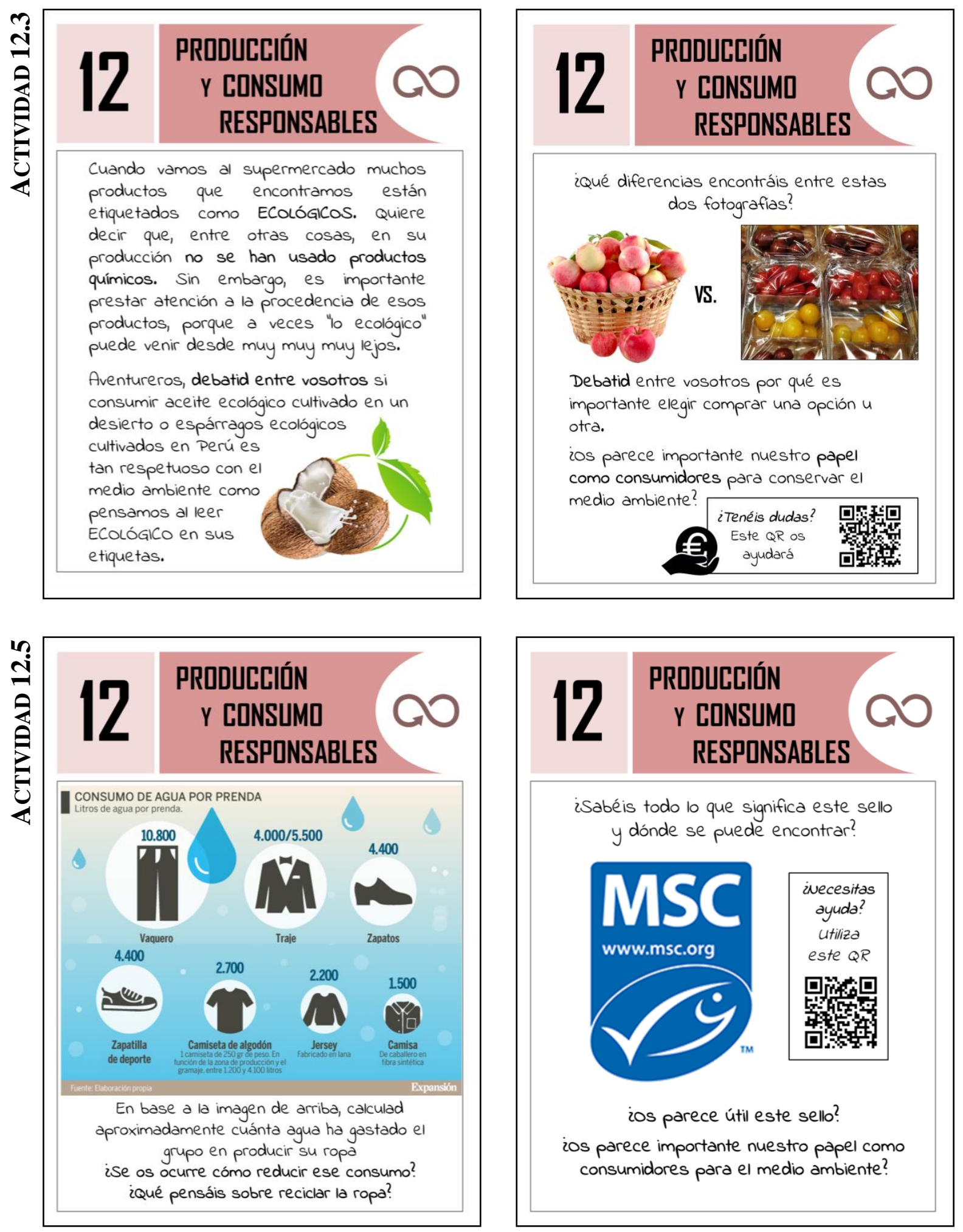

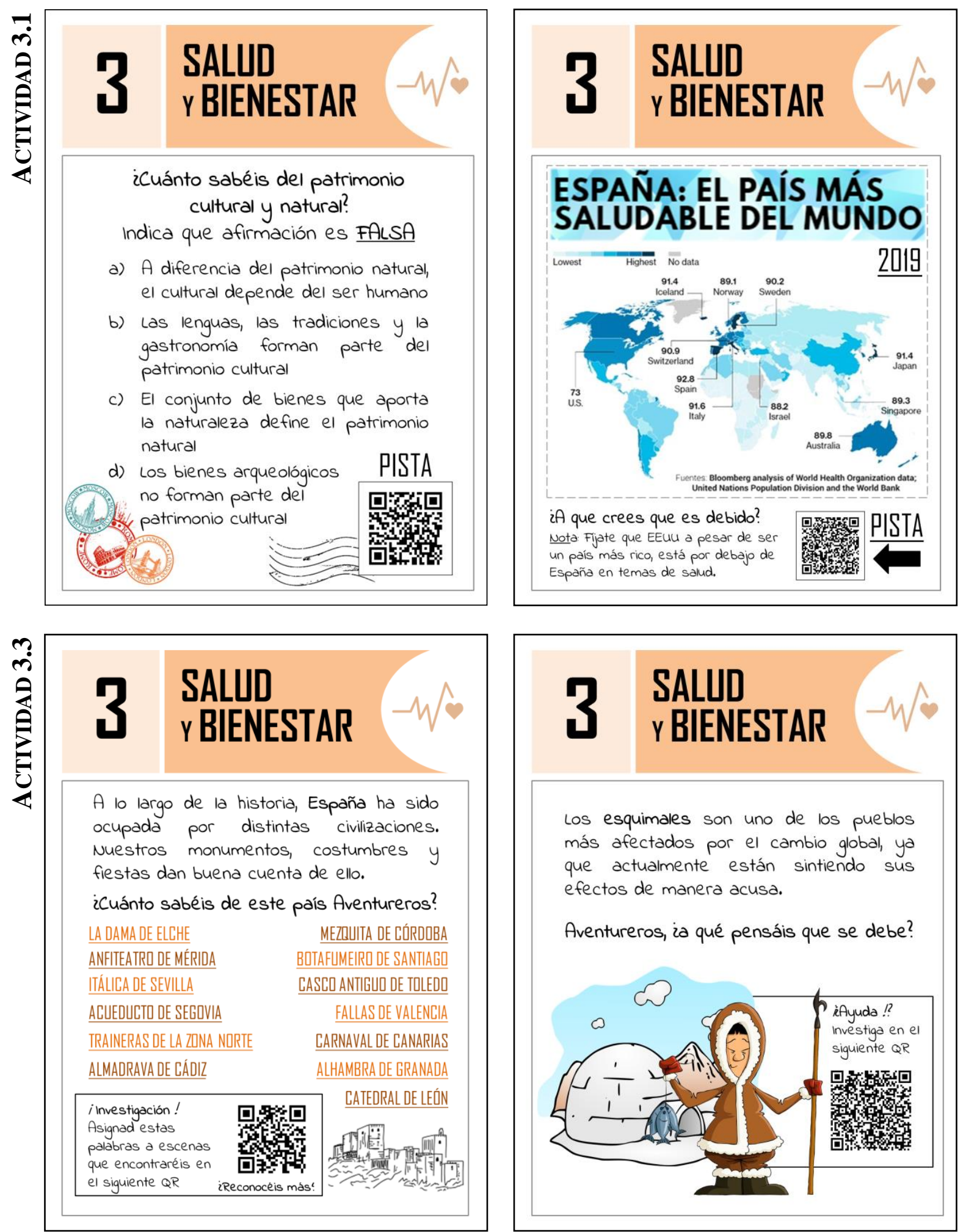

\section{$3 \begin{aligned} & \text { SALUD } \\ & \text { r BIENESTAR }\end{aligned}$}

Los esquimales son uno de los pueblos más afectados por el cambio global, ya que actualmente están sintiendo sus efectos de manera acusa.

Aventureros, ia qué pensáis que se debe?

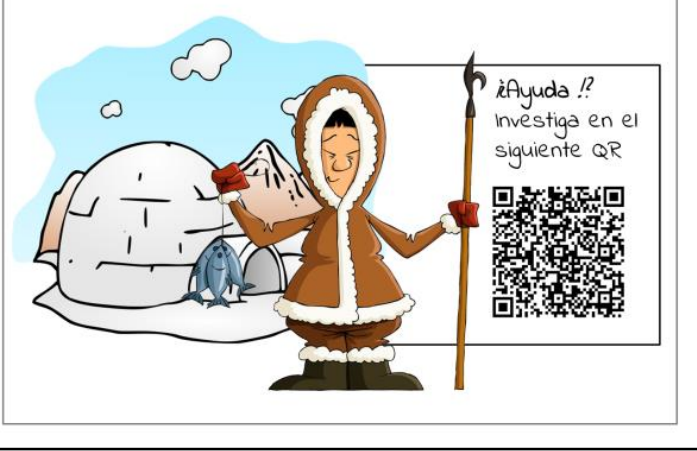



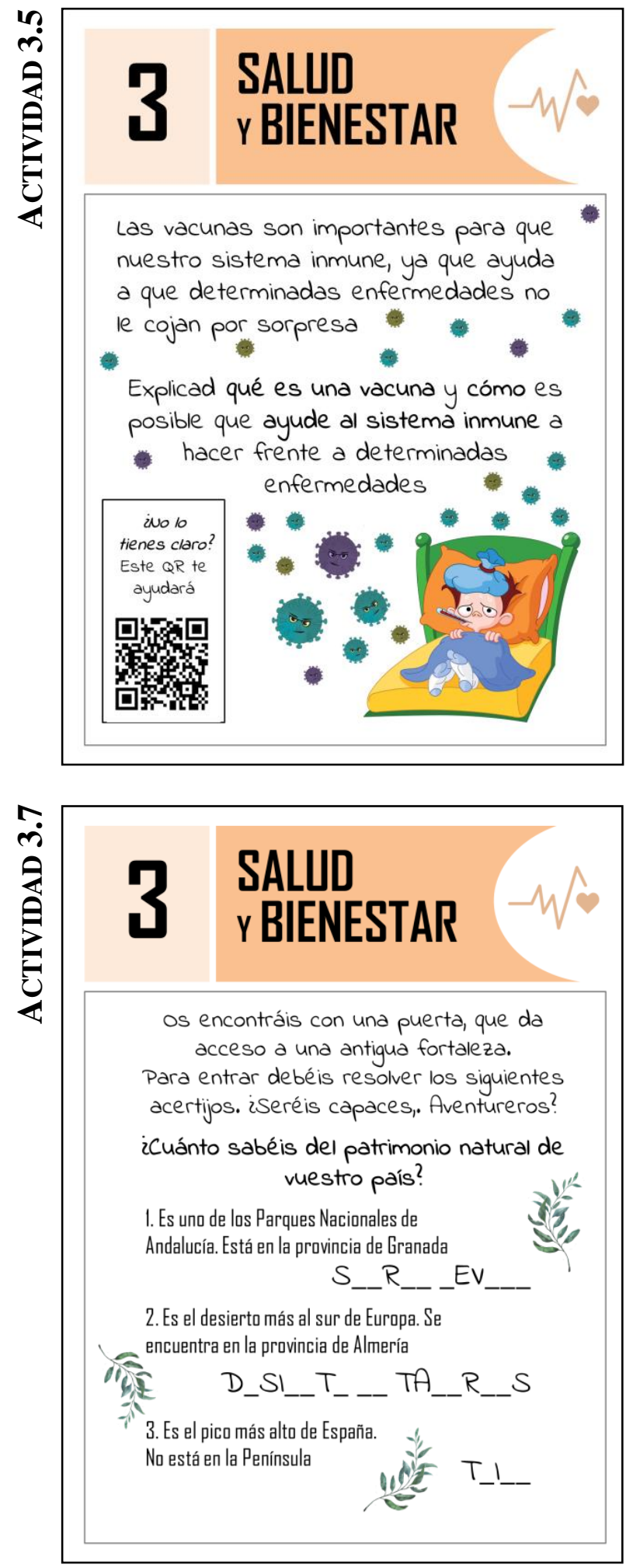

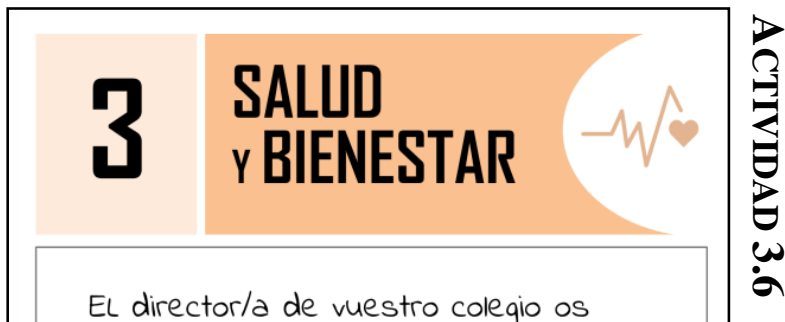

pide consejo para hacer de el un entorno más saludable.

ise os ocurren algunas mejoras para proponerle? Explicad por qué harían de vuestra escuela un sitio más saludable

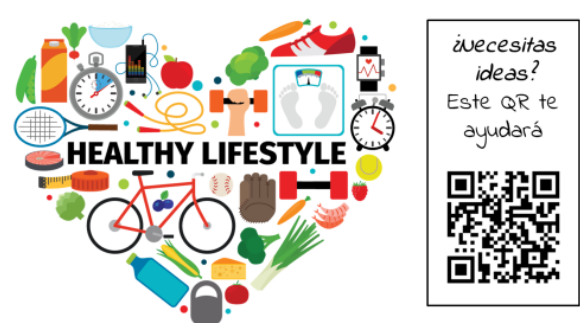

\section{SALLD \\ 3 yBIENESTAR}

Hoy pasamos muchos horas sentados, somos cada vez más sedentarios. El uso abusivo que hacemos de las pantallas Cordenadores, móviles, televisores, tablets...) es uno de los responsables.

¿Cuáles son los principales riesgos de llevar una vida sedentaria?

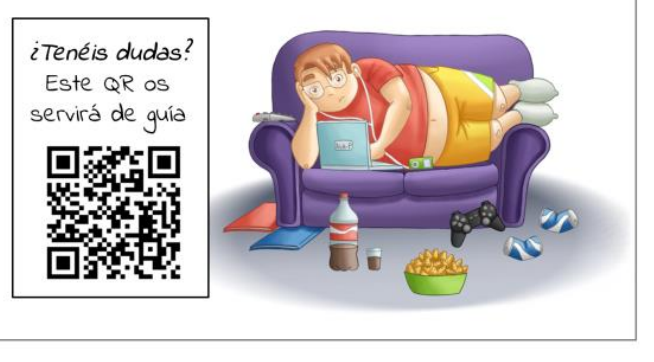



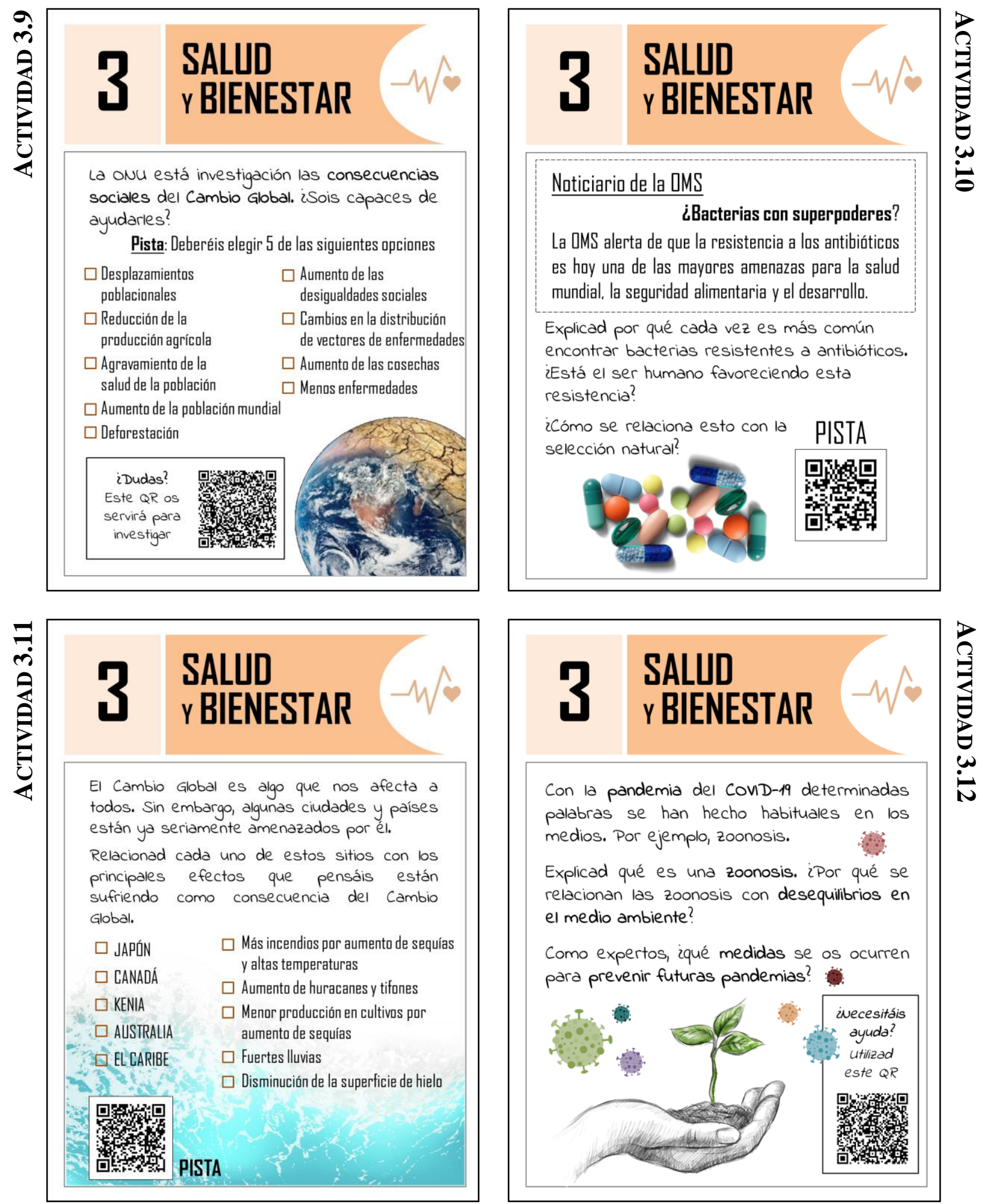
palabras se han hecho habituales en los medios. Por ejemplo, zoonosis.

Explicad qué es una zoonosis. iPor qué se relacionan las zoonosis con desequilibrios en el medio ambiente?

Como expertos, iqué medidas se os ocurren para prevenir futuras pandemias?

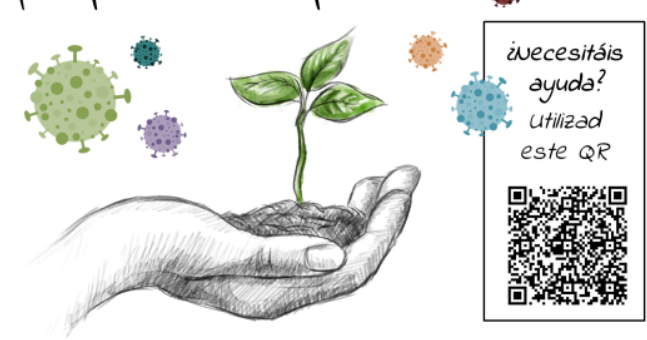


Anexo 10. Asociación entre las actividades diseñadas para el recurso didáctico presentado y los criterios de evaluación y estándares de aprendizaje evaluables de la asignatura de CTMA de $2^{\circ}$ de Bachillerato.

Criterios de evaluación

\section{Bloque 2. Los subsistemas terrestres fluidos, dinámica.}

9. Identificar los riesgos climáticos, valorando los factores que contribuyen a favorecerlos y los factores que contribuyen a paliar sus efectos. CMCT, CSC.

\section{Bloque 3. La contaminación atmosférica.}

1. Argumentar el origen de la contaminación atmosférica, sus repercusiones sociales y sanitarias. CMCT, CSC.

\section{Proponer medidas que} favorecen la disminución de la contaminación atmosférica y del efecto invernadero. CMCT, CSC, SIEP, CAA.

3. Relacionar la contaminación atmosférica con sus efectos biológicos. CMCT, CD.
9.2. Propone medidas para evitar o disminuir los efectos de los riesgos climáticos.
14.6 / 13.4 / 13.5 / 13.6

$/ 3.5$

Actividad/Preguntas relacionadas

Bloque 4. Contaminación de las aguas.

3. Valorar las repercusiones que tiene para la humanizad la contaminación del agua, proponiendo medidas que la eviten o disminuyan. CSC, CD.

5. Conocer y valorar medidas de ahorro de agua, domésticas, industriales y agrícolas. CD, CSC.
1.2. Asocia los contaminantes con su origen, reconociendo las consecuencias sociales, ambientales y sanitarias que producen.

2.1. Describe medidas que previenen o atenúan la contaminación atmosférica y el efecto invernadero.

3.2. Explica los efectos biológicos producidos por la contaminación atmosférica.
$13.1 / 13.4 / 3.4$

13.4

13.3

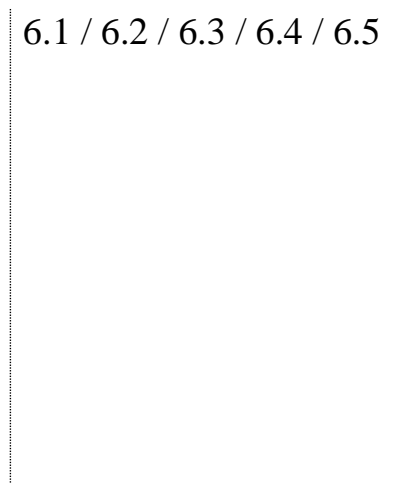

12.5

\section{Bloque 5. La geosfera y riesgos geológicos.}

7. Identificar medidas de uso eficiente determinando sus beneficios. CMCT, CSC, CD.

3.1. Describe el proceso de eutrofización de las aguas valorando las consecuencias del mismo.

3.2. Propone actitudes y acciones, individuales, estatales e intergubernamentales que minimicen las repercusiones ambientales de la contaminación del agua.

8. Valorar los factores 7.1. Valora el uso eficiente de la energía y de los recursos.

$14.4 / 7.1 / 7.3 / 11.2 / 12.1$ / 12.2 responsables del incremento de la desertización en Andalucía. CMCT, CSC, CD. 


\section{Bloque 6. Circulación de materia y energía en la biosfera.}

3. Comprender los mecanismos naturales de autorregulación de los ecosistemas y valorar la repercusión de la acción humana sobre los ecosistemas. CMCT, CSC.

4. Distinguir la importancia de la biodiversidad y reconocer las actividades que tienen efectos negativos sobre ella. CMCT, CSC, CAA.

6. Valorar el suelo como recurso frágil y escaso. CSC.

10. Analizar y valorar la evolución de los recursos pesqueros. CSC

11. Valorar la conservación de las zonas litorales por su elevado valor ecológico. CMCT, CSC.

13. Valorar la riqueza en biodiversidad de Andalucía. CMCT, CSC.
3.2 Conoce los mecanismos naturales de autorregulación de los ecosistemas.

3.3 Argumenta la repercusión de la acción humana sobre los ecosistemas.

4.1 Relaciona las distintas actividades humanas con las repercusiones en la dinámica del ecosistema.

4.2 Argumenta la importancia de la biodiversidad y los riesgos que supone su disminución.

4.3 Relaciona las acciones humanas con su influencia en la biodiversidad del ecosistema.

6.1. Valora el suelo como recurso frágil y escaso.

10.1. Valora el sistema litoral como fuente de recursos y biodiversidad.

10.2. Relaciona la sobreexplotación de los recursos pesqueros con impactos en las zonas litorales.

11.1. Establece la importancia de la conservación de las zonas litorales.
$14.1 / 14.4$ / 14.5 / 14.6 /

$13.3 / 13.5 / 15.2 / 15.4 /$

$15.5 / 11.1 / 12.1 / 12.2 /$

3.12

$14.1 / 14.4$ / $14.5 / 14.6 /$

$14.7 / 13.2 / 15.1 / 15.2 /$

15.3 / 15.4 / $15.5 / 15.6$ /

12.2

15.5

$14.3 / 14.5 / 12.6$

14.2 / 14.4 / 14.5 / 14.6 /

$15.6 / 12.1$

$7.1 / 7.2 / 7.3 / 11.1 / 11.2$

/ $11.3 / 12.3$

$6.5 / 7.2 / 11.1 / 11.2 /$

$12.4 / 12.5 / 12.6$ residuos, las consecuencias de su producción valorando la gestión de los mismos. CMCT, CSC.
1.1. Distingue diferentes modelos uso de los recursos diseñando otros sostenibles. 1.2. Argumenta las diferencias que existen entre el desarrollismo incontrolado, el conservacionismo y el desarrollo sostenible.

3.2. Relaciona el consumo de algunos productos y el deterioro del medio. 3.3. Expone políticas ambientales adecuadas a la 
defensa del medio.

6. Valorar la protección de los

6.1. Argumenta la necesidad

$14.6 / 15.1$ espacios naturales. CEC, CSC. de protección de los espacios naturales y sus consecuencias.

Nota: Las preguntas/actividades 3.1, 3.2, 3.3, 3.5, 3.6, 3.7, 3.8, 3.9 y 3.10 del recurso (Anexo 9) no están contempladas en el Anexo 10 ya que trabajan temas relacionados con la salud humana y el patrimonio natural y cultural, los cuales no son objeto de trabajo del currícullum de la asignatura de CTMA de $2^{\circ}$ de Bachillerato. 